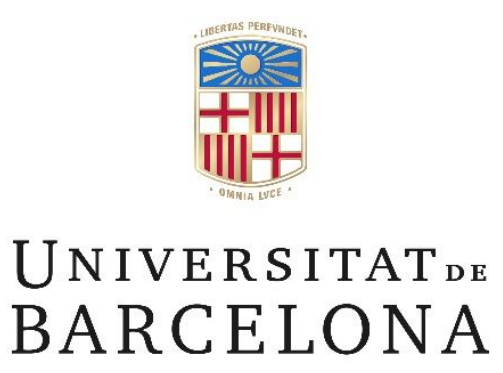

\title{
Molecular mechanisms involved in the immunomodulation induced by LIF in cancer
}

\author{
Ada Sala Hojman
}

\begin{abstract}
ADVERTIMENT. La consulta d'aquesta tesi queda condicionada a l'acceptació de les següents condicions d'ús: La difusió d'aquesta tesi per mitjà del servei TDX (www.tdx.cat) i a través del Dipòsit Digital de la UB (diposit.ub.edu) ha estat autoritzada pels titulars dels drets de propietat intel-lectual únicament per a usos privats emmarcats en activitats d'investigació i docència. No s'autoritza la seva reproducció amb finalitats de lucre ni la seva difusió i posada a disposició des d'un lloc aliè al servei TDX ni al Dipòsit Digital de la UB. No s'autoritza la presentació del seu contingut en una finestra o marc aliè a TDX o al Dipòsit Digital de la UB (framing). Aquesta reserva de drets afecta tant al resum de presentació de la tesi com als seus continguts. En la utilització o cita de parts de la tesi és obligat indicar el nom de la persona autora.
\end{abstract}

ADVERTENCIA. La consulta de esta tesis queda condicionada a la aceptación de las siguientes condiciones de uso: La difusión de esta tesis por medio del servicio TDR (www.tdx.cat) y a través del Repositorio Digital de la UB (diposit.ub.edu) ha sido autorizada por los titulares de los derechos de propiedad intelectual únicamente para usos privados enmarcados en actividades de investigación y docencia. No se autoriza su reproducción con finalidades de lucro ni su difusión y puesta a disposición desde un sitio ajeno al servicio TDR o al Repositorio Digital de la UB. No se autoriza la presentación de su contenido en una ventana o marco ajeno a TDR o al Repositorio Digital de la UB (framing). Esta reserva de derechos afecta tanto al resumen de presentación de la tesis como a sus contenidos. En la utilización o cita de partes de la tesis es obligado indicar el nombre de la persona autora.

WARNING. On having consulted this thesis you're accepting the following use conditions: Spreading this thesis by the TDX (www.tdx.cat) service and by the UB Digital Repository (diposit.ub.edu) has been authorized by the titular of the intellectual property rights only for private uses placed in investigation and teaching activities. Reproduction with lucrative aims is not authorized nor its spreading and availability from a site foreign to the TDX service or to the UB Digital Repository. Introducing its content in a window or frame foreign to the TDX service or to the UB Digital Repository is not authorized (framing). Those rights affect to the presentation summary of the thesis as well as to its contents. In the using or citation of parts of the thesis it's obliged to indicate the name of the author. 


\title{
Molecular mechanisms involved in the immunomodulation induced by LIF in cancer
}

\author{
Ada Sala Hojman
}

Programa de Doctorado en Biomedicina

Universidad de Barcelona (UB)

\begin{abstract}
Vall d'Hebron Instituto de Oncología (VHIO)
Departamento de Investigación Traslacional Grupo de Expresión Génica y Cáncer
\end{abstract}

Tesis Doctoral

Barcelona 2016

Doctorando

Ada Sala Hojman
Director

Joan Seoane Suárez 
"Quien no haya experimentado la irresistible atracción de la ciencia, no podrá comprender su tiranía."

("Frankenstein", de Mary Shelly)

"Si quieres ir rápido, ve solo. Si quieres llegar lejos, ve acompañado."

(Proverbio Africano)

"Investigar es ver lo que todo el mundo ha visto, y pensar lo que nadie más ha pensado."

(Albert Szent-Györgyi) 


\section{TABLE OF CONTENTS}

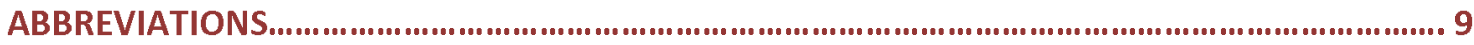

INTRODUCTION

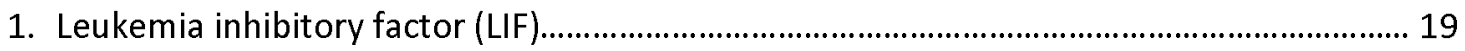

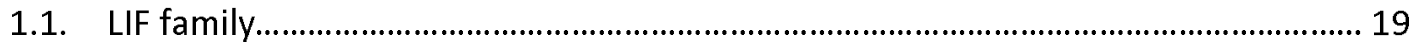

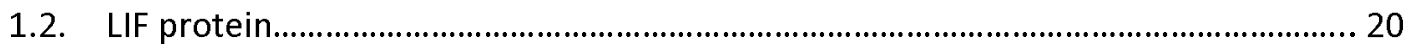

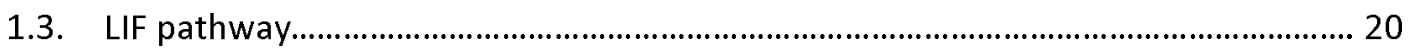

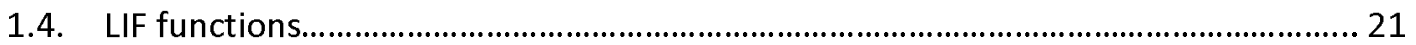

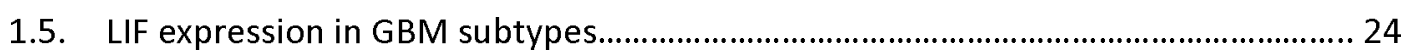

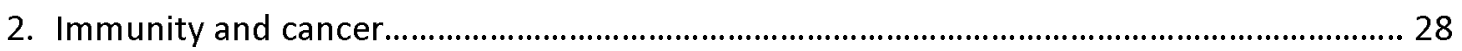

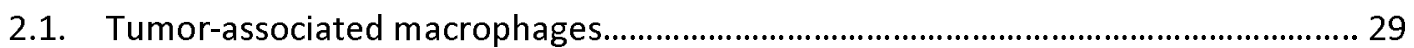

2.2. Myeloid-derived suppressor cells (MDSCs).................................................................... 32

2.3. Regulatory T cells (Tregs)................................................................................................ 33

2.4. Mechanism of immunosuppression of effector T cells: PD-1/PDL1 pathway............ 34

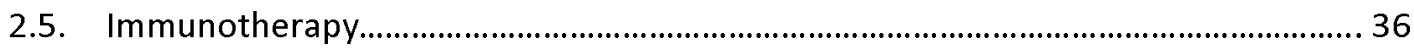

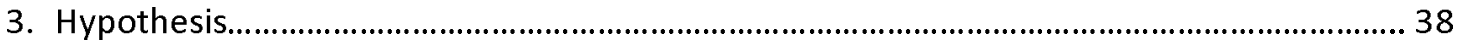

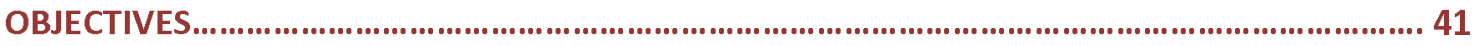

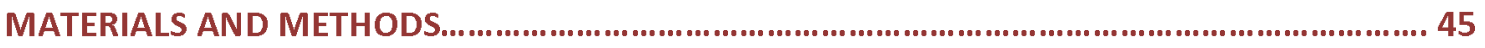

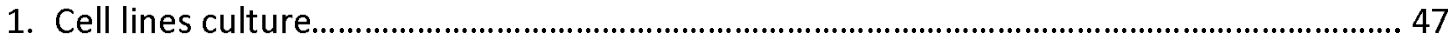

2. Cells from GBM patients isolation and culture........................................................................ 47

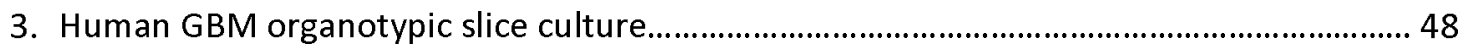

4. Human PBMCs from healthy donors isolation and culture....................................................... 48

4.1. Human monocytes (CD14 ${ }^{+}$cells) from buffy coat........................................................... 48

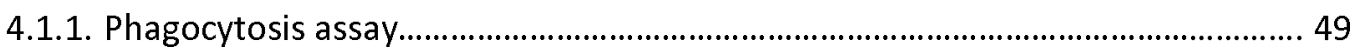

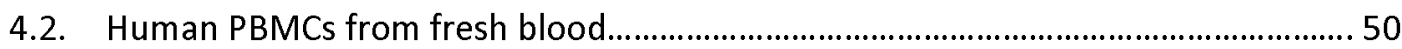

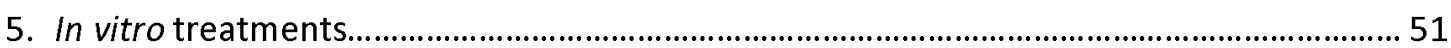

6. DNA purification and lentiviral infection........................................................................... 51

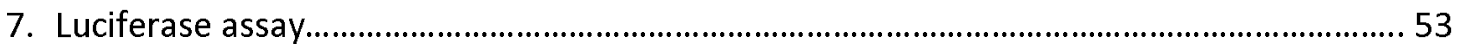

8. RNA extraction, retrotranscription and quantitative Real Time PCR (qRT-PCR)...................53

9. Protein extraction and immunoblotting..................................................................................... 54

10.ELISA

11.Isolation of myeloid $\left(\mathrm{CD} 11 \mathrm{~b}^{+}\right)$cells from tumor-bearing mice................................................ 56

12.Isolation of tumor-associated leukocytes from mice................................................................... 57 
13.Flow cytometry and fluorescence-activated cell sorting.

13.1. Human PBMCs from healthy donors.............................................................................. 58

13.2. Tumor-associated leukocytes from mice........................................................................ 58

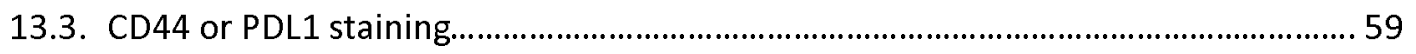

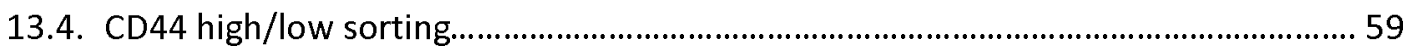

14.Paraffin blocks generation, immunohistochemical and immunofluorescence staining..... 60

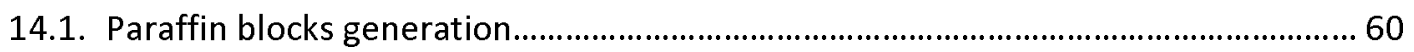

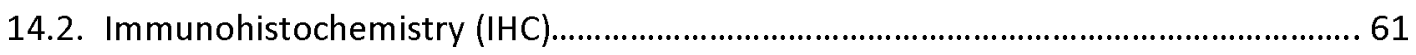

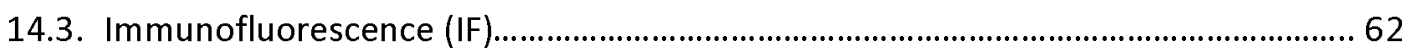

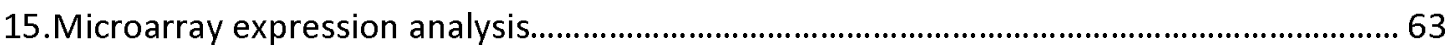

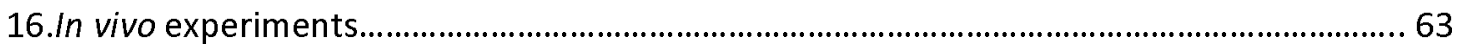

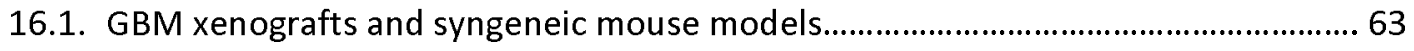

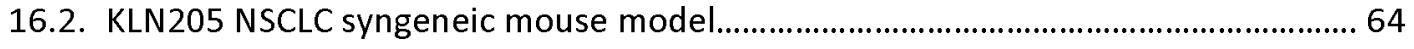

16.3. ID8 ovarian cancer syngeneic mouse model................................................................. 64

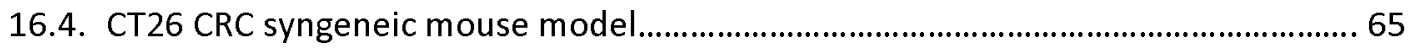

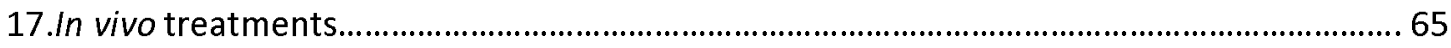

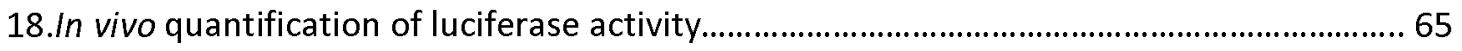

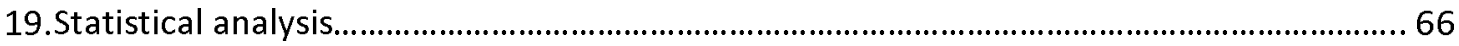

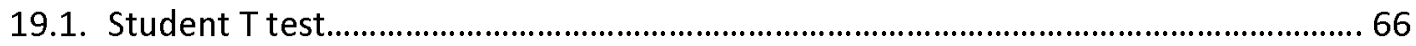

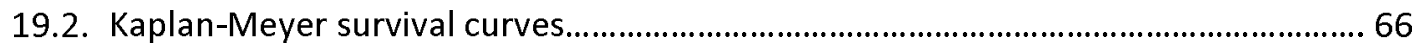

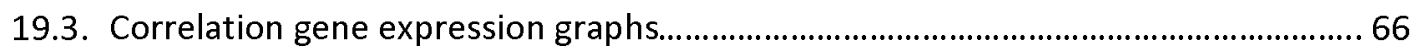

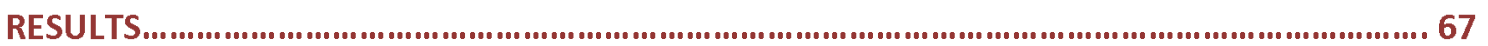

1. Inter-tumor heterogeneity of LIF expression in cancer.......................................................69

2. Study of the anti-tumor response to the blockade of LIF using different syngeneic

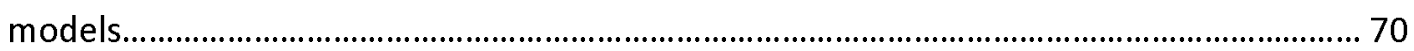

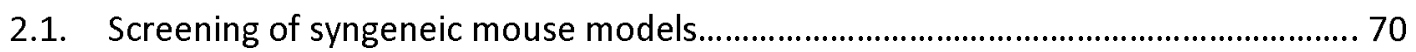

2.2. Characterization of the response to LIF blockade in vivo.............................................. 72

3. LIF regulates tumor-associated myeloid cells (TAMCs) polarization........................................ 74

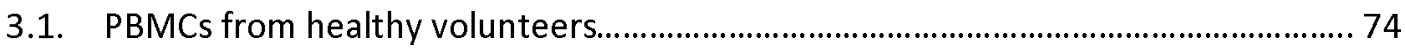

3.2. Syngeneic models: ovarian cancer, NSCLC and CRC.................................................. 78

3.3. Human xenograft GBM model: U251 cell line................................................................ 80

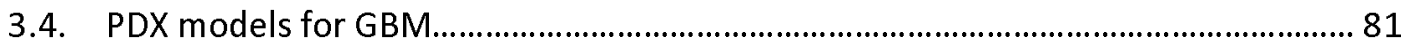

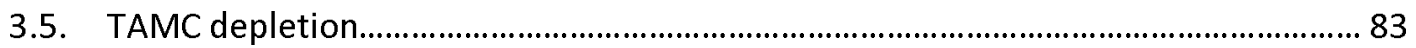

4. LIF blockade prevents Treg and facilitates effector T and NK cell tumor infiltration........... 84 
5. LIF is responsible for the M2-like phenotype of TAMCs in human GBM and confers poor

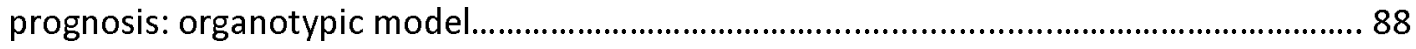

6. LIF blockade inhibits PDL1 expression....................................................................................... 90

6.1. Syngeneic models: ovarian cancer, NSCLC and CRC................................................ 91

6.2. Human xenograft GBM model: U251 cell line.............................................................. 92

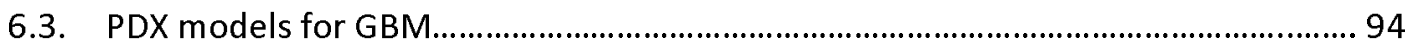

6.4. PDL1 promoter: a possible molecular mechanism........................................................ 95

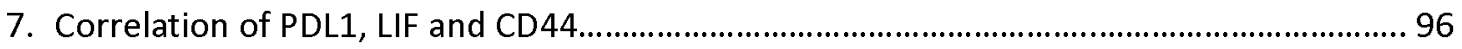

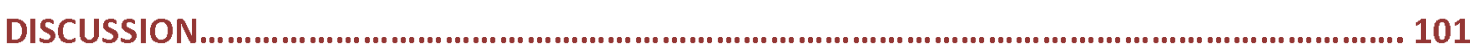

1. LIF blockade prevents TAMCs and Tregs immunosuppression and promotes the infiltration

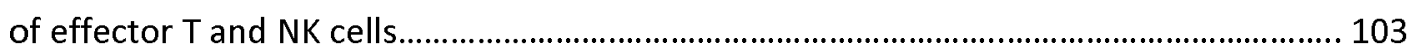

2. LIF blockade inhibits PDL1 expression................................................................................ 106

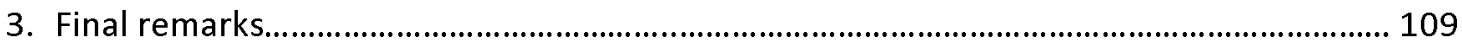

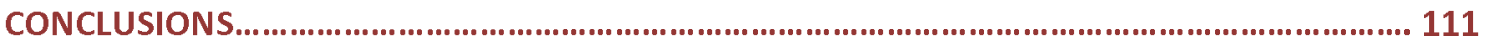

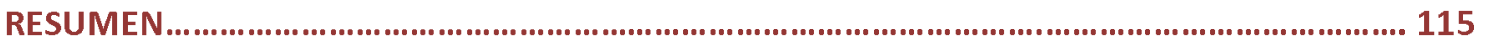

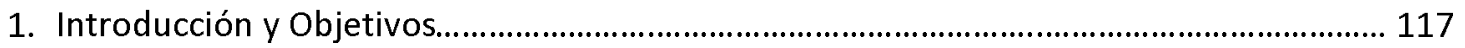

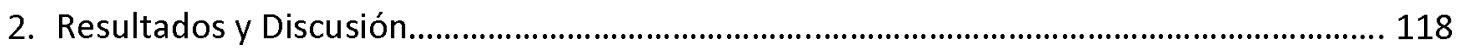

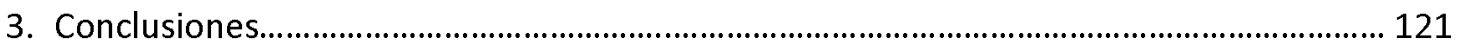

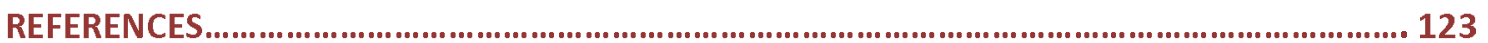

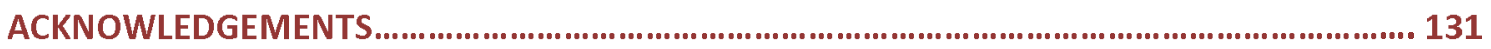


ABBREVIATIONS 


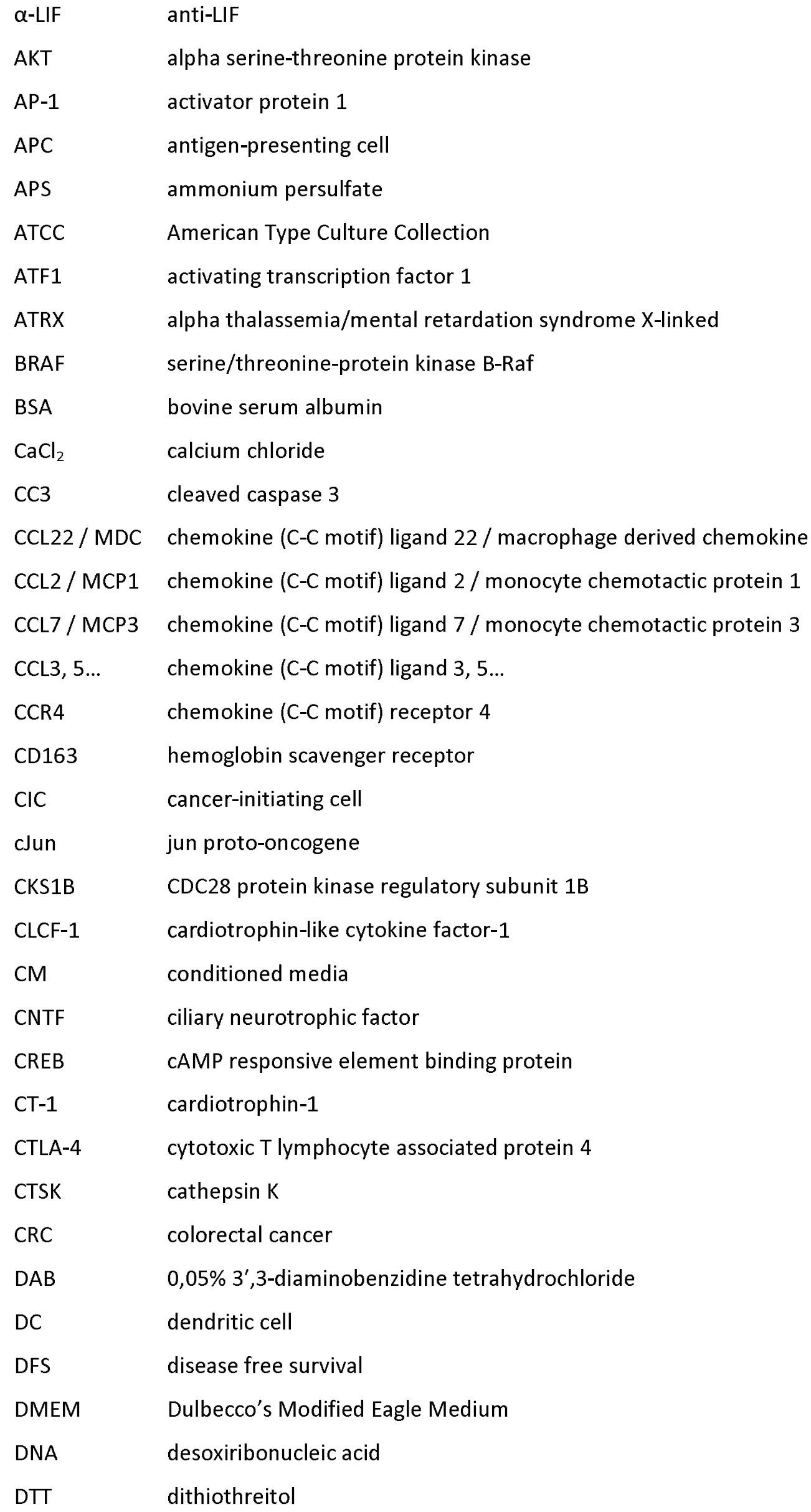




\begin{tabular}{|c|c|}
\hline EAE & experimental autoimmune encephalomyelitis \\
\hline $\mathrm{ECL}$ & enhanced chemiluminescent substrate luminol-based \\
\hline EDTA & ethylene-di-amine-tetra-acetic acid \\
\hline EGF & epidermal growth factor \\
\hline EGFR & epidermal growth factor receptor \\
\hline ELISA & enzyme-linked immunosorbent assay \\
\hline EMEM & Eagle's Minimal Essential Medium \\
\hline ERK1/2 & extracellular signal regulated kinase $1 / 2$ \\
\hline ESC & embryonic stem cell \\
\hline FAS & fas cell surface death receptor \\
\hline FBS & fetal bovine serum \\
\hline FDA & Food and Drug Administration \\
\hline FGF & fibroblast growth factor \\
\hline FMO & fluorescence minus one \\
\hline FosL2 & FOS-like antigen 2 \\
\hline FoxP3 & forkhead box P3 \\
\hline GAPDH & glyceraldehyde-3-phosphate dehydrogenase \\
\hline GBM & glioblastoma \\
\hline GF & growth factor \\
\hline GM-CSF & granulocyte-macrophage colony-stimulating factor \\
\hline G-MDSC & granulocytic MDSC \\
\hline gp130 & glycoprotein 130 (also known as IL-6 signal transducer, IL6-ST) \\
\hline h & hour \\
\hline HBS & HEPES-buffered saline \\
\hline HBSS & Hank's balanced salt solution \\
\hline HEPES & 4-(2-hydroxyethyl)-1-piperazine ethanesulfonic acid \\
\hline $\mathrm{HCl}$ & hydrochloric acid \\
\hline HLA-G, E & major histocompatibility complex class I-G, E \\
\hline HRP & horseradish peroxidase \\
\hline IBA-1 & ionized calcium-binding adapter molecule 1 \\
\hline IDH & isocitrate dehydrogenase \\
\hline IF & immunofluorescence \\
\hline $\mathrm{IHC}$ & immunohistochemistry \\
\hline IL-6, 11, 27... & interleukin-6, 11, 27 \\
\hline IFN $\gamma$ & interferon gamma \\
\hline
\end{tabular}




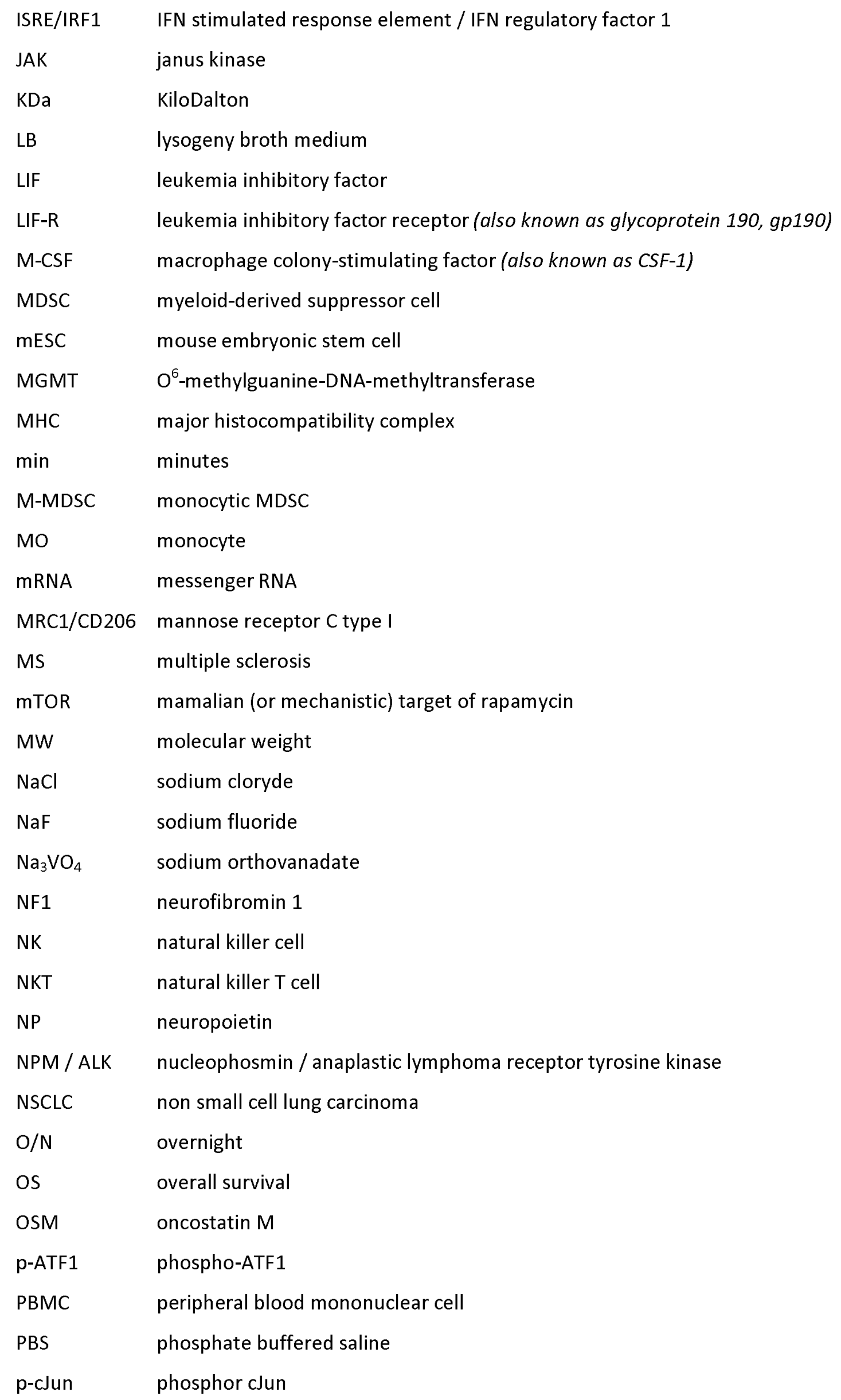




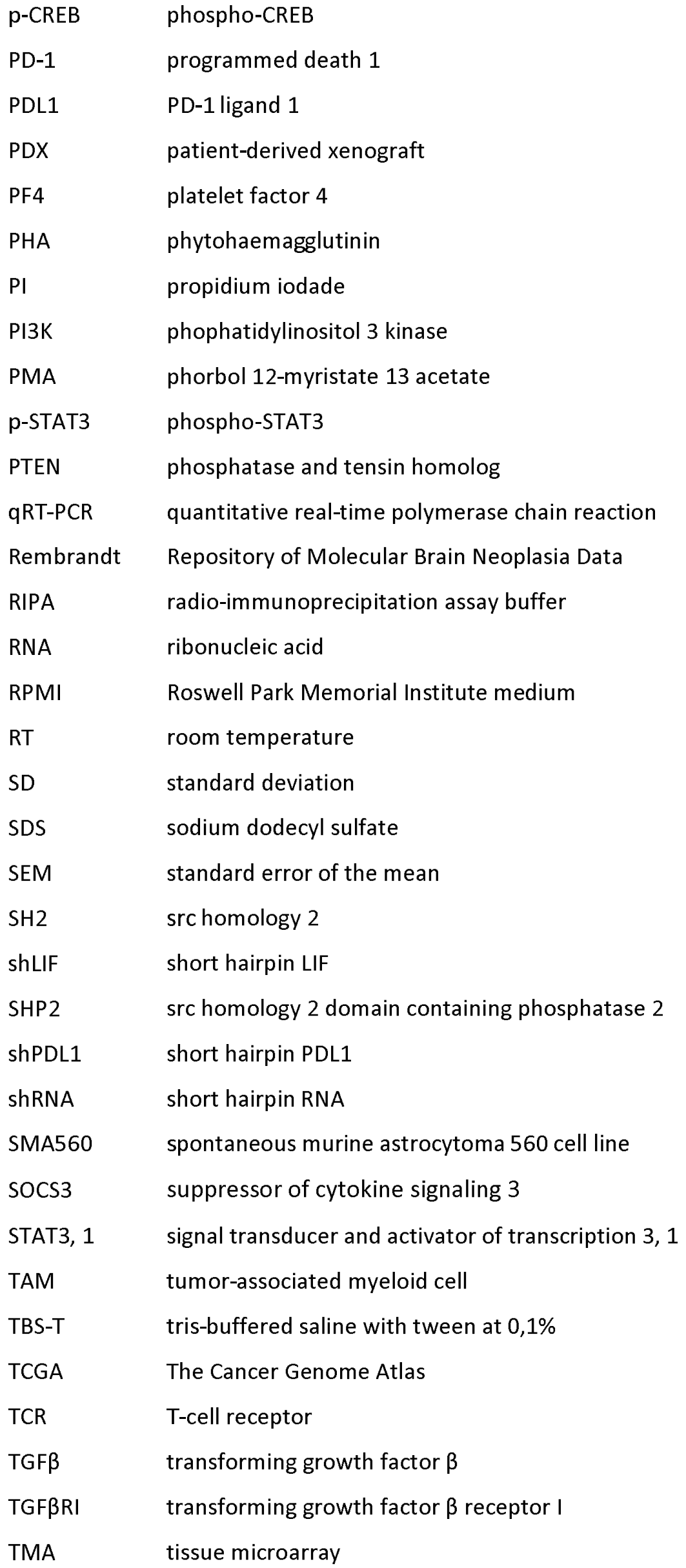


tumor microenvironment

TP53

tumor protein 53

TRAIL

TNF-related apoptosis-inducing ligand

Treg

regulatory $T$ cell

VEGF

vascular endothelial growth factor

WHO

World Health Organization 
INTRODUCTION 


\section{Leukemia inhibitory Factor (LIF)}

\subsection{LIF family}

Leukemia Inhibitory Factor (LIF) is a pleiotropic cytokine that belongs to the IL-6 family. In healthy humans, IL-6 family cytokines are only found in low concentrations or even absent in the serum. However, levels can increase dramatically up to 100,000 fold, especially under inflammatory patho-physiological situations, such as autoimmunity or cancer (Garbers, Hermanns et al. 2012).

IL-6 family cytokines are small, glycosylated proteins that exhibit pro- as well as antiinflammatory properties that may act in a systemic or local fashion. They are involved in a variety of physiological processes, ranging from differentiation and proliferation to apoptosis in their target cells. Members of this family include LIF, IL-6, IL-11, IL-27, OSM, CNTF, CT-1, NP and CLCF1 (Bauer, Kerr et al. 2007, Trouillas, Saucourt et al. 2009, Yue, Wu et al. 2015). These cytokines interact with homo- or heteromeric receptors, all including the common gp130 subunit (also known as IL-6 signaling transducer, IL6-ST), which explains the biological redundancies of many family members (fig. 1) (Mathieu, Saucourt et al. 2012).
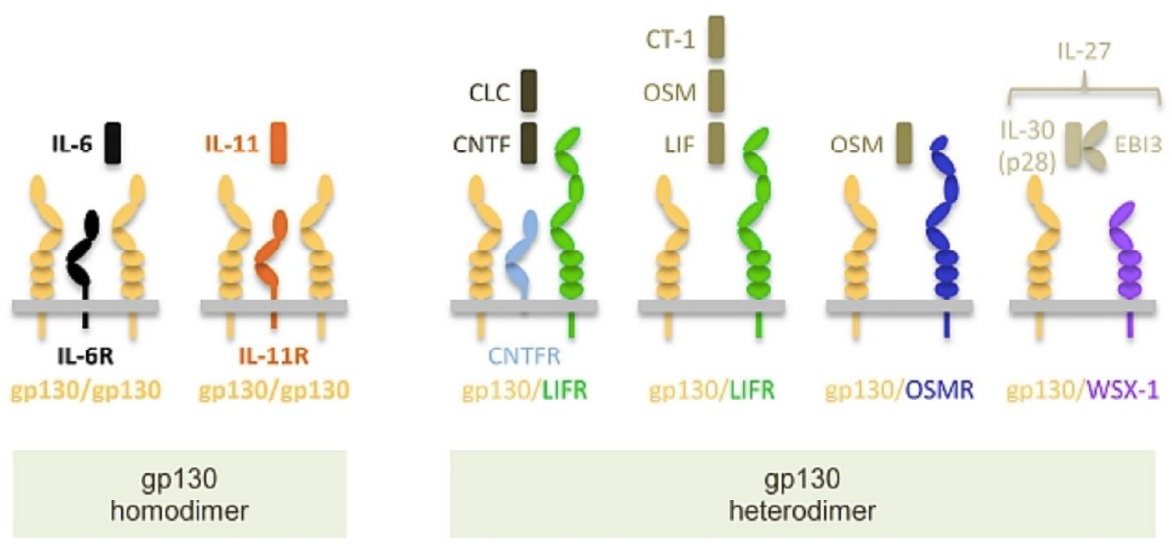

Figure 1. Receptor complexes of the IL-6-type family of cytokines. Gp130 can build homoand heterodimers and thus serves as a central signaling module for several different cytokines. IL-6 and IL-11 signal via a gp130 homodimer (plus individual IL-6R/IL-11R). A gp130/LIFR heterodimer is required for CLC and CNTF (plus CNTFR), whereas CT-1, OSM and LIF do not need any additional receptor. OSM can furthermore signal via gp130/OSMR. IL-27, which consists of IL-30 and the soluble receptor EBI3, induces the formation of a gp130/WSX-1 heterodimer. (adapted from (Garbers, Hermanns et al. 2012)) 


\subsection{LIF protein}

LIF is a 202 amino acid glycosylated protein (P15018, UniProt) secreted by many cell types such as fibroblasts, activated T cells, spleen cells, macrophages, chondrocytes, bone marrow stromal cells, mesenchymal stem cells, endothelial cells, astrocytes and also tumor cells (Trouillas, Saucourt et al. 2009). Currently, three spliced variants of LIF have been identified: a soluble secreted form called LIF-D, an intracellular form found in the nucleus called LIF-T, and a third form localized in the extracellular matrix termed LIF-M. LIF-M and LIF-D mRNA are translated from alternative transcripts that differ at the first exon that encodes for different signal peptides, which target the mature protein to different locations. LIF-T is a truncated isoform that lacks the first exon, which codify for the secretion signal sequence, generating an intracellular protein (Haines, Voyle et al. 1999).

\subsection{LIF pathway}

LIF signals through the common receptor subunit gp130 in association with the low-affinity subunit LIF receptor (LIF-R). Inactive receptors are present at the cell surface in the absence of ligand. The binding of LIF to the LIF-R induces its heterodimerization with gp130. The formation of this complex results in the transphosphorylation and activation of the receptorassociated Janus kinases (JAKs) that subsequently phosphorylate tyrosine residues on the cytoplasmic domain of the receptor. Then, the quiescent signal transducers and activators of transcription 3 (STAT3) monomers are recruited to the activated receptor complex through the interaction with the Src-homology-2 $(\mathrm{SH} 2)$ domains. STAT3 is phosphorylated by the JAKs at the tyrosine 705 residue in the C-terminal domain. This phosphorylation leads to its dimerization with another STAT3 phosphorylated (p-STAT3) at the same residue. Finally, pSTAT3 dimers dissociate from the receptor and translocate into the nucleus, where they bind to promoters and enhancer regions of their target genes. One of its target genes is the suppressor of cytokine signaling 3 (SOCS3), which is an important negative regulator of the LIF/STAT3 pathway (fig. 2).

Although the JAK/STAT3 pathway is the major signaling pathway downstream of LIF, it has been shown that the binding of LIF to the LIF-R/gp130 receptor also leads to the activation of the PI3K/AKT, ERK1/2 and mTOR pathways (Graf, Casanova et al. 2011, Hirai, Karian et al. 2011, Yue, Wu et al. 2015). 


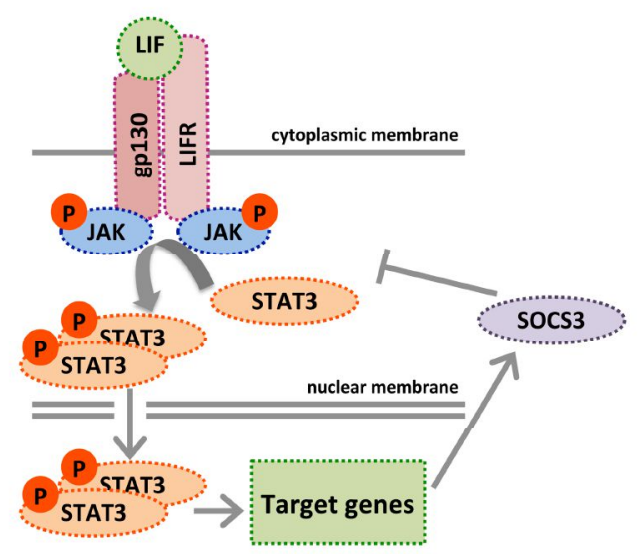

Figure 2. Schematic representation of the LIF pathway. LIF activates its receptor, which phosphorylates and activates JAK/STAT3. Once phosphorylated STAT3, it forms homodimers, which are shuttled into the nucleus and bind to other transcription factors and co-activators or co-repressors to orchestrate the transcriptional program. LIF pathway activity is down-modulated by SOCS3.

\subsection{LIF functions}

The name of LIF, Leukemia Inhibitory Factor, derives from its role promoting both macrophage differentiation and proliferation suppression described using murine M1 myeloid leukaemic cells (Gearing, Gough et al. 1987). Further studies have shown that LIF is a multifunctional protein with a broad of biological functions depending upon the cellular context, cell maturity and cell type (table 1). LIF is a key cytokine for maintaining self-renewal and pluripotency of mouse embryonic stem cells (mESCs) (Hirai, Karian et al. 2011). In fact, LIF is commonly used to maintain its pluripotency in culture. According to this, the withdrawal of LIF allows mESCs to undergo cell differentiation. LIF has also been involved in several differentiation processes. For instance, during neural crest cell differentiation, in late-stage of mouse neuroprogenitors, LIF enhances the survival of sensory neurons and stimulates their formation, an also promotes astrocyte and oligodendrocyte differentiation (He, Li et al. 2006). Moreover, LIF has a prodifferentiating role for adipocytes and for cardiac muscle cells (Trouillas, Saucourt et al. 2009).

Furthermore, LIF plays a crucial role prior to and during embryonic implantation regulating several events, which include the uterine transformation into a receptive state, embryoendometrial interaction, stromal decidualization, trophoblast invasion, blastocyst growth and development, and the infiltration of uterine leukocyte (Horita, Kuroda et al. 2007, Salleh and Giribabu 2014). In agreement, LIF knock-out in female mice causes infertility due to an impairment of blastocysts implantation (Stewart, Kaspar et al. 1992, Yue, Wu et al. 2015). In addition, it has been described that LIF is essential for mammary gland involution after lactation (Kritikou, Sharkey et al. 2003). 
It has been shown that high levels of active LIF are associated with transplantation tolerance due to the direct regulation of naïve $T$ cells differentiation towards a regulatory $T$ cell (Treg) phenotype. This function is promoted by the induction of FoxP3 and the creation of a positive autocrine feedback loop in the LIF signaling pathway (Metcalfe 2005, Muthukumarana, Lyons et al. 2006, Gao, Thompson et al. 2009).

\begin{tabular}{|c|c|}
\hline \multicolumn{2}{|r|}{ Pleiotropic effects of LIF } \\
\hline Context & Effects of LIF \\
\hline $\begin{array}{c}\text { embryonic stem } \\
\text { cells (ESCs) }\end{array}$ & maintenance of $\mathrm{mESC}$ \\
\hline \multirow{6}{*}{$\begin{array}{c}\text { neural stem cells } \\
\text { (NSCs) }\end{array}$} & maintenance of early neuroprogenitor cells \\
\hline & differentiation and survival of oligodendrocytes precursors \\
\hline & differentiation and survival of sensory and motor neurons \\
\hline & differentiation of NSCs into astrocytes \\
\hline & stimulation of neurite outgrowth \\
\hline & pro-myelinating effecte on mixed cultures derived from embryonic mouse forebrain \\
\hline \multirow{2}{*}{$\begin{array}{c}\text { hematopietic } \\
\text { stem cells (HSCs) }\end{array}$} & maintenance of HSC pools \\
\hline & stimulation of megakaryocyte production (platelets production) \\
\hline \multirow{8}{*}{$\begin{array}{l}\text { reproduction and } \\
\text { fertility }\end{array}$} & male germ maturation during spermatogenesis \\
\hline & oocytes and graafian follicle expansion \\
\hline & uterine transformation into a receptive state \\
\hline & embryo-endometrial interaction \\
\hline & stromal decidualization \\
\hline & trophoblast invasion \\
\hline & blastocyst growth and development \\
\hline & infiltration of uterine leukocyte \\
\hline $\begin{array}{l}\text { hormone } \\
\text { regulation }\end{array}$ & hypothalamo-pituitary-adrenal axis: stimulation of adrenal steroidogenesis \\
\hline muscle & proliferation and differentiation of myoblasts (muscle regeneration) \\
\hline vessels & regulation of microvessel density (control of the capillary outgrowth) \\
\hline bones & regulation of bone cell metabolism \\
\hline eyes & maintenance of $\mathrm{CD}_{133^{+}}$retinal cells in undifferentiated state \\
\hline ears & proliferation of auditory cells \\
\hline kidneys & differentiation of kidney mesenchyme to epithelia which then form nephrons \\
\hline liver & production of hepcidin, responsible for anemia development in infammatory conditions \\
\hline \multirow{2}{*}{$\begin{array}{l}\text { anti-inflammatory } \\
\text { factor }\end{array}$} & transplantation tolerance: increment of Tregs \\
\hline & MS: modulating macrophage functions and enhancing Tregs number \\
\hline \multirow{5}{*}{ cancer } & inhibition (in non-tumorigenic cells) or induction (in tumorigenic cells) of cell survival \\
\hline & tumor growth \\
\hline & metastasis \\
\hline & self-renewal of $\mathrm{ClCs}$ \\
\hline & differentiation of macrophages towards an $\mathrm{M} 2$ phenotype (in vitro) \\
\hline
\end{tabular}

Table 1. Pleiotropic effects of LIF. List of LIF biological functions in different contexts. 
LIF has also been associated with some diseases such as multiple sclerosis (MS). MS is a chronic disease of the central nervous system characterized by an inflammatory process associated with demyelination, oligodendrocyte death, axonal injury and neuronal loss. Levy and collaborators reported that activated peripheral blood mononuclear cells (PBMCs) from MS patients secrete lower levels of LIF than activated PBMCs from healthy controls, demonstrating a defective regulation of LIF secretion in those patients. Due to the well-described role of LIF in the induction of neuronal and oligodendrocyte precursors differentiation and survival, they conclude that the lower production of LIF from PBMCs contribute to the insufficient neurogenesis and remyelination of the MS plaques (Levy, Mausner-Fainberg et al. 2015). In fact, it has been reported that systemic administration of LIF ameliorates clinical symptoms of experimental autoinmune encephalomyelitis (EAE), the preclinical animal model of $M S$, by preventing oligodendrocyte death, demyelination (Butzkueven, Zhang et al. 2002) and by limiting axonal damage and loss (Gresle, Alexandrou et al. 2012). Moreover, it has been demonstrated that LIF down-regulates the autoinmune response by modulating macrophage function (Hendriks, Slaets et al. 2008) and by enhancing Treg number (Janssens, Van den Haute et al. 2015).

a

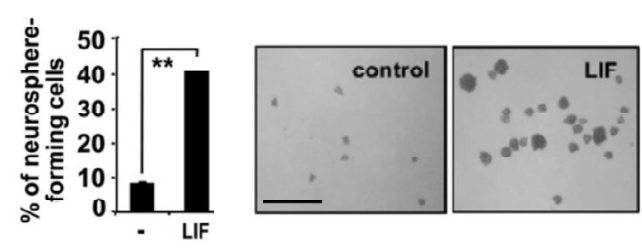

b

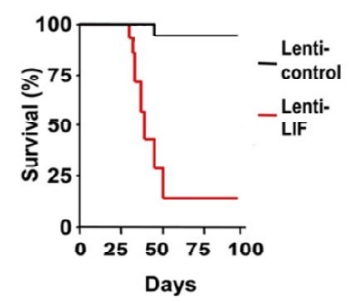

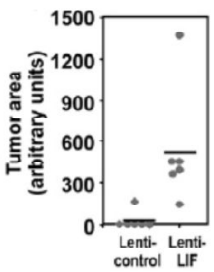

Figure 3. LIF mediates the increase of cancer-initiating cells ( $\mathrm{CICs}$ ) self-renewal and its oncogenic potential. (a) Cells derived from a GBM patient were treated with LIF for 7 days, and the number of newly formed neurospheres were determined. Representative images are shown. Scale bar, 400um. (b) Cells derived from a GBM patient, previously infected with lenti-control or lenti-LIF, were inoculated into the brains of immunocompromised mice. Animal survival was evaluated using a long-rank analysis from Kaplan-Meier survival curve (left panel). Forty days after surgery, images from the entire mouse brains were obtained by MRI and tumor area was quantified (right panel). (Penuelas, Anido et al. 2009)

Notably, work from our lab and others have shown that LIF has an important role in cancer. It is highly expressed in several tumor types and acts as an oncogenic factor through the induction of cancer-initiating cells (CICs) self-renewal (fig. 3a,b) (Penuelas, Anido et al. 2009), through the regulation of cancer-associated fibroblasts (Albrengues, Bourget et al. 2014) and by increasing radio- (Liu, Tsang et al. 2013) and chemoresistance (Yu, Yue et al. 2014). Moreover, it has been also shown that LIF present in the tumor microenvironment (TME) 
induces differentiation of monocytes to a tumor-associated macrophage phenotype, the most abundant immunosuppressive cells in TME (Duluc, Delneste et al. 2007). Furthermore, LIF overexpression is associated with poor prognosis in many tumors, including colorectal cancer (CRC), non-small cell lung carcinoma (NSCLC) and glioblastoma (GBM) among others (fig. 4) (Liu, Tsang et al. 2013, Albrengues, Bourget et al. 2014, Li, Yang et al. 2014, Yu, Yue et al. 2014).
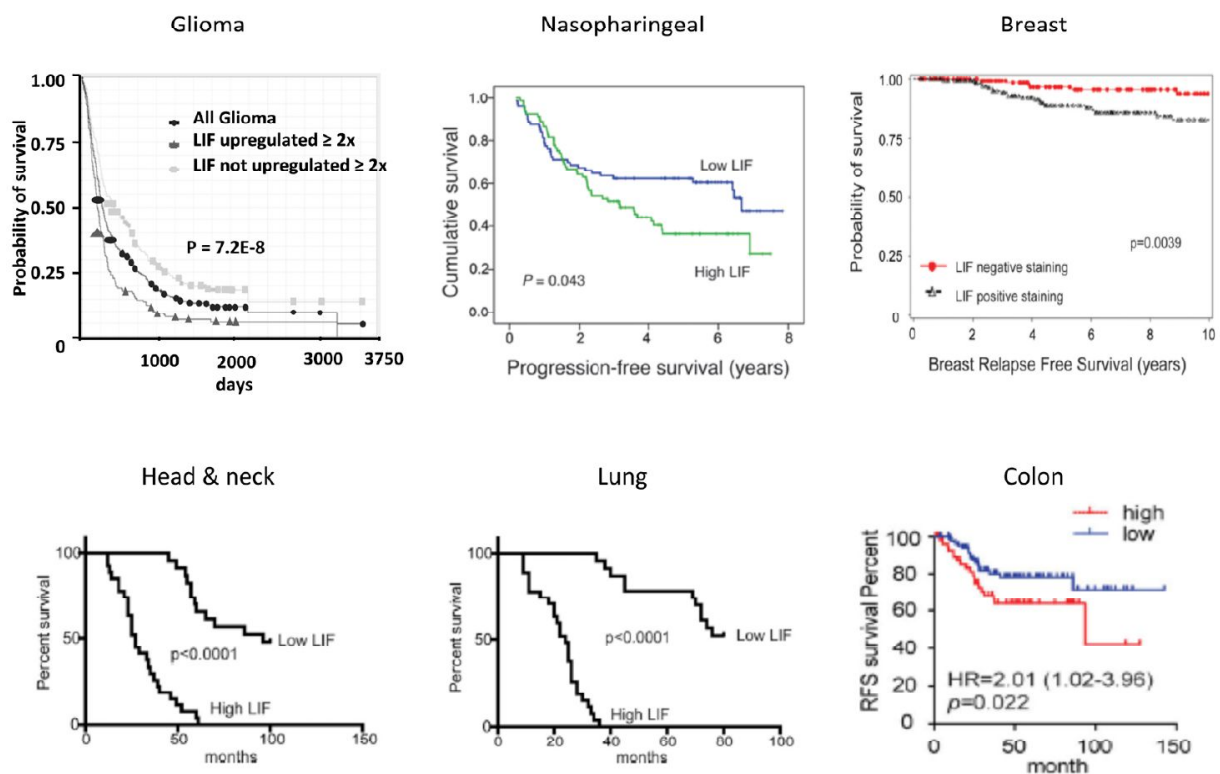

Figure 4. LIF overexpression strongly correlates with a poor prognosis. High expression of LIF is associated with a lower overall survival in different types of tumor (glioma from Rembrandt database; nasopharingeal carcinoma from (Liu, Tsang et al. 2013); breast carcinoma from (Li, Yang et al. 2014); head and neck, and lung cancer from (Albrengues, Bourget et al. 2014); colon cancer from (Yu, Yue et al. 2014)).

\subsection{LIF expression in GBM subtypes}

Gliomas are classified following different criteria. According to the cell type that originates the tumor, they can be classified as:

$>$ Astrocytomas (astrocytes)

$>$ Ependymomas (ependymal cells)

$>$ Oligodendrogliomas (oligodendrocytes)

$>$ Mixed gliomas (oligoastrocytomas)

The World Health Organization (WHO) has classified central nervous system tumors according to the histological characteristics such as cellularity, mitotic activity, pleomorphism, necrosis, and endothelial proliferation. It is the most widely accepted system for classifying these tumors (Louis, Ohgaki et al. 2007): 
WHO grade I: lesions with low proliferative potential, and associated with long-term survival. Surgery alone may be an effective treatment.

$>$ WHO grade II: lesions with low proliferative potential but infiltrative. Despite low-level proliferative activity, often recur. Some grade II tumors tend to progress to higher grades of malignancy.

> WHO grade III: lesions with histologic evidence of malignancy, including nuclear atypia and increased mitotic activity. These lesions have anaplastic histology and infiltrative capacity. They are usually treated with adjuvant radiotherapy and /or chemotherapy.

WHO grade IV: lesions are cytologically malignant, mitotically active, necrosis-prone, and generally associated with neovascularity, infiltration of surrounding tissue, a propensity for craniospinal dissemination, a rapid pre- and postoperative progression and a fatal outcome. The lesions are usually treated with aggressive adjuvant therapy.

The WHO classification system for gliomas provides guidance for the predicted course of the disease and for the choice of the treatment. However, histologically identical tumors may have a very different outcome and response to treatment. Molecular markers that carry both diagnostic and prognostic information add useful information to traditional classification and elucidate clinical observations by redefining tumor subtypes within each WHO category (fig. 5). Therefore, molecular markers (such as IDH mutations, promoter methylation of MGMT, chromosomal deletion of $1 p / 19 q$, mutations of EGFR and ATRX genes, and BRAF fusion or point mutation) have become an integral part of tumor assessment in modern neuro-oncology. In some subtypes of gliomas, the biomarker information may contribute to the therapeutical choice (Siegal 2015).

Glioblastoma (GBM) is the most common and most malignant form of glioma (grade IV). According to Medscape, it is the most frequent primary brain tumor, accounting for approximately $12-15 \%$ of all intracranial neoplasms and $50-60 \%$ of all astrocytic tumors, with an incidence of 2-3 new cases per 100.000 people per year. Patients treated with optimal therapy, including surgical resection, radiotherapy and chemotherapy, have a median survival of approximately 12 months (Stupp, Mason et al. 2005, Bruce, Kennedy et al. 2015). Although it is a non-metastatic type of tumor, GBM cells are highly invasive throughout the brain, leading to the destruction of normal brain tissue. Furthermore, it is resistant to conventional therapies (radio- and chemotherapy) and highly life-threatening (Furnari, Fenton et al. 2007). A major obstacle to treatment is the subversion of the immune system by the tumor to facilitate its proliferation and the malignant degeneration of tumor cells. Immunosuppression is thought to play a major role in the aggressive nature of gliomas and their resistance to current 
therapies. In fact, it has been documented that the presence of immunosuppressive infiltrating cells, such as regulatory $T$ cells (Tregs) and M2-like macrophages, correlates with poor prognosis (El Andaloussi and Lesniak 2006, Hussain, Yang et al. 2006, Heimberger, Abou-Ghazal et al. 2008).

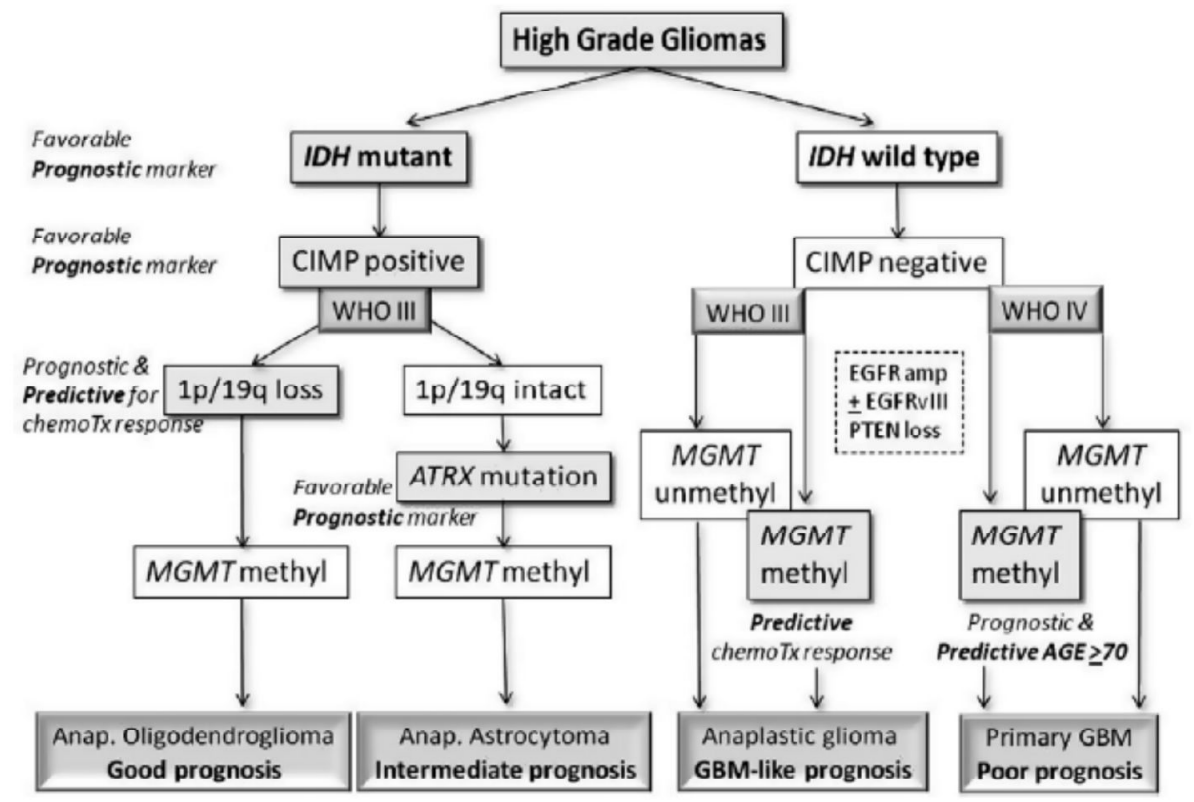

Figure 5. Molecular classification, prognostic and/or predictive implication of biomarkers in high grade gliomas of adults. amp = amplification, Anap. = anaplastic, ATRX $=$ alphathalassemia $/$ mental retardation syndrome $X$-linked, $\mathrm{CIMP}=\mathrm{CpG}$ island methylation phenotype, EGFR = epidermal growth factor receptor, IDH = isocitrate dehydrogenase, methyl = methylated, MGMT $=0^{6}$-methylguanine-DNA-methyltransferase, PTEN = phosphatase and tensin homolog, $\mathrm{Tx}=$ therapy, unmethyl = unmethylated, $\mathrm{WHO}=$ World Health Organization. (Siegal 2015)

According to its genetic and chromosomic alterations, GBM can be divided in 4 different subgroups: classical, proneural, neural and mesenchymal (The Cancer Genome Atlas (TCGA), 2008) (Verhaak, Hoadley et al. 2010), being proneural subtype patients those ones with a better clinical outcome, and mesenchymal subtype patients those ones who present the worst prognosis. The STAT3 pathway has been shown to be a key molecular driver of the mesenchymal transformation (Carro, Lim et al. 2010). In addition, STAT3 has been implicated in tumor-mediated immunosuppression (Wei, Barr et al. 2010, Wu, Wei et al. 2010), which suggests that the mesenchymal subgroup may be more immunosuppressive compared with other GBM subtypes and, possibly, more refractory to immunotherapy. Besides STAT3, Doucette and colleagues have reported an enrichment of other immunosuppressive genes within the mesenchymal subset, such as PDL1, CTLA-4, M-CSF/CSF-1, CCL2, CCL22 and CD163 (Table 2) (Doucette, Rao et al. 2013). Moreover, the mesenchymal subtype is also 
characterized by inactivating mutations or loss of NF1, TP53 and PTEN, and high expression of CD44, among other genes (Phillips, Kharbanda et al. 2006, Tso, Shintaku et al. 2006).

\begin{tabular}{|c|c|c|c|c|c|c|}
\hline \multirow{2}{*}{\multicolumn{2}{|c|}{ Immunosuppressor/gene }} & \multirow{3}{*}{$\begin{array}{l}\text { PMID reference } \\
22672152\end{array}$} & \multicolumn{4}{|c|}{$\begin{array}{l}\text { Number of cases; \% of cases with mRNA } \\
\text { overexpression }\end{array}$} \\
\hline & & & \multirow{2}{*}{$\begin{array}{c}\text { Proneural } \\
\boldsymbol{n}=\mathbf{1 4 1} \\
2 ; 1\end{array}$} & \multirow{2}{*}{$\begin{array}{l}\text { Mesenchymal } \\
n=160 \\
28 ; 18\end{array}$} & \multirow{2}{*}{$\begin{array}{l}\text { Classical } \\
n=147 \\
13 ; 9\end{array}$} & \multirow{2}{*}{$\begin{array}{c}\begin{array}{c}\text { Neural } \\
n=96\end{array} \\
6 ; 6\end{array}$} \\
\hline Immunosuppressive & Galectin-3/LGALS3 & & & & & \\
\hline cytokines and & VEGFNEGFA & 20549821 & $16 ; 11$ & $26 ; 16$ & $32 ; 22$ & $3 ; 3$ \\
\hline \multirow[t]{6}{*}{ checkpoints } & IL-10/L-10 & 22981868 & $4 ; 3$ & $39 ; 24$ & $5 ; 3$ & $13 ; 14$ \\
\hline & IL-23/L-23A & 20404142 & $4 ; 3$ & $21 ; 13$ & $12 ; 8$ & $5 ; 5$ \\
\hline & TGF- $\beta /$ TGFB1 & 9597127 & $5 ; 4$ & $50 ; 31$ & $14 ; 10$ & $2 ; 2$ \\
\hline & PD-1/SPATA2 & 11209085 & $28 ; 20$ & $14 ; 9$ & $58 ; 39$ & $27 ; 28$ \\
\hline & PD-L1/PD-L1 & 22180678 & $0 ; 0$ & $25 ; 16$ & $14 ; 10$ & $5 ; 5$ \\
\hline & CTLA-4/CTLA-4 & 20578982 & $12: 9$ & $30 ; 19$ & $8: 5$ & $11: 11$ \\
\hline \multirow{8}{*}{$\begin{array}{l}\text { Tumor-supportive } \\
\text { macrophage chemotactic } \\
\text { and skewing molecules }\end{array}$} & CSF-1/CSF & 14709771 & $3 ; 2$ & $30 ; 19$ & 4,3 & 1,1 \\
\hline & $\mathrm{CCL} 2 / \mathrm{CCL} 2$ & 22162712 & $5 ; 4$ & $53 ; 33$ & $9 ; 6$ & $7 ; 7$ \\
\hline & CCL-22/CCL-22 & 20518016 & $10 ; 7$ & $33 ; 21$ & $17 ; 12$ & $12 ; 13$ \\
\hline & CD163/CD163 & 15478309 & $8 ; 6$ & $60 ; 38$ & $2 ; 1$ & $11 ; 11$ \\
\hline & CD204/MSR1 & 22083206 & $5 ; 4$ & $53 ; 33$ & $3 ; 2$ & $8 ; 8$ \\
\hline & MIC-1/GDF15 & 20534737 & $7 ; 5$ & $43 ; 27$ & $25 ; 17$ & $14 ; 15$ \\
\hline & Arginase/ARG1 & 20643302 & $9 ; 6$ & $23 ; 14$ & $16 ; 11$ & $22 ; 23$ \\
\hline & $\mathrm{CD} 47 / \mathrm{CD} 47$ & 19666525 & $15 ; 11$ & $30 ; 19$ & $10 ; 7$ & $19 ; 20$ \\
\hline \multirow{7}{*}{$\begin{array}{l}\text { Immunosuppressive } \\
\text { signaling pathways }\end{array}$} & IL-6/LL-6 & 23248265 & $32 ; 23$ & $83 ; 52$ & $16 ; 11$ & $15 ; 16$ \\
\hline & gp130/LL-6ST & 20610800 & $0 ; 0$ & $25 ; 16$ & $17 ; 12$ & $8 ; 8$ \\
\hline & Jak2 & 22684105 & $6 ; 4$ & $22 ; 14$ & $9 ; 6$ & $11 ; 11$ \\
\hline & STAT3/STAT3 & 20053772 & $8 ; 6$ & 31; 19 & $26 ; 18$ & $0 ; 0$ \\
\hline & Pim-1/PIM1 & 22384197 & $4 ; 3$ & $44 ; 28$ & $13 ; 9$ & $6 ; 6$ \\
\hline & socs3/SOCs3 & 10837055 & $5 ; 4$ & $36 ; 23$ & $10 ; 7$ & $3 ; 3$ \\
\hline & STAT5AVSTAT5A & 12835478 & $4 ; 3$ & $48 ; 30$ & $10 ; 7$ & $2 ; 2$ \\
\hline \multirow[t]{4}{*}{ Markers of Tregs } & $\mathrm{CD} 4 / \mathrm{CD} 4$ & 20605226 & $5 ; 4$ & $5 ; 36$ & $0 ; 0$ & $9 ; 9$ \\
\hline & CD278/ICOS & 23026134 & $8 ; 6$ & $23 ; 14$ & $9 ; 6$ & $9 ; 9$ \\
\hline & IDO/ID01 & 22932670 & $6 ; 4$ & $25 ; 16$ & $14 ; 10$ & $4 ; 4$ \\
\hline & FoxP3/FOXP3 & 20068105 & $0: 0$ & $0: 0$ & $0: 0$ & $0: 0$ \\
\hline
\end{tabular}

Table 2. Enrichment of immunosuppressors gene expression in the mesenchymal GBM subset. (Doucette, Rao et al. 2013)

Interestingly, according to the Repository of Molecular BRAin Neoplasia DaTa (Rembrandt) database, patients with GBM exhibit the highest levels of LIF compared to other glioma patients (fig. 6).

LIF gene expression plot

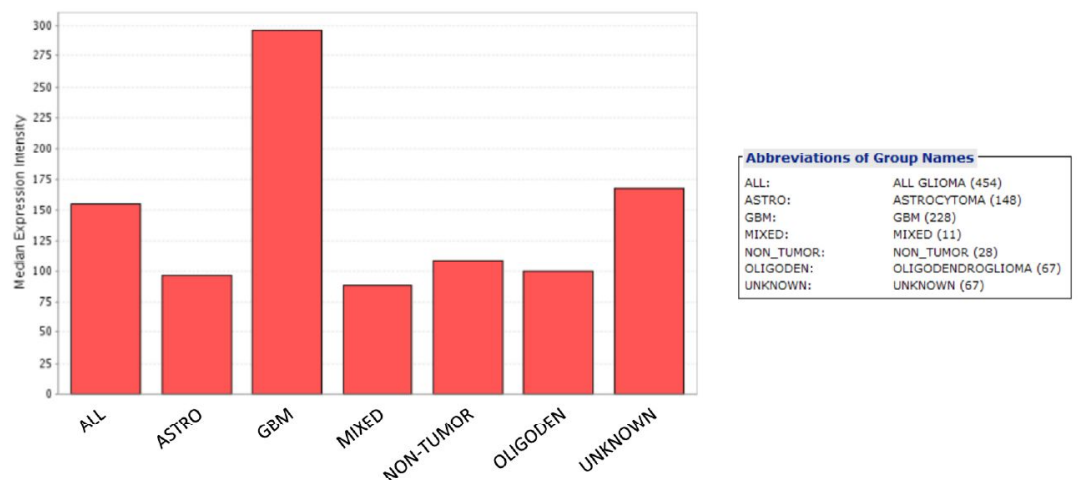

Figure 6. LIF expression levels in glioma subtypes. (data from Rembrandt database) 


\section{Immunity and cancer}

Cancer develops in a complex microenvironment, which contains numerous cell types in addition to tumor cells, such as stromal fibroblasts, infiltrating immune cells, the blood and lymphatic vascular networks, and the extracellular matrix (fig. 7) (Joyce 2005). Rudolf Virchow was the first to propose a link between chronic inflammation and tumorigenesis in 1863, following the observation that infiltrating leukocytes were a feature of tumors (Balkwill and Mantovani 2001). Since then, a plethora of studies have contributed to the characterization of the TME, and recently the evasion of immune destruction has been added as an emerging hallmark of cancer (fig. 8) (Hanahan and Weinberg 2011). However, despite considerable progress, important questions need further elucidation.

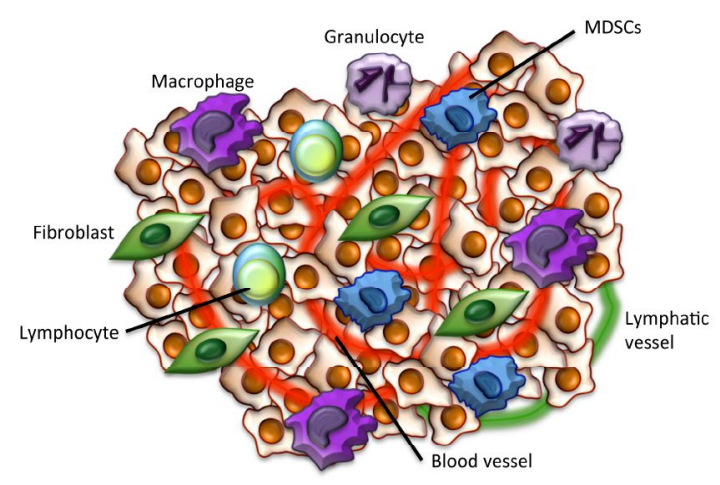

Figure 7. The tumor microenvironment. Cancer cells in primary tumors are surrounded by a complex microenvironment comprising numerous cells including endothelial cells of the blood and lymphatic circulation, stromal fibroblasts and a variety of immune cells, including macrophages, myeloid-derived suppressor cells (MDSCs) and lymphocytes.

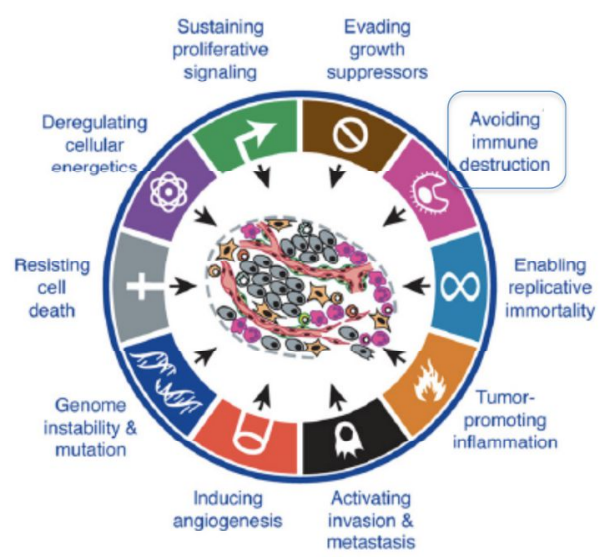

Figure 8. The hallmarks of cancer. This illustration encompasses the acquired capabilities by tumor necessary for growth and progression. The past decade has witnessed remarkable progress toward understanding the mechanistic underpinnings of each hallmark. One of the newest incorporated hallmarks is the capability of cancer cells to evade immunological destruction (Hanahan and Weinberg 2011). 
Tumor-associated inflammation drives tumor growth and can perpetuate itself through an extensive network of cytokines and chemokines, which are produced by immune, stromal and malignant cells in response to different signals. Those factors act in autocrine or paracrine manner to ensure the continuous recruitment of immune cells into the TME. Tumor-associated macrophages, myeloid-derived suppressor cells (MDSCs), and regulatory T cells (Tregs) are the most critical immune cell subsets in this aspect (Grivennikov, Greten et al. 2010), which are considered indicators of an immunosuppressive microenvironment. On the other hand, there are also anti-tumor forces in the immune system, which are mainly composed by infiltrating $\mathrm{CD}^{+} \mathrm{T}$, natural killer (NK) and mature dendritic cells (DCs), and are associated with a favorable prognosis (fig. 9) (Joyce and Pollard 2009).

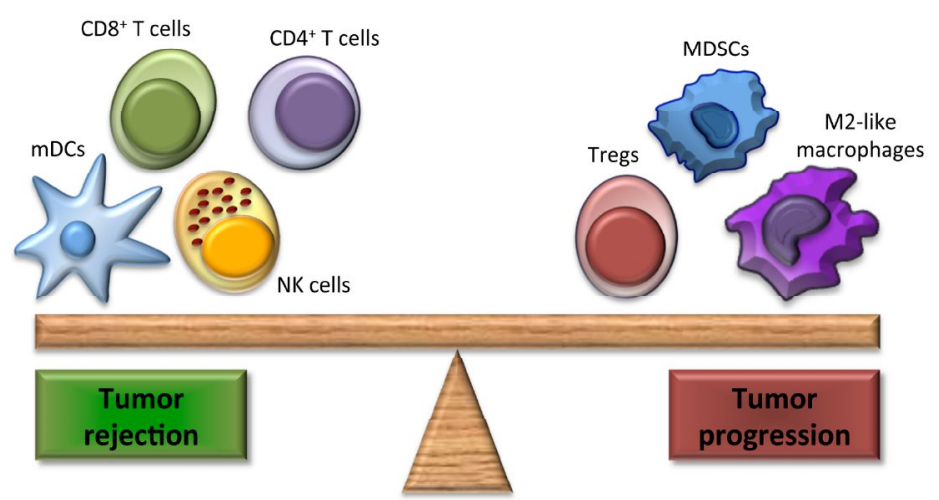

Figure 9. Tumor immunity is a balance between immune mediators that promote tumor progression versus mediators that promote tumor rejection. Citotoxic $\mathrm{CD} 8^{+} \mathrm{T}$ cells, helper $\mathrm{CD}^{+} \mathrm{T}$ cells, natural killer (NK) cells and mature dendritic cells (mDC) promote tumor destruction, while regulatory $T$ cells (Tregs), myeloid-derived suppressor cells (MDSCs) and M2-like macrophages promote tumor progression.

\subsection{Tumor-associated macrophages}

Tumor-associated macrophages are important components of the immune infiltrate and an important source of cytokines. They are basically derived from peripheral reservoirs of monocytes such as the bone marrow and spleen. Nevertheless, some authors asseverate that some of the macrophages within the tumor mass are tissue-resident species (Bingle, Brown et al. 2002, Biswas and Mantovani 2010, Pyonteck, Akkari et al. 2013, Quail and Joyce 2013). Komohara and collaborators provide a possible explanation for the origin of the different subpopulations within the tumor: while the tumor size is small, macrophages from the surrounding tissue accumulate in the tumor recruited by tumor cell-derived chemotactic molecules described below. In that situation, the vast majority of macrophages derives from the surrounding tissue. However, when the tumor size increases, the intra-tumoral vascular 
network is formed and the monocyte-derived tumor-associated macrophages become the dominant population of macrophages within the tumor (Komohara, Jinushi et al. 2014).

Macrophages can be classified into $\mathrm{M} 1$ and $\mathrm{M} 2$ phenotypes. M1 macrophages are capable of killing pathogens and priming anti-tumor immune responses. By contrast, M2 or "alternatively" activated macrophages show increased expression of the anti-inflammatory cytokines and a poor antigen-presenting capacity. In cancer context, the tumor takes advantage of M2-phenotype macrophages, which are able to remodel tissues, promote angiogenesis, invasion and metastasis, suppress adaptive immunity and, consequently, favor the tumor growth. Thus, mostly tumor-associated macrophages are considered to have an M2 phenotype (Mantovani, Allavena et al. 2008, Joyce and Pollard 2009, Grivennikov, Greten et al. 2010). In fact, it has been demonstrated that cancer cells require perivascular M2-like macrophages during the blood vessels invasion (Wyckoff, Wang et al. 2004). Based on the applied stimuli and the achieved transcriptional changes, some authors have classified M2-like macrophages into four subdivisions: $M 2 a, M 2 b, M 2 c$ and $M 2 d$. However, the in vivo translation of these $M 2$ subsets is difficult, because tissues contain mixed macrophage populations with a wide spectrum of activation states (Roszer 2015). For that reason, we will not differentiate between the subtypes and we will talk about general M2-like macrophages.

The immunosuppressive $\mathrm{M} 2$ phenotype is induced by exposure to IL-4, IL-13, M-CSF, IL-10 and TGF $\beta$ among other factors, and those macrophages are attracted to TME by M-CSF, CCL2, CCL12 and VEGF, which may be produced by cancer cells, cancer-associated fibroblasts or other tumor-associated cells (Mantovani, Sozzani et al. 2002, Burkholder, Huang et al. 2014). M2 macrophages are characterized by enhanced expression of CD163 (hemoglobin scavenger receptor) and MRC1/CD206 (mannose receptor C type I), and accelerated production of CCL22/MDC (macrophage-derived chemokine), among others (Mantovani, Sozzani et al. 2002, Komohara, Jinushi et al. 2014, Hughes, Qian et al. 2015, Ruffell and Coussens 2015). However, not all M2-skewed macrophages express all M2 markers, suggesting that the described M1 vs M2 phenotype is an oversimplification (Mantovani, Sozzani et al. 2002). In our work, we have focused on the three mentioned M2 markers due to their widespread use to identify prooncogenic tumor-associated macrophages.

Regarding its immunosuppressive role, tumor-associated macrophages express an array of effector molecules that are the responsible to inhibit the anti-tumor immune responses. These include cell surface molecules (such as PDL1, CD80 and CD86 that inhibit T, B, NK and NKT cells, explained in detail below; HLA-G that inhibit T cell function; HLA-E that inhibits NK cells; and the ligand for the death receptors FAS and TRAIL that triggers apoptosis in target cells), 
cytokines (IL-10 and TGF $\beta$ that inhibit T cells effector functions and induce regulatory functions by the up-regulation of FoxP3 and CTLA-4 in $\mathrm{CD}^{+} \mathrm{T}$ cells), chemokines (CCL5, CCL17, CCL18, CCL20 and CCL22, which recruit Tregs) and enzymes (arginase I, which metabolizes L-arginine, an essential amino acid for proper $\mathrm{T}$ cell function). To sum up, tumor-associated macrophages suppress cytotoxic functions of $T, N K T, N K$, and $B$ cells, suppress DC generation and its function as antigen-presenting cells (APCs), promote T cell apoptosis, inhibit NK cells migration, and recruit and induce Tregs (fig. 10) (Duluc, Corvaisier et al. 2009, Komohara, Jinushi et al. 2014, Noy and Pollard 2014). In fact, it has been observed that the intra-tumoral number of Tregs correlates with the number of tumor-associated macrophages (Komohara, Jinushi et al. 2014).

Furthermore, M1 and M2 macrophages are characterized by a high plasticity and they can alter their polarization state to accommodate different physiological conditions. The presence of high tumor-associated macrophage content generally is associated with poor prognosis (Mantovani, Sozzani et al. 2002, Grivennikov, Greten et al. 2010, Quail and Joyce 2013).

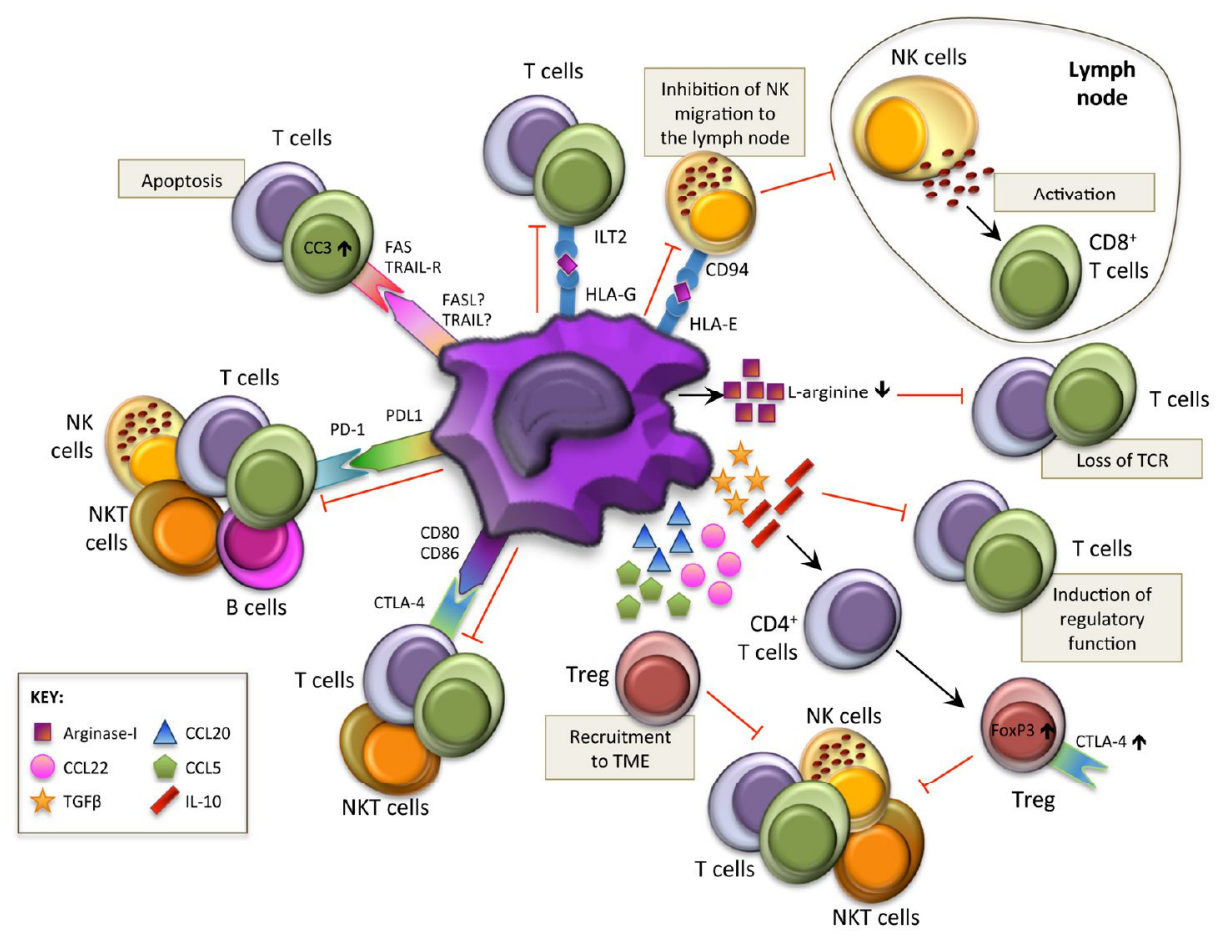

Figure 10. Pro-tumor macrophage mechanisms to inhibit anti-tumor forces. M2-like macrophages express PDL1 and CD80/CD86, the ligands for PD-1 and CTLA-4 respectively that are expressed by the target immmune effector cells (T, NKT and NK cells), which upon activation suppress their cytotoxic functions; the ligand for the death receptors FAS and TRAIL that triggers caspase 3 ( $\mathrm{CC} 3$ )-dependent cell death in target cells; the nonclassical HLA-G that inhibits T cell function through interaction with the costimulatory signal of $T$ cells ILT2; and HLA-E that inhibits NK cells through CD94. Tumor-associated macrophages also secrete the cytokines IL-10 and TGF $\beta$ that inhibit T cells effector functions and induce regulatory functions; and chemokines $\mathrm{CCL} 5, \mathrm{CCL} 20$ and $\mathrm{CCL} 22$, among others, that recruit Treg cells. Those macrophages also secrete Arginase I enzyme that inhibit TCR expression in activated $\mathrm{T}$ cells by the depletion of L-arginine. 


\subsection{Myeloid-derived suppressor cells (MDSCs)}

Hematopoietic stem cells give rise to common myeloid precursors, which subsequently originate monocytes and granulocytes, all of them expressing CD11b. Morphologically, MDSCs consist of a mixture of monocytic and granulocytic cells. Recently, specific markers that identify two major subsets of MDSCs were described, and currently MDSCs can be subdivided into two major groups: granulocytic MDSCs (G-MDSCs) and monocytic MDSCs (M-MDSCs) (fig. 11). As can be discerned from their names, G-MDSCs have a morphology similar to that of granulocytes, and M-MDSC have a morphology similar to that of monocytes. Moreover, they differ not only in morphology, but also in the mechanisms by which they suppress immune function. G-MDSCs require close cell-to-cell contact with T cells, while M-MDSCs effectively suppress antigen-independent $\mathrm{T}$ cell responses without requiring direct contact. Both subsets have been reported to play a crucial role in cancer, but the proportion of G-MDSCs and MMDSCs in different tumor models is highly variable and depends on factors that are not yet well understood. It is important to point out that the morphological and functional heterogeneity of MDSCs is not limited to these two major subsets. There are likely other intermediate groups of cells with a distinct phenotype reflecting different stages of cell differentiation (Youn and Gabrilovich 2010). In cancer context, MDSCs are accumulated in blood, in spleen and in bone marrow, and are recruited to the TME by VEGF, GM-CSF, M-CSF, IL-3 and IL- 6 among other factors secreted by the tumor. It may happen a latter pathway through which MDSCs evolve into a M2 macrophage-like phenotype. Thus, MDSCs are functionally defined as a heterogeneous population of immunosuppressive immature myeloid cells which, together with tumor-associated macrophages, with which share several markers, represent a continuum of a unique myeloid cell-differentiation program induced by tumorderived factors to support tumor development (Sica and Bronte 2007, Gabrilovich and Nagaraj 2009).

MDSCs are able to disrupt the major mechanisms of immunosurveillance including DC differentiation and presentation of antigen, $T$ cell activation, M1-like macrophage polarization, and inhibition of NK cell cytotoxicity and B cells. Thus, they have the capacity to suppress both the innate and the adaptive immune response. In addition, MDSCs are able to induce the development of Tregs (Sica and Bronte 2007, Gabrilovich and Nagaraj 2009, Burkholder, Huang et al. 2014). It has been shown that tumor-infiltrated or peripheral MDSCs are associated with tumor growth and malignant progression (Joyce and Pollard 2009, Quail and Joyce 2013, Burkholder, Huang et al. 2014). 


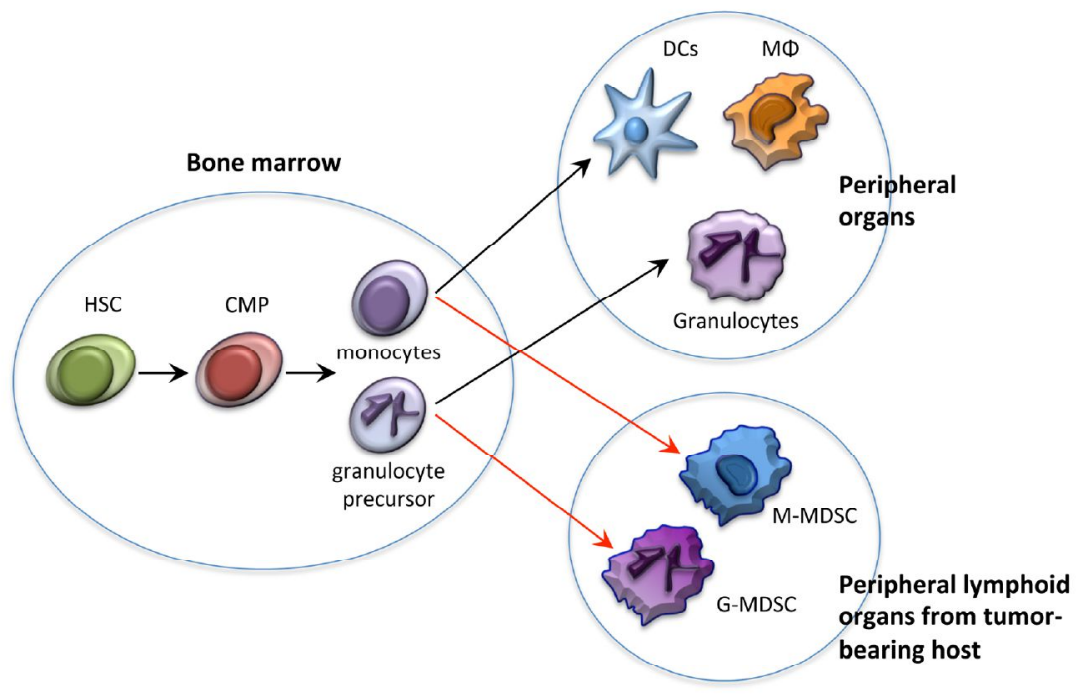

Figure 11. Scheme of MDSC differentiation pathway in cancer. The origin of MDSCs is part of the normal process of myelopoiesis, which takes place in the bone marrow. Hematopoietic stem cells (HSCs) differentiate into common myeloid progenitor (CMP) cells, and then into monocytes and granulocytes precursors. Normally, immature myeloid cells migrate to different peripheral organs, where they differentiate into dendritic cells (DCs), macrophages (MD) or granulocytes. However, factors produced in the tumor microenvironment, prevent the differentiation of immature myeloid cells and induce their activation. These cells exhibit immunosuppressive functions and are therefore known as myeloid-derived suppressor cells (MDSCs). Black lines denote myeloid cell differentiation under physiologic conditions. Red lines show MDSCs development in tumor-bearing host.

\subsection{Regulatory T cells (Tregs)}

Tregs are a small subset of T lymphocytes characterized by the expression of CD25 and FoxP3, which modulate the immune system maintaining the self-antigen tolerance, and which prevent the development of immunopathologies, such as autoimmune diseases. However, in the tumor context, Tregs are recruited by the tumor-secreted chemokines, such as CCL22 secreted by M2 macrophages and MDSCs, as described above. Progressively, Tregs accumulate in the blood and lymphoid organs to, finally, infiltrate the tumor area where significantly suppress immune responses by cell-to-cell contact (for instance, through CTLA-4 expression, as described below) or through soluble factor-dependent mechanisms (TGF $\beta$ and IL-10 among others), leading to immune tolerance to tumor cells (Curiel, Coukos et al. 2004, Gobert, Treilleux et al. 2009, Crane, Ahn et al. 2012). Tregs block the activation of $\mathrm{CD}^{+}$and $\mathrm{CD} 8^{+} \mathrm{T}$ cells, B cells and NKT cells, prevent DC maturation, kill mature DCs, and suppress NK cells principally by impairing its effector functions, and also affecting late stages of its differentiation (Beyer and Schultze 2006, Joyce and Pollard 2009, Shevach 2009, PedrozaPacheco, Madrigal et al. 2013). Moreover, Tregs are able to lead monocyte differentiation towards an M2 phenotype (Tiemessen, Jagger et al. 2007). Similar to M2 macrophages and 
MDSCs, it has been observed an increased number in peripheral blood and tumor-infiltrating $\mathrm{CD}^{+}$Tregs that correlates with a poor prognosis in cancer patients (Grivennikov, Greten et al. 2010, Choi, Kim et al. 2012, Burkholder, Huang et al. 2014, Anz, Rapp et al. 2015).

Although Tregs are commonly identified as $\mathrm{CD} 4^{+} \mathrm{CD} 25^{+} \mathrm{FoxP}^{+} \mathrm{T}$ cells, it has been reported that there are a small emerging subset of $\mathrm{CD} 8^{+}$Tregs with suppressive activities ( $\mathrm{CD} 8^{+} \mathrm{CD} 25^{+} \mathrm{Fox}^{+} 3^{+}$). They are not deeply studied due to the initial technical difficulties in its characterization, and due to they were outshined by the emergence of $\mathrm{CD} 4^{+}$Tregs (Wang and Alexander 2009). $C D 8^{+}$ Tregs are present at steady state at low levels both in human and mouse peripheral blood. Churlaud and colleagues showed that $\mathrm{CD} 8^{+}$Tregs are able to suppress the effector $\mathrm{T}$ cell proliferation at similar levels, or even better, than $\mathrm{CD}^{+}$Tregs. Thus, their extraordinary suppressive activity makes them important components in the immune system response. The mechanisms implicated in its suppressive activity include direct lysis of target cells and secretion of immunosuppressive cytokines, prevention of DC maturation, and suppression of mature DCs, T cells and B cells (Churlaud, Pitoiset et al. 2015). In cancer, it has been demonstrated that $\mathrm{CD} 8^{+}$Tregs from colorectal cancer (CRC) and prostate tumors have strong immunosuppressive properties, which may contribute to tumoral immune escape and disease progression (Kiniwa, Miyahara et al. 2007, Chaput, Louafi et al. 2009).

\subsection{Mechanism of immunosuppression of effector T cells: PD-1/PDL1 pathway}

Besides altering the balance of immune cell populations increasing the number of $M 2$ macrophages, MDSCs and Tregs, tumors show other abilities to escape immunesurveillance, such as by the direct suppression of effector T cell response, which appear to be the dominant forces of the anti-tumor response and, therefore, the primary targets of tumor-induced immunosuppression (Burkholder, Huang et al. 2014, Sharma and Allison 2015). Tumors express antigens that could be recognized by host T cells, although immunological clearance of tumors is rare. Part of this failure is due to the immunosuppression promoted by the tumor itself, which takes advantage of the host systems for its own benefit.

In a normal context, $\mathrm{T}$ lymphocytes become activated via a two-signal process in which first, $\mathrm{T}$ cell receptor (TCR) must bind to an antigen presented on a major histocompatibility complex (MHC) protein expressed on the cell surface of another cell and second, CD28 must concurrently bind with its ligands, CD80 or CD86. Without this second signal, the adaptive immune response is inhibited by a mechanism named $T$ cell anergy. As part of a safety mechanism that modulates the intensity of the immune response, $\mathrm{T}$ cell anergy may also result when the co-inhibitory receptor cytotoxic T lymphocyte-associate protein-4 (CTLA-4) competes 
with $C D 28$ to bind its ligands, CD80 and CD86, or if programmed death-1 (PD-1) receptor binds its ligand, PDL1 (fig. 12a) (Burkholder, Huang et al. 2014). In fact, the own T cell activation leads to an autocrine feedback negative loop which up-regulates CTLA-4 and PD-1 expression and attenuates immune responses limiting the extension of immune-mediated tissue damage (Freeman 2008, Sharma and Allison 2015). The impact of PDL1/PD-1 interactions has been well characterized in PD-1-expressing T cells, but also in B cells, DCs and NKTs.

a

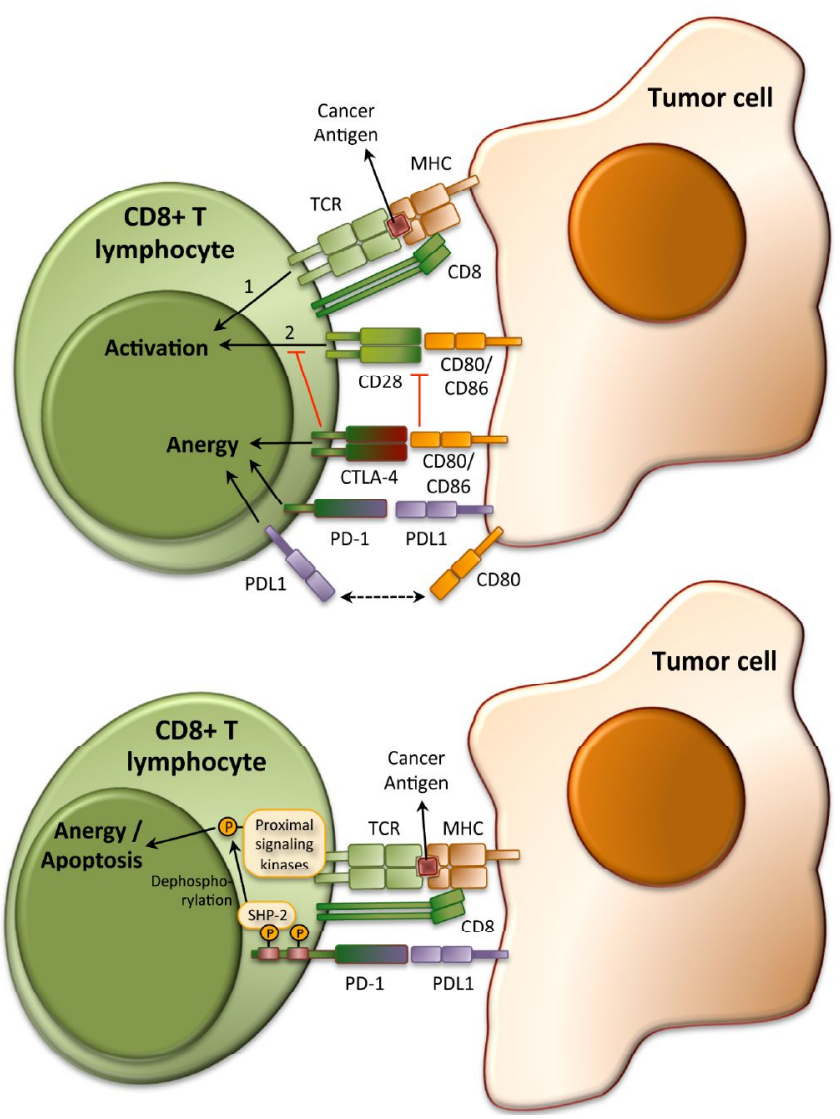

Figure 12. Mechanism of direct immunosuppression of effector $T$ cells. (a) $T$ cell activation requires at least two signals to become fully activated. The first occurs when Tcell receptor (TCR) binds to major histocompatibility complex (MHC), and the second when CD28 binds to CD80 or CD86. As part of a safety mechanism to prevent over-active autoimmune responses, $T$ cell up-regulates CTLA-4, which competes to bind CD28 ligands, and PD-1 expression. The up-regulation of those receptors leads to the T cell own anergy. Moreover, CD80 has been identified as an another binding partner for PDL1, also expressed by T cells, with an immunosuppressive effect. (b) PDL1 binds to its receptor PD1 , which leads to the phophorylation of PD-1 cytoplasmic domain and to the recruitment of SHP-2 phosphatase. SHP-2 dephosphorilates TCR, which results in T cell anergy and/or apoptosis.

Several authors have reported that PDL1 expression in tumors is a key component of the suppressive tumor milieu, and its expression is inversely correlated with patients' survival (Duraiswamy, Freeman et al. 2013). When PDL1 binds to its receptor PD-1 on lymphocytes, it promotes the tyrosine phosphorylation of the PD-1 cytoplasmic domain and the recruitment of 
phosphatases, particularly SHP2. This leads to the dephosphorylation of TCR proximal signaling molecules and to the attenuation of the TCR/CD28 signal, which results in T cell anergy and/or apoptosis (fig. 12b) (Freeman, Long et al. 2000, Freeman 2008)

Besides the expression on tumor cells surface, PDL1 is also expressed on T cells, where it is able to down-regulate $T$ cell cytokine own production which results in T cell inhibition, and on Tregs and tumor-associated myeloid cells (TAMCs), where its function is to inhibit anti-tumor immune cells (Latchman, Liang et al. 2004, Duraiswamy, Freeman et al. 2013). Furthermore, Butte and colleagues have identified CD80 as a binding partner for PDL1, demonstrating a specific and significant bidirectional interaction that inhibits $\mathrm{T}$ cell response (Butte, Keir et al. 2007) (fig. 12a). Additionally, PDL1/PD-1 engagement increases the pool of Tregs, although it is unclear whether the interaction of PD-1 with its ligand converts naivve CD4 ${ }^{+} \mathrm{FoxP}^{-} \mathrm{T}$ cells to FoxP3 $^{+}$Tregs, expands FoxP3 ${ }^{+}$Tregs, or selectively reduces FoxP3- T-cell population. On the other hand, PD-1 receptor is expressed on DCs, B cells, NKT cells, and on activated CD4 ${ }^{+}$and CD8 ${ }^{+} T$ cells (Sumpter and Thomson 2011).

PDL1 expression has been shown in situ on a wide variety of solid tumors including lung, colon, ovarian and gliomas among others, and its expression strongly correlates with unfavorable prognosis (Keir, Butte et al. 2008). In addition, PD-1 expression is up-regulated in tumor infiltrating lymphocytes, and this may also contribute to tumor immunosuppression (Blank, Brown et al. 2003). Studies using animal models demonstrate that PDL1 expression in tumors inhibits T cell activation and lysis of tumor cells and eventually leads to an increased tumorspecific T cell death (Dong, Strome et al. 2002, Hirano, Kaneko et al. 2005). Moreover, it has been shown that PDL1 blockade improves the outcome of other immunotherapies. For instance, Strome and colleagues demonstrated that administration of anti-PDL1 concomitantly with activated $T$ cell increases the rejection of a PDL1-expressing squamous cell carcinoma (Strome, Dong et al. 2003). Thus, it is not surprising that recently PD-1 and PDL1 are considered some of the most attractive targets in cancer immunotherapy.

\subsection{Immunotherapy}

Over the last decades, a lot of effort has been invested in the understanding of the genetic pathways involved in cancer in order to develop therapies to target the tumor cells. Initially, some tumors with mutations affecting a particular signaling pathway demonstrated to be very sensitive to certain therapies. However, the emergence of resistance mechanisms comprised the patient's life very often (Sharma and Allison 2015).

Recently, tumors are being studied as a set of different cell types what is called the TME. 
Understanding the pathways involved in cancer-related inflammation could enable the development of therapies that target specifically the inflammatory components of the microenvironment. Those drugs should prevent immune cells that favor tumor growth from migrating to the tumor site or should re-educate the tumor-promoting inflammatory infiltrate, converting a tumor-promoting microenvironment on a tumor inhibiting-microenvironment, by promoting tumor-specific adaptive immune responses (Mantovani, Allavena et al. 2008). But it has been shown that only a fraction of patients have presented an effective response. It has been proposed that targeting multiple immune checkpoints with different mechanisms (such as CTLA-4 and PD-1/PDL1) could represent an improvement for a greater number of patients. As mentioned above, PD-1/PDL1 pathway is considered an attractive target in cancer immunotherapy. In fact, several antibodies against PD-1 and PDL1 are in development in different clinical trials, and two antibodies against PD-1 (Pembrolizumab and Nivolumab) were approved by FDA in 2014 for patients with advanced melanoma and NSCLC (Table 3). It has been shown promising results in multiple tumor types (melanoma, NSCLC, CRC, renal, ovarian, bladder, head and neck, gastric carcinomas) of antibodies against both targets. Although limited to a fraction of patients, most of the responses, when observed, are rapid and durable (Kim and Eder 2014, Sharma and Allison 2015).

\begin{tabular}{|c|c|c|c|c|}
\hline Agent & Target & Description & $\begin{array}{l}K_{\mathrm{b}} \text { Binding } \\
\text { Affinity }\end{array}$ & \begin{tabular}{|l} 
Study \\
[Reference]
\end{tabular} \\
\hline $\begin{array}{l}\text { Nivolumab } \\
\text { (BMS-936558, ONO-4538, MDX-1106) }\end{array}$ & PD-1 & Finally human lgG4 & $3 \mathrm{nM}$ & Topalian et al[7] \\
\hline $\begin{array}{l}\text { Pembrolizumab } \\
\text { (MK-3475, lambrolizumab) }\end{array}$ & PD-1 & Humanized lgG4 kappa & $28 \mathrm{pM}$ & Hamid et al[65] \\
\hline Pidilizumab (CT-011) & PD-1 & Humanized anti-PD-1 lgG1 kappa & $20 \mathrm{nM}$ & Atkins et al[15] \\
\hline AMP-224 & PD-1 & B7-DC/lgG1 fusion protein & NA & Infante et al[66] \\
\hline MSBU010/18C (EMD-Serono) & PD-L1 & Fully human IgGı & NA & Heery et al $[6 /]$ \\
\hline MEDI4736 & PD-L1 & Engineered human lgG1 kappa & NA & Lutzky et al[18] \\
\hline MPDL $3280 \mathrm{~A}$ & PD-L1 & Engineered lgG1 & NA & Herbst et al[49] \\
\hline
\end{tabular}

Table 3. Anti-PD-1 and anti-PDL1 antibodies in clinical development. Nivolumab and Pembrolizumab were approved by FDA in 2014 for melanoma patients, and Nivolumab was approved in 2015 for NSCLC patients (Kim and Eder 2014).

Furthermore, growing body of evidences suggest that the establishment of an effective antitumor immune response in patients will be essential for the success of any anti-tumor therapy, regardless its modality (fig. 13a,b) (Mantovani, Allavena et al. 2008, Burkholder, Huang et al. 2014, Sharma and Allison 2015). Understanding how different therapeutic agents affect the responsiveness to immunotherapy will be crucial for the choice of drugs combinations in each particular case. Some preclinical and early clinical studies with encouraging results suggest that 
this could be an attractive approximation. However, despite the considerable progress, many important questions regarding the mechanisms of action remain to be answered. Therefore, immunotherapy is becoming a new pillar of the war against cancer along with surgery, radiation, chemotherapy or genetically targeted therapy (Burkholder, Huang et al. 2014, Sharma and Allison 2015).

a

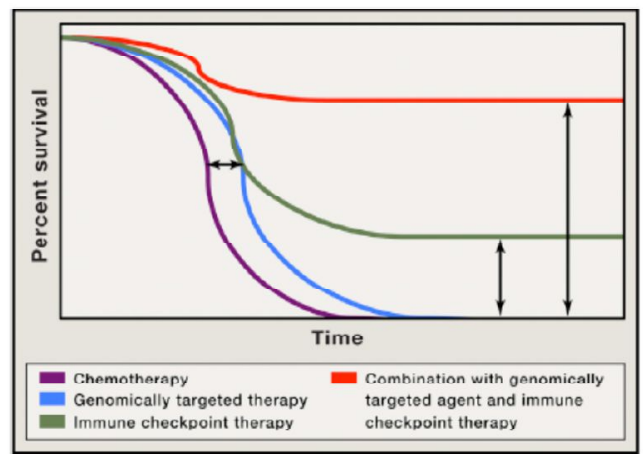

b

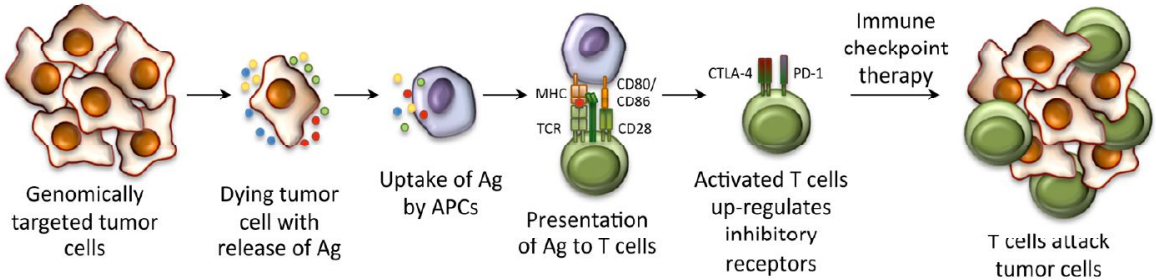

Figure 13. The combination of immunotherapy with other anti-tumor therapies may improve the anti-tumor response and the overall survival. (a) Representation of KaplanMeier survival curves with genomically targeted agents (blue line) as compared to standard therapies (purple line), indicating an improvement in median overall survival but lack of durable responses. In response to immune checkpoint therapy (green line), there is an improved median overall survival and durable responses only in a fraction of patients. But with a combination of genomically targeted agents and immune checkpoint therapy (red line) the majority of patients show an improved median overall survival with durable response (Sharma and Allison 2015). (b) Tumor cells dye as a result of genomically targeted therapies releasing tumor antigens $(\mathrm{Ag})$. Those $\mathrm{Ag}$ are presented by antigen-presenting cells (APCs) and recognized by $\mathrm{T}$ cells, which become activated. As a feedback mechanism, activated $T$ cells up-regulate inhibitory receptors, such as CTLA-4 and PD-1. Immune checkpoint therapy prevents the attenuation of $\mathrm{T}$ cell responses promoted by those inhibitory receptors, thereby allowing $T$ cells to kill tumor cells.

\section{Hypothesis}

In our work, we have characterized the role of LIF in the immune system in the context of cancer. The fact that LIF acts as an oncogenic factor and that it is highly expressed in certain tumor types, together with its immunomodulatory function in different biological processes such as embryo implantation, transplantation tolerance, multiple sclerosis (MS), and possibly in promoting the differentiation of macrophages towards a M2-like phenotype in ovarian 
carcinoma (Metcalfe, Watson et al. 2005, Schofield and Kimber 2005, Duluc, Delneste et al. 2007, Trouillas, Saucourt et al. 2009, Janssens, Van den Haute et al. 2015), allowed us to generate the hypothesis that tumors expressing high levels of LIF will promote an immune tolerant microenvironment that will compromise the anti-tumor immune response. 


\section{OBJECTIVES}


The LIF signaling pathway is aberrantly activated in some patients across different types of cancer and confers poor prognosis. The aim of this thesis is the study of the molecular mechanisms involved in the immunomodulation induced by LIF in cancer.

The main objectives are listed below:

Evaluate LIF expression across different tumor types.

$>$ Study the response to the blockade of LIF using different murine syngeneic models and patient-derived tumor xenograft models.

$>$ Characterize the effect of LIF on immune cell populations within the tumor microenvironment.

$>$ Validate our findings in organotypic models.

$>$ Study a possible molecular mechanism induced by LIF that leads to the inhibition of effector anti-tumor immune cells.

Study the correlation between LIF, cancer-initiating cell population and immune suppression in GBM. 
MATERIALS AND METHODS 


\section{Cell lines culture}

All the cell lines were cultured in surface-treated plates (BD Falcon) using Dulbecco's Modified Eagle Medium (DMEM) (Gibco, Invitrogen), Roswell Park Memorial Institute medium (RPMI) (Gibco, Invitrogen) or Eagle's Minimal Essential Medium (EMEM) (ATCC) supplemented with $10 \%$ Fetal Bovine Serum (FBS) (Gibco, Invitrogen), 40U/ml Penicillin and 40 $\mathrm{\mu g} / \mathrm{ml}$ Streptomycin (PenStrep) (Gibco, Invitrogen) and 0,25 $\mathrm{g} / \mathrm{ml}$ Plasmocin (Invivogen) (Table 4). Cells were kept at $37{ }^{\circ} \mathrm{C}$ in an atmosphere of $5 \% \mathrm{CO}_{2}$, and frozen with $\mathrm{FBS} 10 \%$ DMSO (Sigma). Cells were maintained in a subconfluent state. Before reaching the confluence, cells were rinsed with PBS and incubated with Trypsin-EDTA (Gibco, Invitrogen) at 37으 $\mathrm{C}$ until cells detachment. Medium was added to inactivate trypsin and cells were subsequently diluted in fresh media. For in vitro assays, cell lines were seeded in surface treated multi-wells (Nunc).

\begin{tabular}{|cccc|}
\hline Cell lines & Origin & Culture media & Obtained from \\
\hline CT26 & Mouse CRC & RPMI + 10\% FBS & ATCC \\
ID8 & Mouse ovarian cancer & DMEM + 10\% FBS & $\begin{array}{c}\text { Dr. Coukos (Ludwing Institute } \\
\text { for Cancer Research, Lausanne) }\end{array}$ \\
\hline HM1 & Mouse ovarian cancer & DMEM + 10\% FBS & RIKEN \\
\hline KLN205 & Mouse NSCLC & EMEM + 10\% FBS & ATCC \\
\hline GL261 & Mouse GBM & RPMI + 10\% FBS & Charles River \\
\hline SMA560 & Mouse GBM & DMEM + 10\% FBS & Dr. Weller (University of Zurich) \\
\hline A172 & Human GBM & DMEM + 10\% FBS & ATCC \\
\hline LN229 & Human GBM & DMEM + 10\% FBS & ATCC \\
\hline U251 & Human GBM & DMEM + 10\% FBS & ATCC \\
\hline U373 & Human GBM & DMEM + 10\% FBS & ATCC \\
\hline U87 & Human GBM & DMEM + 10\% FBS & ATCC \\
\hline T98G & Human GBM & DMEM + 10\% FBS & ATCC \\
\hline HEK 293T & Human embryonic kidney & DMEM + 10\% FBS & ATCC \\
\hline
\end{tabular}

Table 4. List of cell lines used

\section{Cells from GBM patients isolation and culture}

Human GBM specimens were obtained from the Vall d'Hebron University Hospital. The clinical protocol was approved by the Vall d'Hebron Institutional Review Board (CEIC), with informed consent obtained from all subjects.

Tumor samples were processed within $30 \mathrm{~min}$ after surgical resection. Tumor pieces were chopped with a scalpel and digested with $100 \mu \mathrm{l}$ of collagenase I (200U/ml) (Sigma) and $500 \mu \mathrm{l}$ of DNase I (500U/ml) (Sigma) for $1 \mathrm{~h}$ at 37으 $\mathrm{C}$ with 1400 rpm agitation. The single-cell suspension was filtered through a $70 \mu \mathrm{m}$ cell strainer (BD Falcon) and washed with PBS. Cells were pelleted by centrifugation at $400 \mathrm{~g}$ during $5 \mathrm{~min}$ and erythrocytes were lysed with $1 x$ erythrocyte lysis 
buffer (stock solution 10x: 8,99g NH $\mathrm{NH}_{4} \mathrm{CL} \mathrm{g} \mathrm{KHCO}_{3}+0,037 \mathrm{~g}$ EDTA-NA $+\mathrm{H}_{2} \mathrm{O}$ up to $100 \mathrm{ml}$ ) for $4 \mathrm{~min}$ at room temperature (RT). After, cells were washed with PBS and centrifuged $5 \mathrm{~min}$ at 400g. Pelleted cells were resuspended, and subsequently cultured in Neurobasal medium (Gibco, Invitrogen) supplemented with B27 (Gibco, Invitrogen), 20ng/ml EGF and 20ng/ml FGF2 (PeproTech), 40U/ml Penicillin and 40 $\mathrm{gg} / \mathrm{ml}$ Streptomycin (PenStrep) (Gibco, Invitrogen), $0,4 \mu \mathrm{g} / \mathrm{ml}$ of Fungizone-Amphotericin B (Gibco, Invitrogen) and $0,25 \mu \mathrm{g} / \mathrm{ml}$ Plasmocin (Invivogen). Patient-derived cells grew in suspension forming neurospheres, and were enriched in glioma initiating cells. They were kept at 370 in $5 \% \mathrm{CO}_{2}$, and frozen using Bambanker cell freezing media (Cultek). Neurospheres were disaggregated manually using a micropipette to avoid the formation of spheres aggregates using Accutase (Sigma). For in vitro assays, these cells were seeded in non-tissue culture treated multi-wells (BD Falcon).

\section{Human GBM organotypic slice culture}

Fresh tumor tissue specimens were obtained during surgical resections of GBM from patients at Vall d'Hebron University Hospital. This study and the tissue collection protocol were approved by the Vall d'Hebron Institutional Review Board (CEIC), with informed consent obtained from all subjects. After resection, the harvested tissue was immediately placed into ice cold Hank's balanced salt solution (HBSS) (Gibco, Invitrogen) and transported immediately to the laboratory where it was processed under sterile conditions. Surgical specimens were cut with a scalpel into rectangular blocks of $5-10 \mathrm{~mm}$ length and $1-2 \mathrm{~mm}$ width. The resultant pieces were further sectioned into $300 \mu \mathrm{m}$ thick slices using a Mcllwain tissue chopper (Lafayette Instruments) and placed into a Petri dish containing PBS. The brain slices were gently separated under a stereomicroscope (SZ61 Olympus) with 2 sterile scalpels and individually transferred into membrane culture inserts (Millipore) within 6 well plates. Before placing the inserts into 6 well plates, $1,2 \mathrm{ml}$ of Neurobasal medium (Gibco, Invitrogen) supplemented as described above were placed into each well. The cultures were kept at $37^{\circ} \mathrm{C}$ in an atmosphere of $5 \% \mathrm{CO}_{2}$. Culture medium was refreshed the first day after preparation and every consecutives 2 days. After 2 days, slices were treated with either vehicle or anti-LIF $(10 \mu \mathrm{g} / \mathrm{ml})$ for 3 days. Then, slices were rinsed twice in PBS, fixed with formalin over-night $(\mathrm{O} / \mathrm{N})$ and paraffin-embedded sections were prepared.

\section{Human PBMCs from healthy donors isolation and culture}

\subsection{Human monocytes ( $\mathrm{CD} 14^{+}$cells) from buffy coat}

Buffy coats were obtained from the Blood and Tissues Bank, from the Department of Health from the Generalitat of Catalunya. The clinical protocol was approved by the Vall d'Hebron 
Institutional Review Board (CEIC). $10 \mathrm{ml}$ of buffy coat from healthy donors were diluted in $20 \mathrm{ml}$ PBS supplemented with $10 \%$ heat-inactivated FBS $(45 \mathrm{~min}, 56 \% \mathrm{C})$, and these $30 \mathrm{ml}$ were added on the top of $10 \mathrm{ml}$ of ficoll (Lymphosep, Biowest) very slowly to prevent breaking the density gradient. The gradients were centrifuged at $2000 \mathrm{rpm}$ for $25 \mathrm{~min}$ at RT without brakers. Using a pipette, the peripheral blood mononuclear cells (PBMCs) layer (fig. 14a) was carefully transferred into a new centrifuge tube. Next, the plasma, which is essentially free of cells, was transferred into the same tube with the aim to be sure that all PBMCs were recovered. This step must be done with care in order to transfer the minimum amount of ficoll. After that, cells were washed twice with PBS with 10\% heat-inactivated FBS and centrifuged at 1500rpm for $5 \mathrm{~min}$. Pelleted cells were resuspended in $1 \mathrm{ml}$ of MACS sterile buffer (PBS pH7,2+0,5\% BSA + 2mM EDTA) and counted with the Coulter Counter (Beckman Coulter) (making a 1:20 dilution), which gave the number of total leukocytes, and also the percentage of lymphocytes and monocytes. Then, keeping cells cold, monocytes were isolated with CD14 magnetic beads (Miltenyi) following manufacturer instructions using the autoMACS separator (Miltenyi). The volumes of the reagents were calculated taking into account the total leukocyte population. The magnetic separation was performed using the Possel program from the autoMACS. After $\mathrm{CD} 4^{+}$cells isolation, cells were counted again with an automated cell counter (Countess, Invitrogen), verifying the purity of the isolation by comparing this counting with the extrapolation of the number of cells from the initial percentage of monocytes from Coulter Counter. The purity of CD14 $4^{+}$isolated cells was also checked by qRT-PCR of the positive and negative fraction. Finally, cells were washed with PBS, centrifuged at $400 \mathrm{~g}$ for $5 \mathrm{~min}$, and seeded at $1 \times 10^{6}$ cells/well in 12 well surface treated plates (Nunc) in RPMI supplemented with $10 \%$ heat-inactivated FBS, 20ng/ml Granulocyte Macrophage-Colony Stimulating Factor (GMCSF, Sigma) and $1: 1$ of the corresponding $72 \mathrm{~h}$ conditioned media of U251 control, shLIF or treated with anti-LIF neutralizing antibody. Cell media was refreshed (identically) 3 days after seeding and at day 5 supernatants were processed for CCL22 ELISA and cells were lysed for mRNA extraction (see in corresponding sections below). All these procedures were done in sterile conditions.

\subsubsection{Phagocytosis assay}

For the phagocytosis assay, 500.000 of Zymosan A Bioparticles labeled with fluorescein (Life Technologies) were added to each well at day 5 after seeding and incubated for $1 \mathrm{~h}$ at $37^{\circ} \mathrm{C}$. Cells were then washed $4 x$ with cold PBS, fixed with $4 \%$ formaldehyde and the percentage of phagocytic capacity was calculated by cell counting ( 6 fields/condition). 
a

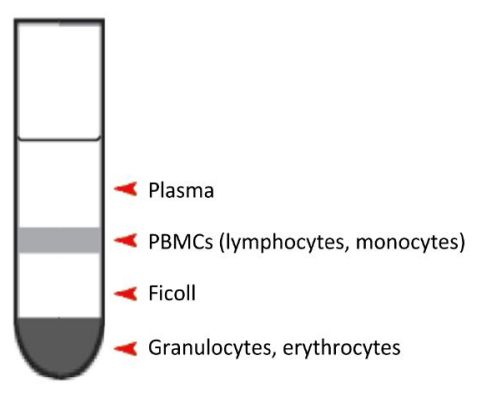

b

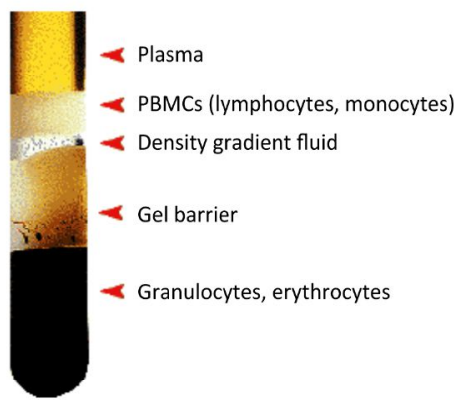

Figure 14. Scheme of density gradients. (a) Density gradient to isolate PBMCs from buffy coat from Blood and Tssues Bank. (b) Density gradient to isolate PBMCs from fresh whole blood from healthy donors.

\subsection{Human PBMCs from fresh blood}

Fresh blood was obtained from healthy donors. 4 vacutainer CPT tubes (BD Bisociences) were drawn from the volunteer and were centrifuged at $3100 \mathrm{rpm}$ for $25 \mathrm{~min}$ at RT without brakers. Using a pipette, the upper layer, which included PBMCs (lymphocytes and monocytes) and plasma (fig. 14b), was transferred into a centrifuge tube and centrifuged at $1250 \mathrm{rpm}$ for $15 \mathrm{~min}$ at RT. Pelleted cells were washed with PBS, centrifuged at 1500rpm for $10 \mathrm{~min}$, resuspended in $1 \mathrm{ml}$ of BioWhittaker X-Vivo 15 Medium (Cultek) and counted with the Coulter Counter (Beckman Coulter) (making a 1:20 dilution), which gave the number of total leukocytes. All this procedure was done in sterile conditions.

For CD69 T cells cytometry panel, cells were seeded at a rate of $2 \times 10^{6}$ cells in $1 \mathrm{ml}$ in vacutainer tubes (BD Biosciences) in X-Vivo 15 Medium (Cultek) supplemented with $1 \mu \mathrm{g} / \mathrm{ml}$ ionomicin (Sigma) and 50ng/ml PMA (Sigma) to stimulate lymphocytes, and the corresponding treatments: $20 \mathrm{ng} / \mathrm{ml}$ of human recombinant LIF (Milipore) or $50 \mu \mathrm{l}$ of the U251 $72 \mathrm{~h}$ conditioned media previously concentrated 5-6x using centrifugal filters $3 \mathrm{~K}$ (Millipore) with $10 \mu \mathrm{g} / \mathrm{ml}$ anti-LIF antibody (developed in house) or $10 \mu \mathrm{g} / \mathrm{ml} \mathrm{lgG}$ rat. After $4 \mathrm{~h}$ treatment, cells were processed and stained with the corresponding antibodies specified in Table 13 (for flow cytometry staining protocol see the corresponding section below).

For Tregs cytometry panel, cells were seeded at a rate of $2 \times 10^{6}$ cells in $1 \mathrm{ml}$ in vacutainer tubes (BD Biosciences) in X-Vivo 15 Medium (Cultek) supplemented with $5 \mu \mathrm{g} / \mathrm{ml}$ PHA (Sigma) to stimulate lymphocytes, and the corresponding treatments: $20 \mathrm{ng} / \mathrm{ml}$ of recombinant human LIF (Milipore) or $50 \mu \mathrm{l}$ of the corresponding $\mathrm{U} 25172 \mathrm{~h}$ conditioned media previously concentrated $5-6 x$ using centrifugal filters $3 \mathrm{~K}$ (Millipore) with $10 \mu \mathrm{g} / \mathrm{ml}$ anti-LIF antibody (developed in house) or $10 \mu \mathrm{g} / \mathrm{ml}$ lgG rat. At day 3, cells were processed and stained with the corresponding 
antibodies indicated in Table 13 (for flow cytometry staining protocol see the corresponding section below).

In both panels, cells for compensation and FMO samples were seeded distributed in different tubes at the rate of $2 \times 10^{6}$ cells $/ \mathrm{ml}$, with a maximum of $3 \mathrm{ml} / \mathrm{tube}$.

\section{In vitro treatments}

Cells were treated with different cytokines or inhibitors as summarized in Table 5:

\begin{tabular}{|clc|}
\hline Treatment & Company (cat. $\mathrm{n}$ ㅇ) & Concentration \\
\hline Polyclonal anti-LIF D3 (BFT-5D8-D3) antibody & developed in house & $10 \mu \mathrm{g} / \mathrm{ml}$ \\
\hline Rat IgG & developed in house & $10 \mu \mathrm{g} / \mathrm{ml}$ \\
\hline Human recombinant LIF & Millipore (LIF1010) & $20 \mathrm{ng} / \mathrm{ml}$ \\
\hline Murine recombinant LIF & Ray Bootech (228-11049-1) & $20 \mathrm{ng} / \mathrm{ml}$ \\
\hline
\end{tabular}

Table 5. List of treatments used for in vitro assays.

In vitro treatments were done in FBS free conditions. For adherent cell lines, the day after the cells were seeded, the corresponding supplemented medium (Table 4) was replaced by the same non-supplemented medium. For suspension neurospheres, the cells were counted and seeded directly with non-supplemented Neurobasal medium (Gibco, Invitrogen).

\section{DNA purification and lentiviral infection}

Bacterial glycerol stocks containing pLKO.1 lentiviral vectors with a RNA interference targeting murine or human LIF were purchased from Open Biosystems (fig. 15a), or luciferase lentiviral vectors (pLenti-CMV or pLenti-PGK constitutively expressing firefly luciferase with puromycin or neomycin resistance respectively) were purchased from Addgene (fig. 15b).

a

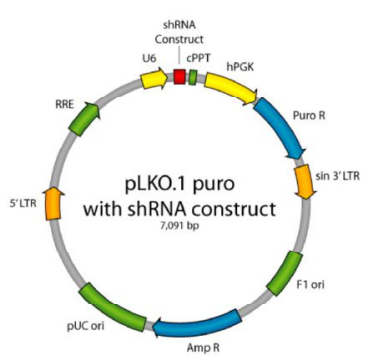

b

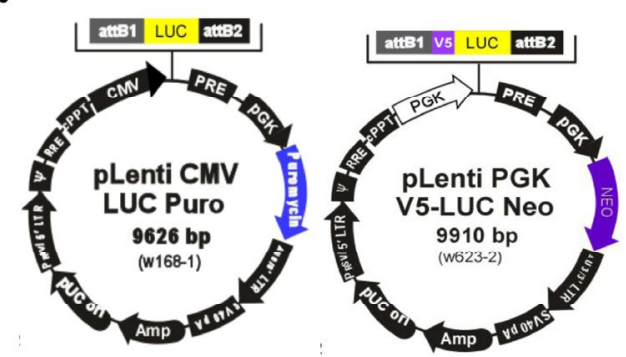

Figure 15. Lentiviral vectors. (a) Map of pLKO.1 vector containing a shRNA insert with puromycin resistance purchased from Open Biosystems. (b) Map of pLenti pCMV and PGK vectors with puromycin and neomycin resistance respectively, expressing luciferase. These vectors are used to monitor tumor growth by in vivo imaging. 
Lentiviral vectors were grown in Ampicillin (Sigma) - Lysogeny Broth (LB, Panreac) agarose plates. Then, single colonies were grown in LB with $50 \mu \mathrm{g} / \mathrm{ml}$ Ampicillin (Sigma) and DNA was extracted using endo-free plasmid maxi kit (Qiagen). The purified constructs were quantified by Nanodrop (Thermo Scientific).

For the lentiviral infection, $293 \mathrm{~T}$ cells at $70 \%$ of confluence were transfected using the calcium phosphate transfection method with pMD2.G enveloping plasmid, psPAX.2 packaging plasmid, and either luciferase, pLKO.1 or pLKO.1-shLIF human or murine. 1h before the transfection, the medium was replaced adding fresh medium with $25 \mu \mathrm{M}$ chloroquine (Sigma). Then, the transfection was done adjusting the plasmid quantities as described in Table 6, and mixing them in a falcon:

\begin{tabular}{|c|cc|}
\hline Plasmid & $\mu \mathrm{g} /$ plate $100 \mathrm{~mm}$ & $\mu \mathrm{g} /$ plate $150 \mathrm{~mm}$ \\
\hline Enveloping plasmid (pMD2.G) & 3 & 8.75 \\
\hline Packaging plasmid (psPAX2) & 5.5 & 16.25 \\
\hline Lentiviral of interest & 8.5 & 25 \\
\hline
\end{tabular}

Table 6. Plasmid quantities for 293T calcium phosphate transfection

The following reagents were added on the top of plasmid mix in the order indicated in Table 7:

\begin{tabular}{|c|cc|}
\hline Reagent & $\mu \mathrm{l} /$ plate $100 \mathrm{~mm}$ & $\mu \mathrm{l} /$ plate $150 \mathrm{~mm}$ \\
\hline $\mathrm{TE} 0,1 \mathrm{x}$ & 250 & 750 \\
\hline $\mathrm{H}_{2} \mathrm{O}$ & 125 & 375 \\
\hline $\mathrm{CaCl}_{2} 2,5 \mathrm{M}$ & 42 & 125 \\
\hline
\end{tabular}

Table 7. Reagents needed for $293 \mathrm{~T}$ calcium phosphate transfection. [TE $0,1 \times$ (TRIS pH8 1mM, EDTA 0,1mM)]

The mix was vortexed, and then the HBS (stock solution $2 \mathrm{x}$ : HEPES $100 \mathrm{mM}+\mathrm{NaCl} 280 \mathrm{mM}+$ $\mathrm{Na}_{2} \mathrm{HPO}_{4} 1,5 \mathrm{mM}$ ) was added drop by drop using a pipette while vortexing the mix. Add the final mix immediately on the $293 \mathrm{~T}$ cells plate slowly while moving de plate. After an $\mathrm{O} / \mathrm{N}$, medium was replaced by fresh medium with $5 \mathrm{mM}$ of sodium butyrate. $8 \mathrm{~h}$ later, it was replaced again by fresh medium without sodium butyrate (the medium that the target cells need) and recombinant lentivirus was harvested for an additional $24 \mathrm{~h}$. For infection, medium containing recombinant lentivirus was filtered with $45 \mu \mathrm{m}$ filter (Millipore), and added to target cell lines or to previously dissociated neurospheres, with $8 \mu \mathrm{g} / \mathrm{ml}$ polybrene (Sigma). Following $\mathrm{O} / \mathrm{N}$ incubation, cells were washed and incubated in fresh medium. Infected cells were selected with puromycin $(5 \mu \mathrm{g} / \mathrm{mL}$, Sigma) or neomycin $(700 \mu \mathrm{g} / \mathrm{mL}$, Invitrogen). 
In the case of shLIF, the cells were previously infected with pLenti-PGK luciferase with neomycin resistance. After the antibiotic selection, the resulting cells were infected with the corresponding pLKO.1 plasmid (the empty vector or vectors with the shRNA targeting LIF) and then selected using puromycin.

\section{Luciferase assay}

To verify the levels of luciferase expressed by tumor cells with luciferase lentiviral vectors before to inoculate them into the mice, we checked the luciferase expression levels in vitro. Briefly, 100.000 cells were centrifuged at $400 \mathrm{~g}$ for $5 \mathrm{~min}$, washed with PBS, centrifuged again, and resuspended in $40 \mu \mathrm{l}$ of Passive Lysis Buffer (Promega). Cells were frozen, thawed and thoroughly mix with the pipette to enhance lysis. The $40 \mu$ l of lysed cells were mixed with $80 \mu \mathrm{l}$ luciferin reagent (Promega), and luminescence was measured using FB12 Sirius (Berthold Detection Systems).

\section{RNA extraction, retrotranscription and quantitative Real Time PCR (qRT-PCR)}

For adherent cell lines, cells were seeded at 150.000 cells/well in 6 well surface treated plates (Nunc) in the corresponding supplemented medium (Table 4). After 8-16h, the cells were washed twice with PBS, and the medium was replaced by the same medium but nonsupplemented. In the case of suspension neurospheres, cells were counted, washed with PBS, and seeded at 250.000 cells/well in 12 well non-surface treated plates (BD Falcon) directly with non-supplemented Neurobasal medium (Gibco, Invitrogen).

Then, after 8-16h in starvation, cells were treated as described in the section of treatments

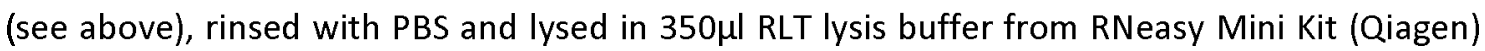
in the plate. RLT-lysed cells were frozen at $-80{ }^{\circ} \mathrm{C}$, thawed after at least $30 \mathrm{~min}$ on ice, and scraped from the plate. mRNA was purified following manufacturer's instructions. RNA concentration and quality was assessed with a Nanodrop (Thermo Scientific). For small samples, the RNA extraction Micro Kit (Qiagen) was used. RNA concentration and quality was assessed with Qubit ${ }^{\circledR} 2.0$ (Invitrogen).

300-500ng of mRNA from each sample were retrotranscribed using the iscript cDNA synthesis kit (BioRad) according to manufacturer's instructions, in the T100 Thermal Cycler (BioRad).

To analyze gene expression, after cDNA synthesis, qRT-PCR was performed using Taqman probes (Applied Biosystems) and Taqman Real-Time PCR master mix (Applied Biosystems) according to the manufacturer's recommendations. Real-time amplification was carried out in 384 well CLR/WHT plates (BioRad) in a final volume of $10 \mu$ l using the CFX384 Real Time System 
C1000 Touch Thermal Cycler (BioRad). The program used for amplification is decribed

in Table 8.

\begin{tabular}{|c|}
\hline Amplification cDNA program \\
\hline $50 \circ$ for $2^{\prime}$ \\
\hline 95 - for $10^{\prime}$ \\
\hline $95 \circ$ for $15^{\prime \prime}$ \\
\hline $600^{\circ}$ for $1^{\prime}$ \\
\hline Go to $3 \times 39$ cycles \\
\hline
\end{tabular}

Table 8. Program used for qRT-PCR.

Results were expressed as fold change calculated by the $\Delta \Delta \mathrm{Ct}$ method and normalized by the expression of an endogenous housekeeping gene (GAPDH, 18S, POLR2A or ACTIN). A value of 1 was given to the control sample.

\section{Protein extraction and immunoblotting}

For adherent cell lines, cells were seeded at 150.000 cells/well in 6 well surface treated plates (Nunc) in the corresponding supplemented medium (Table 4). After 8-16h, wells were washed twice with PBS, and the medium was replaced by the same medium but non-supplemented. For suspension neurospheres, cells were counted, washed with PBS, and seeded at 400.000 cells/well in 6 well non-surface treated plates (BD Falcon) directly with non-supplemented Neurobasal medium (Gibco, Invitrogen).

Then, after 8-16h in starvation, cells were treated with the corresponding treatments (Table 5),

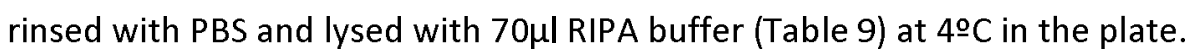

\begin{tabular}{|c|}
\hline RIPA buffer $1 \mathrm{x}$ \\
\hline $50 \mathrm{mM}$ Tris-HCl pH 7.4 \\
$1 \% \mathrm{NP} 40$ \\
\hline $0,5 \% \mathrm{Na}-$ Deoxycholate \\
$0,1 \% \mathrm{SDS}$ \\
$150 \mathrm{mM} \mathrm{NaCl}$ \\
\hline $50 \mathrm{mM} \mathrm{NaF}$ \\
\hline $25 \mathrm{mM} \beta-G l i c e r o l p h o s p h a t e$ \\
\hline $0,4 \mathrm{mM} \mathrm{Na}{ }_{3} \mathrm{O}_{4}$ \\
\hline $\begin{array}{c}\text { Protease inhibitors (complete mini protease inhibitor } \\
\text { cocktail tablets, from Roche: } 1 \text { tablet/10ml) }\end{array}$ \\
\hline
\end{tabular}

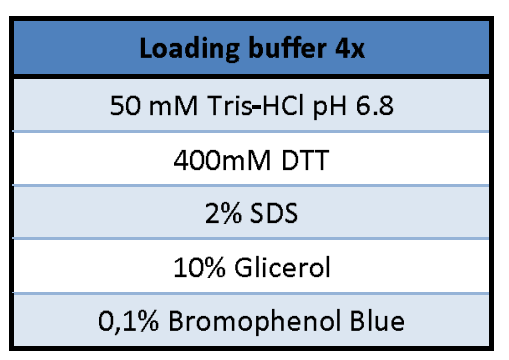

Table 10. Loading buffer $(4 x)$ recipe

Table 9. RIPA buffer recipe

RIPA lysed cells were frozen at -80 으, thawed after at least $30 \mathrm{~min}$, scraped from the plate, centrifuged at $16.100 \mathrm{~g}$ for $20 \mathrm{~min}$ at $4{ }^{\circ} \mathrm{C}$, and cell membranes were discarded. Whole protein 
extracts were quantified using the BCA protein assay kit (Pierce, Thermo Fisher Scientific) and the Perkin Elmer Victor3 1420 Multilabel Counter (Perkin Elmer), and the same amount of protein $(30-50 \mu \mathrm{g})$ was mix with loading buffer (Table 10$)$, boiled for $5 \mathrm{~min}$ at $100^{\circ} \mathrm{C}$, and loaded in a SDS-acrylamide gel for protein separation (Table 11). Protein marker VI (Tris-Glycine 4$20 \%$, Panreac) was used for protein weight reference.

\begin{tabular}{|c|c|c|c|c|c|c|}
\hline & Reagents $(20 \mathrm{ml})$ & $\begin{array}{c}6 \% \\
\text { acril. }\end{array}$ & $\begin{array}{c}8 \% \\
\text { acril. } \\
\end{array}$ & $\begin{array}{l}10 \% \\
\text { acril. } \\
\end{array}$ & $\begin{array}{l}12 \% \\
\text { acril. }\end{array}$ & $\begin{array}{l}14 \% \\
\text { acril. }\end{array}$ \\
\hline \multirow{6}{*}{$\frac{\stackrel{4}{.5}}{3}$} & $\mathrm{H}_{2} \mathrm{O}$ & $10,6 \mathrm{ml}$ & $9,3 \mathrm{ml}$ & $7,9 \mathrm{ml}$ & $6,6 \mathrm{ml}$ & $5,2 \mathrm{ml}$ \\
\hline & $\begin{array}{c}30 \% \text { Acrylamide / } \\
\text { bis solution } 29: 1 \\
\text { (BioRad) }\end{array}$ & $4 \mathrm{ml}$ & $5,3 \mathrm{ml}$ & $6,7 \mathrm{ml}$ & $8 \mathrm{ml}$ & $9,4 \mathrm{ml}$ \\
\hline & 1,5M Tris $\mathrm{pH} 8.8$ & $5 \mathrm{ml}$ & $5 \mathrm{ml}$ & $5 \mathrm{ml}$ & $5 \mathrm{ml}$ & $5 \mathrm{ml}$ \\
\hline & $10 \%$ SDS & $200 \mu l$ & $200 \mu l$ & $200 \mu l$ & $200 \mu 1$ & $200 \mu$ \\
\hline & $10 \%$ APS (Sigma) & $200 \mu l$ & $200 \mu l$ & $200 \mu \mid$ & $200 \mu l$ & $200 \mu$ \\
\hline & Temed (Sigma) & $80 \mu \mathrm{l}$ & $80 \mu l$ & $80 \mu l$ & $80 \mu l$ & $80 \mu 1$ \\
\hline
\end{tabular}

\begin{tabular}{|c|c|c|}
\hline & Reagents (8ml) & \\
\hline \multirow{6}{*}{ 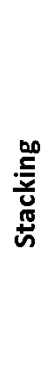 } & $\mathrm{H}_{2} \mathrm{O}$ & $5,5 \mathrm{ml}$ \\
\hline & $\begin{array}{c}30 \% \text { Acrylamide / } \\
\text { bis solution } 29: 1 \\
\text { (BioRad) }\end{array}$ & $1,3 \mathrm{ml}$ \\
\hline & $1 \mathrm{M}$ Tris $\mathrm{pH} 6,8$ & $1 \mathrm{ml}$ \\
\hline & $10 \%$ SDS & $80 \mu l$ \\
\hline & $10 \%$ APS (Sigma) & $80 \mu 1$ \\
\hline & Temed (Sigma) & $8 \mu l$ \\
\hline
\end{tabular}

Table 11. Resolving and stacking SDS-acrylamide gel composition

After gel was resolved, proteins were transferred to a nitrocellulose membrane $0,45 \mu \mathrm{m}$ (BioRad) at $100 \mathrm{~V}$ during $100 \mathrm{~min}$ or at $30 \mathrm{~V} \mathrm{O} / \mathrm{N}$. Membrane was blocked for non-specific interactions with $5 \%$ milk or $3 \%$ BSA in TBS-Tween $0,1 \%$ (TBS-T) for $30 \mathrm{~min}-1 \mathrm{~h}$ at RT, and incubated $\mathrm{O} / \mathrm{N}$ at 4 으 $\mathrm{C}$ in constant agitation with specific antibodies (Table 12). The primary antibody was rinsed for $30 \mathrm{~min}$ ( 3 washes of $10 \mathrm{~min}$ ) with TBS-T. Then membrane was incubated with the secondary HRP-conjugated antibody (GE Healthcare) for $1 \mathrm{~h}$ at RT in constant agitation. Membrane was rinsed again with TBS-T for 30min ( 3 washes of $10 \mathrm{~min}$ ), and was developed with ECL (Immobilon Western, Millipore), or with West Dura super-signal (Thermo Scientific) when protein amount was low.

\begin{tabular}{|c|c|c|c|c|c|}
\hline Antigen & Company (cat. $\mathrm{n}$ ㅇ) & Molecular weight & Source & Dilution & Incubation \\
\hline FosL2 & Sta Cruz (sc-171) & $40 \mathrm{KDa}$ & Rabbit & $1: 500$ & $\mathrm{O} / \mathrm{N}$ \\
\hline GAPDH & Trevigen (2275-PC-100) & $37 \mathrm{KDa}$ & Rabbit & 1:10.000 & $1 \mathrm{~h}$ \\
\hline p-clun & Sta Cruz (sc-822) & $39 \mathrm{Kda}$ & Mouse & $1: 500$ & $\mathrm{O} / \mathrm{N}$ \\
\hline pCREB/pATF1 & Cell Signaling (9198) & $43 \mathrm{KDa}$ & Rabbit & $1: 1.000$ & $\mathrm{O} / \mathrm{N}$ \\
\hline PDL1 & AbCam (ab58810) & $30 \mathrm{KDa}$ & Rabbit & $1: 1.000$ & $\mathrm{O} / \mathrm{N}$ \\
\hline pSTAT3 (Tyr705) & Cell Signaling (9145) & $88-92 \mathrm{KDa}$ & Rabbit & $1: 1.000$ & $\mathrm{O} / \mathrm{N}$ \\
\hline STAT3 & Cell Signaling (9132) & $88-92 \mathrm{KDa}$ & Rabbit & $1: 1.000$ & $\mathrm{O} / \mathrm{N}$ \\
\hline Actin (HRP conjugated) & AbCam (Ab49900) & $42 \mathrm{KDa}$ & Mouse & $1: 25.000$ & $20 \mathrm{~min}$ \\
\hline $\begin{array}{l}\text { Secondary anti-mouse } \\
\text { HRP conjugated }\end{array}$ & GE Healthcare (NA931V) & - & Sheep & $1: 5.000$ & $1 \mathrm{~h}$ \\
\hline $\begin{array}{l}\text { Secondary anti-rabbit } \\
\text { HRP conjugated }\end{array}$ & GE Healthcare (NA940V) & - & Donkey & $1: 5.000$ & $1 \mathrm{~h}$ \\
\hline
\end{tabular}

Table 12. List of antibodies used for immunoblotting. 


\section{ELISA}

We performed ELISA to quantify the amount of protein secreted to media. We used Quantikine ELISA kits for human and murine LIF, and Duoset kit for human CCL22/MDC (R\&D). For adherent cell lines, cells were seeded at 40.000 cells/well in 12 well surface treated plates (Nunc) in $700 \mu \mathrm{l}$ of the corresponding supplemented medium (Table 4). For suspension neurospheres, cells were seeded at 250.000 cells/well in 24 well non-surface treated plates (BD Falcon) with $500 \mu \mathrm{l}$ supplemented Neurobasal medium (Gibco, Invitrogen).

After 72h, media was collected and concentrated 5-6x using centrifugal filters 3K (Millipore). For the quantitative determination of protein levels, we followed manufacturer's specifications. Colorimetric reaction was measured at $450 \mathrm{~nm}$ wave-length and corrected for background at 560nm using the Perkin Elmer Victor3 1420 Multilabel Counter (Perkin Elmer). Conditioned media from monocytes ( $\mathrm{CD} 14^{+}$cells) from buffy coat were diluted $100 \mathrm{x}$ before performing the ELISA assay.

\section{Isolation of myeloid $\left(C^{2} 11 b^{+}\right)$cells from tumor-bearing mice}

Mice were euthanized and tumors (entire left lung in KLN205 model, and subcutaneous tumor bulk in CT26 model) or ascitic fluid (ID8 model) were obtained.

Solid tumors were chopped with a scalpel and digested with $2,5 \mathrm{mg} / \mathrm{ml}$ collagenase Type 4 (Worthington) and $200 \mathrm{U} / \mathrm{ml}$ DNase I (Sigma) for $25 \mathrm{~min}$ at $37^{\circ} \mathrm{C}$ with $1400 \mathrm{rpm}$ agitation. The cell suspension was filtered through a $70 \mu \mathrm{m}$ cell strainer (BD Falcon) with the help of the $5 \mathrm{ml}$ syringe plunger, and washed with PBS. Cells were pelleted by centrifugation at $400 \mathrm{~g}$ during $10 \mathrm{~min}$ and erythrocytes were lysed with $1 \mathrm{x}$ erythrocyte lysis buffer (stock solution 10x: 8,99g $\mathrm{NH}_{4} \mathrm{CL}+1 \mathrm{~g} \mathrm{KHCO}_{3}+0,037 \mathrm{~g}$ EDTA-NA $+\mathrm{H}_{2} \mathrm{O}$ up to $100 \mathrm{ml}$ ) for $4 \mathrm{~min}$ at RT. The ascitic fluid samples were directly centrifuged and erythrocytes were lysed with the $1 x$ erythrocyte lysis buffer for 2-3 rounds. It is important the complete lysis of erythrocytes before the magnetic bead separation since they may interfere with $\mathrm{CD} 11 \mathrm{~b}^{+}$beads-cells interaction.

After that, cells were washed again with PBS and centrifuged at $400 \mathrm{~g}$ for $5 \mathrm{~min}$. Then, pelleted cells were resuspended in $1 \mathrm{ml}$ of MACS sterile buffer (PBS pH7,2+0,5\% BSA + 2mM EDTA) and counted with an automated cell counter (Countess, Invitrogen). Then, myeloid cells were isolated using CD11b magnetic beads (Miltenyi) and the multiMACS Cell24 Separation (Miltenyi) following manufacturer instructions. Before loading the cell suspensions onto the columns, they were filtered through a 70 $\mathrm{mm}$ MACS SmartStrainer (Miltenyi). The magnetic separation was performed in a multi-24 column block (Miltenyi). After CD11 $b^{+}$cells isolation, 
cells were counted, rinsed with PBS and lysed in $350 \mu$ l RLT lysis buffer from RNeasy Mini Kit (Qiagen). RLT-lysed cells were frozen at $-80^{\circ} \mathrm{C}$, thawed after at least $30 \mathrm{~min}$ on ice, and mRNA was purified following manufacturer's instructions. RNA concentration and quality was assessed with a Nanodrop (Thermo Scientific). For small samples, the RNA extraction Micro Kit (Qiagen) was used. RNA concentration and quality was assessed with Qubit ${ }^{\circledR} 2.0$ (Invitrogen).

\section{Isolation of tumor-associated leukocytes from mice}

Mice were euthanized and tumors (entire left lung in KLN205 model, diaphragm in ID8 model, and subcutaneous tumor bulk in CT26 model) were isolated. Tumors were chopped with a scalpel and digested with $2,5 \mathrm{mg} / \mathrm{ml}$ collagenase Type 4 (Worthington) and $200 \mathrm{U} / \mathrm{ml}$ DNase I (Sigma) for $25 \mathrm{~min}$ at $37^{\circ} \mathrm{C}$ with $1400 \mathrm{rpm}$ agitation. The cell suspension was filtered through a $70 \mu \mathrm{m}$ cell strainer (BD Falcon) with the help of the $5 \mathrm{ml}$ syringe plunger, and washed with PBS up to $25 \mathrm{ml}$. These $25 \mathrm{ml}$ were added on the top of $10 \mathrm{ml}$ of ficoll (Ficoll-Paque Premium, GE Healthcare) very slowly to prevent breaking the density gradient. The gradients were centrifuged at $1500 \mathrm{rpm}$ for $30 \mathrm{~min}$ at $19^{\circ} \mathrm{C}$ without brakers. Using a pipette, the PBMCs layer (fig. 14a) was carefully transferred into a new centrifuge tube. Next, the plasma, which is essentially free of cells, was transferred into the same tube to be sure that all PBMCs were recovered. This step must be done with care in order to transfer the minimum amount of ficoll. After that, cells were washed with up to $50 \mathrm{ml}$ PBS and centrifuged at $400 \mathrm{~g}$ for $10 \mathrm{~min}$. Pelleted cells were resuspended in $1 \mathrm{ml}$ of PBS and counted with an automated cell counter (Countess, Invitrogen). Up to $2 \times 10^{6}$ cells were used from each tumor for the corresponding panel specified in Table 13 (for flow cytometry staining protocol see the corresponding section below).

Spleen from a control mouse was used for the compensation and FMOs tubes, using $2 \times 10^{6}$ cells per tube. The spleen was processed as follows: it was mechanically disintegrated using a $5 \mathrm{ml}$ syringe plunger through a $100 \mu \mathrm{m}$ cell strainer (BD Falcon), and washed with PBS. Cells were pelleted by centrifugation at $400 \mathrm{~g}$ during $10 \mathrm{~min}$ and erythrocytes were lysed with $1 \mathrm{x}$ erythrocyte lysis buffer (stock solution 10x: 8,99g NH${ }_{4} \mathrm{CL}+1 \mathrm{~g} \mathrm{KHCO}_{3}+0,037 \mathrm{~g}$ EDTA-NA $+\mathrm{H}_{2} \mathrm{O}$ up to $100 \mathrm{ml}$ ) for $4 \mathrm{~min}$ at RT. After that, cells were washed again with PBS and centrifuged at $400 \mathrm{~g}$ for $10 \mathrm{~min}$. Then, pelleted cells were resuspended in $20 \mathrm{ml}$ of PBS and counted with an automated cell counter (Countess, Invitrogen). $2 \times 10^{6}$ cells were used for each tube. 


\section{Flow Cytometry and Fluorescence-Activated Cell Sorting}

\subsection{Human PBMCs from healthy donors}

In $\mathrm{CD}^{+}$and $\mathrm{CD}^{+} \mathrm{T}$ cell activation ( $\mathrm{CD}^{+} 9^{+} \mathrm{T}$ cells) and Treg cytometry panels of human PBMCs isolated from healthy donors, after the corresponding treatments (described in the corresponding section above), cells were collected, rinsed with PBS and resuspended in 50 $\mu$ l PBS $+10 \%$ heat-inactivated FBS $(45 \mathrm{~min}, 56 \% \mathrm{C})$ to block Fc receptors. Then, $50 \mu$ l of the surface antibodies mix (Table 13) were added into each sample reaching the final volume of $100 \mu \mathrm{l}$ and incubated for $30 \mathrm{~min}$ on ice. In the compensation and FMOs tubes, $50 \mu \mathrm{l}$ of PBS $+10 \%$ heatinactivated FBS and the corresponding antibodies were added. The corresponding isotypes antibodies were added in the FMOs tubes.

After that, cells stained for panels for only surface targets (T cell activation) were washed with PBS, centrifuged at $1500 \mathrm{rpm} 5 \mathrm{~min}$ at $4{ }^{\circ} \mathrm{C}$, resuspended in $300 \mu \mathrm{l}$ of $\mathrm{PBS}$ and read into the $\mathrm{BD}$ FACSCanto $^{\text {TM }}$ II cell analyzer (BD Biosciences). On the other hand, cells stained for Treg panels (which contains FoxP3, an intracellular protein) were washed with PBS, centrifuged at $1500 \mathrm{rpm} 5 \mathrm{~min}$ at $4{ }^{\circ} \mathrm{C}$, and pelleted cells were processed with the Transcription Factor Buffer Set (BD Biosciences) for human cells following manufacturer instructions. Finally, cells were resuspended in $300 \mu \mathrm{l}$ of PBS and read into the FACSCanto ${ }^{\mathrm{TM}} \|$ cell analyzer (BD Biosciences). Data were analyzed with FCS Express.

\subsection{Tumor-associated leukocytes from mice}

Once the cells were counted and placed in $5 \mathrm{ml}$ polystyrene round-bottom tubes (BD Falcon) (up to $2 \times 10^{6}$ cells were used for each sample), were washed with $1 \mathrm{ml}$ PBS, centrifuged 1500rpm 5min, resuspended in 50 $\mu$ l of 1:25 diluted anti-CD16/CD32 (BD Biosciences) to block Fc receptors, and incubated for $15 \mathrm{~min}$ at RT. Then, $50 \mu$ l of the surface antibodies mix (Table 13) were added into each sample reaching the final volume of $100 \mu \mathrm{l}$, and incubated for $30 \mathrm{~min}$ on ice. In the compensation and FMOs tubes, 50 $\mu \mathrm{l}$ of PBS and the corresponding antibodies were added. The corresponding isotypes antibodies were added in the FMOs tubes. After that, the cells stained for the surface proteins panels ( $T$ cells and NKs) were washed with PBS, centrifuged at $1500 \mathrm{rpm} 5 \mathrm{~min}$ at $4{ }^{\circ} \mathrm{C}$, resuspended in $300 \mu \mathrm{l}$ of $\mathrm{PBS}$ and read into the $\mathrm{BD}$ LSRFortessa ${ }^{\mathrm{TM}}$ cell analyzer (BD Biosciences). On the other hand, cells stained for Treg panels (which contains FoxP3, an intracellular protein) were washed with PBS, centrifuged at $1500 \mathrm{rpm} 5 \mathrm{~min}$ at 4 으, and pelleted cells were processed with the anti-mouse/rat FoxP3 staining set (eBioscience) following manufacturer instructions. Finally, cells were resuspended 
in $300 \mu \mathrm{l}$ of PBS and read into the BD LSRFortessa ${ }^{\mathrm{TM}}$ cell analyzer (BD Biosciences). Data were analyzed with FCS Express.

\subsection{CD44 or PDL1 staining}

For adherent cell lines, cells were seeded at 150.000 cells/well in 6 well surface treated plates (Nunc) in $1,5 \mathrm{ml}$ for the corresponding supplemented medium (Table 4). After 8-16h, wells were washed twice with PBS, and the medium was replaced by the same medium but nonsupplemented. For suspension neurospheres, the cells were counted, washed with PBS, and seeded at 250.000 cells/well in 12-well non-surface treated plates (BD Falcon) directly with $500 \mu \mathrm{l}$ of non-supplemented Neurobasal medium (Gibco, Invitrogen). Then, after 8-16h in serum (cell lines) or growth factors (neurospheres) starvation, cells were treated with the corresponding treatments (Table 5) for the appropriate period of time. To verify endogenous expression, the cells were directly collected from maintenance culture plates with complete media.

Once the treatments were finished, cells were collected, rinsed with PBS and blocked with an IgG blocking solution (1:10.000) (R\&D) for $10 \mathrm{~min}$ at 4 으. After that, cells were incubated with fluorescent-conjugated CD44 antibodies for $20 \mathrm{~min}$ at 4 으, or with PDL1 antibodies for $2 \mathrm{~h}$ at 4으 (Table 13). Then, cells were rinsed with PBS and resuspended in a Propidium lodade (PI) containing solution $(1 \mu \mathrm{g} / \mathrm{ml})$. Cells were immediately assessed by flow cytometry using FACSCalibur Cell Analyzer (BD Biosciences) and CellQuest Pro Software (BD Biosciences). Data were analyzed with FCS Express.

\subsection{CD44 high/low sorting}

Neurospheres were collected, rinsed with PBS, disaggregated using Accutase (Sigma) and counted. Cells were diluted at a rate of $5 \times 10^{6}$ cells $/ \mathrm{ml}$ PBS and incubated for $30 \mathrm{~min}$ with a 1:50 diluted PE-conjugated anti-CD44 antibody at 4을 light. Cells were rinsed with PBS, resuspended in Neurobasal medium in a concentration of $10 \times 10^{6}$ cells $/ \mathrm{ml}$ and filtered through a CellTrics $30 \mu \mathrm{m}$ filter (Partec) into $5 \mathrm{ml}$ polypropylene round-bottom tubes (BD Falcon), 3ml/tube. Cells were sorted on CD44 $4^{\text {high }}$ or $\mathrm{CD} 44^{\text {low }}$ expressing cells using Moflo Cell Sorter (Beckman Coulter) and collected in polypropylene tubes (BD Falcon). Cells were afterwards lysed for RNA extraction. 


\begin{tabular}{|c|c|c|c|c|c|c|c|}
\hline Panel & $\begin{array}{l}\text { Antigen (cellular } \\
\text { compartment) }\end{array}$ & Conjugated & Clone & Company (cat. $n$ ㅇ) & Reactivity & Dilution & Application \\
\hline \multirow{6}{*}{ Tregs } & CD45 (surface) & PerCP-Cy5.5 & 30-F11 & BD Biosciences (550994) & mouse & $1: 200$ & \multirow{6}{*}{ Flow Cytometry } \\
\hline & CD3 (surface) & BV421 & $145-2 C 11$ & BD Biosciences (562600) & mouse & $1: 25$ & \\
\hline & CD4 (surface) & FITC & GK1.5 & BD Biosciences (557307) & mouse & $1: 250$ & \\
\hline & CD8 (surface) & $\mathrm{APC}-\mathrm{Cy} 7$ & $53-6.7$ & BD Biosciences (557654) & mouse & 1:40 & \\
\hline & CD25 (surface) & APC & PC61.5 & eBioscience (17-0251) & mouse & $1: 20$ & \\
\hline & $\begin{array}{c}\text { FoxP3 } \\
\text { (intracellular) }\end{array}$ & PE & FJK-16s & eBioscience (12-5773) & mouse & $1: 40$ & \\
\hline \multirow{5}{*}{$\begin{array}{c}\text { T cells and } \\
\text { NKs }\end{array}$} & CD45 (surface) & PerCP-Cy5.5 & 30-F11 & BD Biosciences (550994) & mouse & $1: 200$ & \multirow{5}{*}{ Flow Cytometry } \\
\hline & CD3 (surface) & BV421 & $145-2 \mathrm{C} 11$ & BD Biosciences (562600) & mouse & $1: 25$ & \\
\hline & CD4 (surface) & FITC & GK1.5 & BD Biosciences (557307) & mouse & $1: 250$ & \\
\hline & CD8 (surface) & $\mathrm{APC}-\mathrm{Cy} 7$ & $53-6.7$ & BD Biosciences (557654) & mouse & $1: 40$ & \\
\hline & CD49b (surface) & $\mathrm{PE}$ & DX5 & BD Biosciences ( 553858 ) & mouse & $1: 40$ & \\
\hline \multirow{5}{*}{ Tregs } & CD3 (surface) & FITC & HIT3a & BD Biosciences (555339) & human & $1: 50$ & \multirow{5}{*}{ Flow Cytometry } \\
\hline & CD4 (surface) & PerCP-Cy5.5 & RPA-T4 & BD Biosciences (560650) & human & $1: 100$ & \\
\hline & CD8 (surface) & APC-H7 & SK1 & BD Biosciences (560179) & human & $1: 40$ & \\
\hline & CD25 (surface) & $\mathrm{PE}$ & M-A251 & BD Biosciences (555432) & human & 1:10 & \\
\hline & $\begin{array}{c}\text { FoxP3 } \\
\text { (intracellular) }\end{array}$ & $\begin{array}{c}\text { Alexa Fluor } \\
647 \\
\end{array}$ & $259 \mathrm{D} / \mathrm{C7}$ & BD Biosciences (560045) & human & $1: 10$ & \\
\hline \multirow{4}{*}{$\begin{array}{c}\text { T cells } \\
\text { activation }\end{array}$} & CD3 (surface) & FITC & HIT3a & BD Biosciences (555339) & human & $1: 50$ & \multirow{4}{*}{ Flow Cytometry } \\
\hline & CD4 (surface) & PerCP-Cy5.5 & RPA-T4 & BD Biosciences (560650) & human & $1: 100$ & \\
\hline & CD8 (surface) & $\mathrm{APC}-\mathrm{H} 7$ & SK1 & BD Biosciences (560179) & human & $1: 40$ & \\
\hline & CD69 (surface) & PE & FN50 & BD Biosciences (555531) & human & $1: 20$ & \\
\hline- & CD11b (surface) & PE & $\mathrm{M} 1 / 70$ & BD Biosciences (553311) & mouse & $1: 50$ & Flow Cytometry \\
\hline- & CD44 (surface) & FITC & G44-26 & BD Biosciences (555478) & human & $1: 25$ & Flow Cytometry \\
\hline- & CD44 (surface) & APC & G44-26 & BD Biosciences (559942) & human & $1: 10$ & Flow Cytometry \\
\hline- & CD44 (surface) & PE & G44-26 & BD Biosciences (555479) & human & $1: 50$ & Sorting \\
\hline- & PDL1 (surface) & APC & MIH5 & BD Biosciences (564715) & mouse & $1: 50$ & Flow Cytometry \\
\hline- & PDL1 (surface) & FITC & $\mathrm{MIH} 1$ & BD Biosciences (558065) & human & $1: 20$ & Flow Cytometry \\
\hline
\end{tabular}

Table 13. List of antibodies used for flow cytometry and sorting

\section{Paraffin blocks generation, immunohistochemical and immunofluorescence}

\section{staining}

\subsection{Paraffin blocks generation}

For tissue microarray (TMA) generation from GBM, three $0.6 \mathrm{~mm}$ cores were taken from separate areas selected by an expert pathologist, and each one was arrayed into recipient blocks in a $1 \mathrm{~mm}$ spaced grid (Serviquimia). For tissue paraffin blocks generation, the corresponding tissue was taken from the mouse and placed into the recipient blocks in a $1 \mathrm{~mm}$ spaced grid (Serviquimia). For pellets of cells paraffin blocks generation, 3-5 150mm culture 
plates at $80-90 \%$ of confluence were rinsed with PBS and incubated with 10mM EDTA for $10 \mathrm{~min}$ at $37{ }^{\circ} \mathrm{C}$. Medium was added to inactivate EDTA, centrifuged at $400 \mathrm{~g}$ for $5 \mathrm{~min}$ and transferred into a $1,5 \mathrm{ml}$ eppendorf (VWR) with medium. Then, cells were spun, and the pellet was lifted without disrupting it with formalin. Finally, tissue sections and pelleted cells were $24 \mathrm{~h}$ formalin-fixed, paraffin-embedded and cut into $3 \mu \mathrm{m}$ sections.

TMAs from multitumor and NSCLC were purchased from Folio Biosciences, and TMAs from ovarian cancer and CRC were kindly provided by Dr. Vicente Peg (Vall d'Hebron University Hospital) and Dr. Diego Arango (Vall d'Hebron Institute of Research, VHIR) respectively.

\subsection{Immunohistochemistry (IHC)}

The slides were heated at $65 \circ \mathrm{C} \mathrm{O} / \mathrm{N}$, deparafinized in 3 consecutives incubations in xylene (Panreac) for $10 \mathrm{~min}$ each, and progressively hydrated with $100 \%-90 \%-70 \%$ ethanol solutions. Antigen retrieval was performed in a histoprocessor T/T MEGA (Milestone) using pH6 (115으, 3min) or pH9 (110ㄷ, 3min) Citrate Antigen Retrieval Solution (DAKO) depending on the antibody (Table 14), peroxidase blocking was done with $10 \% \mathrm{H}_{2} \mathrm{O}_{2}$ for $10 \mathrm{~min}$ at RT, 3 washes was performed with TBS-Tween $0,1 \%$ (TBS-T) for $5 \mathrm{~min}$ each at RT, and then slides were incubated in a blocking solution (2-3\% BSA) for $1 \mathrm{~h}$ at RT, all in constant agitation. After 3 more washes with TBS-T for 5 min each at RT, primary antibody was added at the right concentration diluted in the Dako Real ${ }^{\top M}$ Antibody Diluent (Dako) on the top of the section in a humid chamber, and incubated $\mathrm{O} / \mathrm{N}$ at $4^{\circ} \mathrm{C}$ or for $30 \mathrm{~min}$ at $\mathrm{RT}$ (Table 14). Then, 3 washes with TBS-T were done, different Dako detection systems were used (Table 14) following the manufacturer's instructions, 3 more washes with TBS-T, and the slices were immediately developed with freshly prepared $0,05 \% 3^{\prime}, 3$-diaminobenzidine tetrahydrochloride (DAB). Finally, the slides were counterstained with Harris hematoxylin (Sigma) for 20 seconds, flushed in abundant water for $3 \mathrm{~min}$, progressively dehydrated in a series of ethanol solutions $(70 \%$ $90 \%-100 \%)$ followed by 3 incubations in xylene solutions, and mounted with DPX mounting medium (Millipore). Before viewing in a light microscope (Olympus BX61 microscope) and storage at RT, the slides were air dry to eliminate the xylene remains.

The quantification of LIF staining in TMAs was evaluated by an expert pathologist and expressed as $H$ score. The $H$ score was determined by the formula: $3 \times$ percentage of strong staining $+2 \times$ percentage of moderate staining + percentage of weak staining, giving a range of 0 to 300 (Ishibashi, Suzuki et al. 2003). Quantification of CC3 was performed with ImageJ, counting the total number of cells of 3 different fields of each mouse, 5 mice/group, and calculating the percentage of positive cells. 


\begin{tabular}{|ccccccc|}
\hline Antigen & Company (cat. $\mathrm{n}$ ) & Reactivity & Dilution & Incubation & $\begin{array}{c}\text { Antigen } \\
\text { retrieval }\end{array}$ & Detection system \\
\hline CC3 & Cell Signaling (9661) & mouse & $1 / 500$ & $\mathrm{O} / \mathrm{N}$ & pH6_3min & Dako (K5007) \\
\hline CD4 & Leica (NCL-L-CD4- & mouse & $1 / 100$ & 30min, RT & pH9_3min & Dako (K5007) \\
\hline CD8 & Bioss (bs-0648R) & mouse & $1 / 200$ & $\mathrm{O} / \mathrm{N}$ & pH9_3min & Dako (K5007) \\
\hline CD11b & AbCam (ab133357) & mouse & $1 / 1000$ & $\mathrm{O} / \mathrm{N}$ & pH6_3min & Dako (K5007) \\
\hline CD45 & AbCam (ab10558) & mouse & $1 / 1000$ & $\mathrm{O} / \mathrm{N}$ & pH6_3min & Dako (K5007) \\
\hline CD68 & AbCam (ab955) & mouse & $1 / 100$ & $\mathrm{O} / \mathrm{N}$ & pH6_3min & Dako (K5007) \\
\hline CD335 & Bioss (bs-2417R) & mouse & $1 / 200$ & $\mathrm{O} / \mathrm{N}$ & pH6_3min & Dako (K5007) \\
\hline Ki67 & AbCam (ab15580) & mouse & $1 / 200$ & $\mathrm{O} / \mathrm{N}$ & pH6_3min & Dako (K5007) \\
\hline LIF & Atlas (HPA018844) & human & $1 / 200$ & $\mathrm{O} / \mathrm{N}$ & pH6_3min & Dako (K5007) \\
\hline LIF & AbCam (ab135629) & mouse & $1 / 200$ & $\mathrm{O} / \mathrm{N}$ & pH6_3min & Dako (K4069) \\
\hline MRC1 & AbCam (ab64693) & mouse & $1 / 400$ & $\mathrm{O} / \mathrm{N}$ & pH6_3min & Dako (K5007) \\
\hline MRC1 & AbCam (ab64693) & human & $1 / 4000$ & $30 \mathrm{~min}, \mathrm{RT}$ & pH6_3min & Dako (K5007) \\
\hline PDL1 & AbCam (ab58810) & human, mouse & $1 / 100$ & $\mathrm{O} / \mathrm{N}$ & pH6_3min & Dako (K4069) \\
\hline pSTAT3 & Cell Signaling (9131) & human, mouse & $1 / 50$ & $\mathrm{O} / \mathrm{N}$ & pH9_3min & Dako (K4069) \\
\hline
\end{tabular}

Table 14. List of antibodies used for immunohistochemistry (IHC).

\subsection{Immunofluorescence (IF)}

The slides were heated at $65^{\circ} \mathrm{C} \mathrm{O} / \mathrm{N}$, deparafinized by 3 consecutives incubations in xylene (Panreac) for $10 \mathrm{~min}$ each, and progressively hydrated with $100 \%-90 \%-70 \%$ ethanol solutions. Antigen retrieval was performed in a histoprocessor T/T MEGA (Milestone) using pH6 (115으, 3min) or pH9 (110을 $3 \mathrm{~min})$ Citrate Antigen Retrieval Solution (DAKO) depending on the antibody (Table 15), 2 washes were done with PBS for $10 \mathrm{~min}$ each at RT, and permeabilization was performed with PBS-TWEEN $1-2 \%$ for $20 \mathrm{~min}$ at RT, all in constant agitation. After 2 more washes, unspecific interactions were blocked by incubating cells with PBS 3\% BSA for $1 \mathrm{~h}$ at RT, then 2 more washes were performed, and finally primary antibodies were added at the right concentration diluted in PBS 3\% BSA on the top of the section in a humid dark chamber and incubated $\mathrm{O} / \mathrm{N}$ at 4 으 (Table 15). Following day, primary antibodies were washed with PBS, and fluorescent-labeled secondary antibodies (Invitrogen) were added together with DAPI (Sigma) for nuclear staining (Table 15) for $1 \mathrm{~h}$ at RT. Finally, 2 more washes were performed in the dark, and the cover-slides were mounted with Vectashield (Vector Laboratories). The samples were immediately assessed under fluorescence microscope (Olympus BX61 microscope) or stored at 4 으 or at $-20{ }^{\circ} \mathrm{C}$ for long-term storage protected from light.

Quantification of immunofluorescences were performed with ImageJ, counting all or up to 100 cells $\mathrm{CD} 11 \mathrm{~b}^{+}$or IBA-1 $1^{+}$of 2-3 different fields of each mouse, 3-5 mice/group, and calculating 
the percentage of those cells positive for MRC1, CCL22 or CD163. For organotypic slices, 3-4 fields of each patient $(n=3)$ were quantified.

\begin{tabular}{|c|c|c|c|c|c|c|c|c|}
\hline Antigen & Host & Company (cat. n의) & Reactivity & Dilution & Incubation & $\begin{array}{l}\text { Antigen } \\
\text { retrieval }\end{array}$ & Secondary Ab & $\begin{array}{l}\text { Dil. Second. } \\
\text { Ab. }\end{array}$ \\
\hline CCL22 & goat & Santa Cruz (sc-12288) & mouse & $1 / 50$ & $\mathrm{O} / \mathrm{N}$ & pH6_3min & Alexa Fluor 594 & $1 / 1000$ \\
\hline CD11b & rabbit & AbCam (ab133357) & mouse & $1 / 2000$ & $\mathrm{O} / \mathrm{N}$ & pH6_3min & Alexa Fluor 488 & $1 / 500$ \\
\hline IBA-1 & rabbit & Wako (019-19741) & mouse & $1 / 1000$ & $\mathrm{O} / \mathrm{N}$ & pH6_3min & Alexa Fluor 488 & $1 / 500$ \\
\hline CCL22 & rabbit & AbCam (ab9847) & human & $1 / 100$ & $\mathrm{O} / \mathrm{N}$ & pH6_3min & Alexa Fluor 594 & $1 / 2000$ \\
\hline CD163 & mouse & Leica (NCL-L-CD163) & human & $1 / 200$ & $\mathrm{O} / \mathrm{N}$ & pH6_3min & Alexa Fluor 594 & $1 / 1000$ \\
\hline MRC1 & rabbit & AbCam (ab64693) & human & $1 / 500$ & $\mathrm{O} / \mathrm{N}$ & pH6_3min & Alexa Fluor 594 & $1 / 2000$ \\
\hline IBA-1 & goat & AbCam (ab5076) & human & $1 / 50$ & $\mathrm{O} / \mathrm{N}$ & pH6_3min & Alexa Fluor 488 & $1 / 500$ \\
\hline DAPI & - & Sigma (D9542) & - & $5 \mu \mathrm{g} / \mathrm{ml}$ & $1 \mathrm{~h}, \mathrm{RT}$ & - & - & - \\
\hline
\end{tabular}

Table 15. List of antibodies used for immunofluorescence (IF)

\section{Microarray expression analysis}

RNA was assayed on the Affymetrix microarray platform with the Human Gene 2.1 ST or Mouse Gene 2.1 ST, and analyzed with R statistical software version 3.1.2 and analysis and annotation packets from Bioconductor (Progenika Biopharma, Grifols). The microarray data have been deposited in the Gene Expression Omnibus (GEO)/NCBI public database (accession no GSE79851 and GSE79852).

\section{In vivo experiments}

All mouse experiments were approved by and performed according to the guidelines of the Institutional Animal Care Committee of the Vall d'Hebron Institute of Research (VHIR) in agreement with the European Union and national directives.

\subsection{GBM xenografts and syngeneic mouse models}

To generate the xenografts, $3 \times 10^{5}$ cells were used per mouse in the case of patient-derived

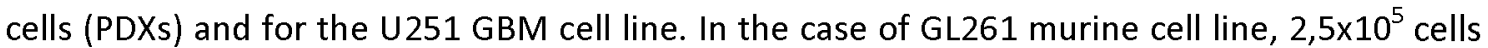
per mouse were used. The cells were collected, rinsed with PBS, centrifuged at $400 \mathrm{~g}$ for $5 \mathrm{~min}$ and resuspended in $5 \mu$ l of PBS. Cells were kept on ice to avoid cell death.

8-week-old Balb/c nude mice (Janvier Laboratories) for PDXs and U251, or 8-week-old C57BL/6 mice (Janvier Laboratories) for GL261, were anaesthetized with intraperitoneal administration of Ketamine (Ketolar50 ${ }^{\circledR}$ ) / Xylacine (Rompún $\left.{ }^{\oplus}\right)(75 \mathrm{mg} / \mathrm{Kg}$ and $10 \mathrm{mg} / \mathrm{Kg}$ respectively). Each mouse was carefully situated in the stereotactic device and immobilized. Hair from head was removed with depilatory cream, and the head skin was cut with a scalpel to expose the skull. $A$ small incision was performed carefully with a drill in the coordinates $1,8 \mathrm{~mm}$ lateral and $1 \mathrm{~mm}$ 
anterior to the Lambda. Cells were inoculated using a Hammilton $30 \mathrm{G}$ syringe into the right corpus striatum, at 2,5mm of depth. Head incision was closed with Hystoacryl tissue adhesive (Braun) and mice were injected with subcutaneous analgesic Meloxicam (Metacam ${ }^{\circledR}$ ) $(1 \mathrm{mg} / \mathrm{Kg})$.

Tumor progression was monitored by body weight and by bioluminescence measurements using the Xenogen IVIS ${ }^{\circledR}$ Spectrum (Caliper Life Sciences). Mice were euthanized when they exhibited clinical signs of disease or distress (i.e. neurological symptoms, cachexia, anorexia or increased respiratory rates).

The anti-LIF treatment started on day 6 after inoculation in U251 and GL261 models (Table 16). In PDXs models, the treatment started when the IVIS Spectrum showed a tumor progression. 6-10 mice per group were inoculated.

\subsection{KLN205 NSCLC syngeneic mouse model}

$5 \times 10^{5}$ KLN205 non-small cell lung cancer (NSCLC) cells were inoculated per mouse. The cells were collected, rinsed with PBS, centrifuged at $400 \mathrm{~g}$ for $5 \mathrm{~min}$ and resuspended in $50 \mu$ of PBS. Cells were kept on ice to avoid cell death.

8-week-old DBA/2 mice (Janvier Laboratories) were anaesthetized with intraperitoneal administration of Ketamine (Ketolar50 ${ }^{\circledast}$ ) / Xylacine (Rompún $\left.{ }^{\circledR}\right)(75 \mathrm{mg} / \mathrm{Kg}$ and $10 \mathrm{mg} / \mathrm{Kg}$ respectively). Each mouse was carefully situated on its side and immobilized. Cells were inoculated into the left lung by intercostal puncture with a $27 \mathrm{G}$ syringe, and mice were injected with subcutaneous analgesic Meloxicam (Metacam $\left.{ }^{\circledR}\right)(1 \mathrm{mg} / \mathrm{Kg})$.

Tumor progression was monitored by body weight and by bioluminescence measurements using the Xenogen IVIS ${ }^{\circledast}$ Spectrum (Caliper Life Sciences). Mice were euthanized when exhibited clinical signs of disease or distress (i.e. cachexia, anorexia or increased respiratory rates).

The anti-LIF treatment started on the day indicated on each graph (Table 16). 8-10 mice per group were inoculated.

\subsection{ID8 ovarian cancer syngeneic mouse model}

$5 \times 10^{6}$ ID8 ovarian cancer cells were inoculated per mouse. The cells were collected, rinsed with PBS, centrifuged at $400 \mathrm{~g}$ for $5 \mathrm{~min}$ and resuspended in $200 \mu \mathrm{l}$ of PBS. Cells were kept on ice to avoid cell death. They were intraperitoneally injected into 8-week-old C57BL/6 mice (Janvier Laboratories) with a $27 \mathrm{G}$ syringe. 
Tumor progression was monitored by body weight and by abdominal girth using a caliper (Fisher Scientific). Mice were euthanized when the development of ascites began to interfere with normal body functions (i.e. ambulation, eating, drinking).

The anti-LIF treatment started on day 12 after inoculation (Table 16). 10 mice per group were inoculated.

\subsection{CT26 CRC syngeneic mouse model}

$5 \times 10^{5}$ CT26 colorectal cancer (CRC) cells were inoculated per mouse. The cells were collected, rinsed with PBS, centrifuged at $400 \mathrm{~g}$ for $5 \mathrm{~min}$ and resuspended in $100 \mu \mathrm{l}$ of PBS. Cells were kept on ice to avoid cell death. They were subcutaneously injected on both flanks into 8-week-old Balb/c mice (Janvier Laboratories) with a 27G syringe.

Tumor progression was monitored by body weight and by tumor measurements using a caliper (Fisher Scientific). Mice were euthanized when the tumors reached a maxim volume of $1600 \mathrm{~mm}^{3}$, or when signs of necrosis were observed.

The anti-LIF treatment started on day 3 after inoculation (Table 16). 10 mice per group were inoculated.

\section{In vivo treatments}

Mice were treated with different drugs as summarized in Table 16:

\begin{tabular}{|c|c|c|c|c|}
\hline Treatment & Company (cat. $n$ ㅇ) & Dose & Frequency of administration & $\begin{array}{c}\text { Route of } \\
\text { administration }\end{array}$ \\
\hline Polyclonal anti-LIF (BFT-5D8-D3) Ab & own laboratory / Aldevron & $300 \mu \mathrm{g}$ & 2 doses/week & intraperitoneal \\
\hline Clodronate liposomes & $\begin{array}{c}\text { clodronateliposomes } \\
\text { (33363) }\end{array}$ & $1 \mathrm{mg}$ & $\begin{array}{c}1 \text { dose } 4 \text { days before inoculation }+ \\
\text { every } 2 \text { days }\end{array}$ & intraperitoneal \\
\hline Monoclonal anti-mouse CCL22 Ab & R\&D (MAB4391) & $40 \mu \mathrm{g}$ & a total of 4 doses ( 2 doses/week) & intraperitoneal \\
\hline Monoclonal anti-mouse CD4 Ab & BioXCell (BEOOO3) & $200 \mu \mathrm{g}$ & $\begin{array}{c}1 \text { dose } 2 \text { days before inoculation }+ \\
2 \text { doses/week }\end{array}$ & intraperitoneal \\
\hline Monoclonal anti-mouse CD8 $\mathrm{Ab}$ & BioXCell (BE0061) & $200 \mu \mathrm{g}$ & $\begin{array}{c}1 \text { dose } 2 \text { days before inoculation }+ \\
2 \text { doses/week }\end{array}$ & intraperitoneal \\
\hline Monoclonal anti-mouse PDL1 Ab & BioXCell (BP0101) & $200 \mu \mathrm{g}$ & a total of 3 doses (every 3 days) & intraperitoneal \\
\hline
\end{tabular}

Table 16. List of treatments used for in vivo experiments.

The control group was treated only with PBS, after verifying with a pilot experiment that there were no differences between a group of mice treated with PBS or treated with rat IgG.

\section{In vivo quantification of luciferase activity}

As it has been mentioned before, orthotopic GBM and NSCLC tumors progression was monitored by bioluminescence measurements using the Xenogen IVIS ${ }^{\circledR}$ Spectrum (Caliper Life 
Sciences). Cells were stably infected with constitutively active luciferase vectors (fig. 15b) as described above, and luciferase activity was assessed in vitro prior to the inoculation of the cells in the mouse as described above.

To quantify the luciferase activity in vivo, mice were anaesthetized using isofluorane, and injected intraperitoneally with luciferin substrate (PerkinElmer) $(167 \mu \mathrm{g} / \mathrm{Kg})$. Luciferase intensity was measured and analyzed with Living Image ${ }^{\circledR}$ 4.3.1, and correlated with tumor size.

\section{Statistical analysis}

\subsection{Student T test}

Data were analyzed using GraphPad Prism 5.0 software. To compare two different groups we used Student's T-test (paired or unpaired) for parametric variables and Mann-Whitney test for non-parametric variables.

For in vitro experiments data in graphs are presented as mean $\pm S D$, and for in vivo experiments data in graphs are presented as mean \pm SEM.

\subsection{Kaplan-Meyer survival curves}

GraphPad Prism 5.0 software was used for generation of Kaplan-Meier survival curves showing the probability of overall survival (OS) and the disease-free survival (DFS), based on data from cBioPortal database (http://www.cbioportal.org) (GBM TCGA 2013, $n=147$ ). P value was calculated using GraphPad.

\subsection{Correlation gene expression graphs}

To calculate the correlation between different genes in patient samples and the statistical significance, the Spearman correlation test (Spearman rho value $(\rho)$ ) and the $P$ value were used. 


\section{RESULTS}




\section{Inter-tumor heterogeneity of LIF expression in cancer}

In order to assess the expression of LIF across tumor types, we performed an IHC to detect LIF expression in tissue microarrays of samples from 19 different tumor types. In the case of GBM, NSCLC, ovarian cancer and CRC, we extended our analysis to around 100 specimens per tumor type. Interestingly, we observed a wide inter-tumor heterogeneity in LIF expression. Certain tumors showed extremely high expression levels, while other tumors exhibited no expression of LIF (fig. 16a,b). When expressed, LIF staining was widespread but especially circumscribed to the tumor mass. The aberrant overexpression of LIF observed in some tumors might suggest that LIF could confer a selective advantage acting as an oncogenic factor. This concept was in part supported by the fact that NSCLC and CRC patients with tumors expressing high levels of LIF exhibited a shorter overall survival (Albrengues, Bourget et al. 2014, Yu, Yue et al. 2014). As a whole, the results indicated that aberrant LIF expression tends to be present in the most aggressive tumors suggesting that LIF could be facilitating tumor progression.

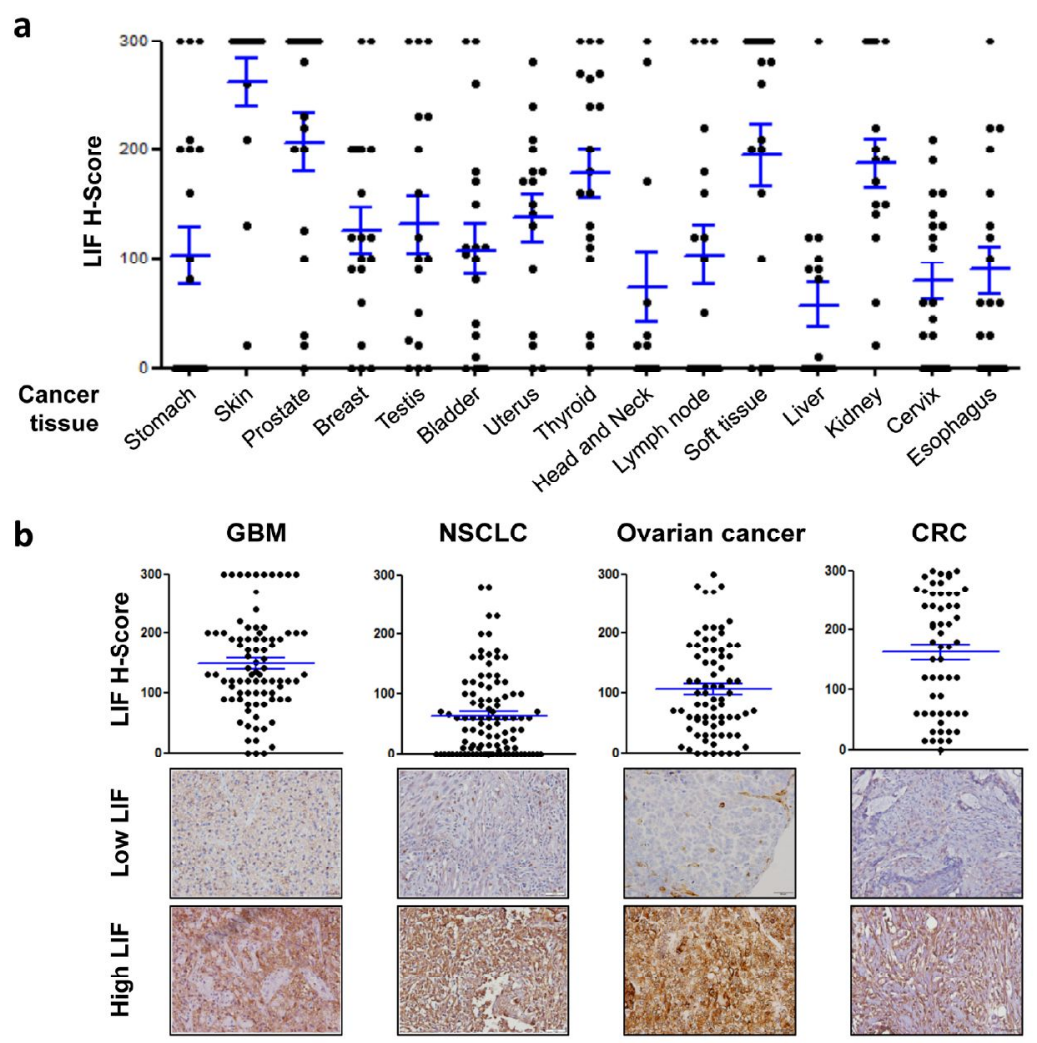

Figure 16. LIF expression in human tumors. (a,b) LIF IHC was performed in multitumor tissue microarrays (a) and in tissue microarrays from human GBM, NSCLC, ovarian cancer and CRC (b), and the degree of staining was scored using H-score method. Data are presented as mean \pm SEM. Representative images are shown. Scale bar, $50 \mu \mathrm{m}$. 


\section{Study of the anti-tumor response to the blockade of LIF using different syngeneic models}

\subsection{Screening of syngeneic mouse models}

To study the oncogenic effect of LIF in tumors, we decided to use syngeneic immunocompetent mouse models expressing high levels of LIF. First of all, we did a screening of murine cell lines from different tumor types checking its basal levels of LIF secretion and studying its response to recombinant LIF or to anti-LIF neutralizing antibody, verifying the induction or reduction of STAT3 phosphorylation (p-STAT3) (fig. 17a,b).
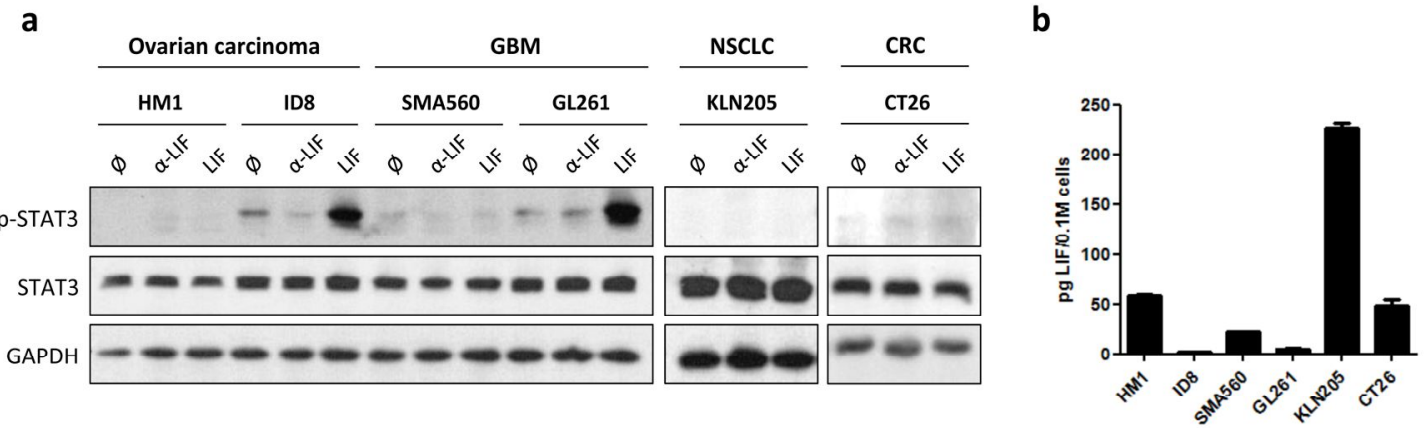

Figure 17. LIF pathway characterization in mouse tumor cell lines. (a) A battery of murine cell lines were treated with anti-LIF for $16 \mathrm{~h}$ or recombinant LIF for $4 \mathrm{~h}$. The levels of $\mathrm{p}$ STAT3, STAT3 and GAPDH were determined by immunoblotting. (b) Secreted LIF protein basal levels were determined by ELISA after $72 \mathrm{~h}$. Data are presented as mean \pm SD.

Several advances in experimental immunotherapy for GBM have been achieved using mouse glioma cells GL261, given that they share several important biomarkers and mutations with human GBM (Jacobs, Valdes et al. 2011, Maes and Van Gool 2011, Oh, Fakurnejad et al. 2014). The results indicate that those cells were sensitive to recombinant LIF, however, they did not respond to anti-LIF neutralizing antibody, and they showed low secretion levels of LIF in vitro (fig. 17a,b). Since it is well known that some cells present a different behavior in vitro than in vivo, we decided to inoculate them orthotopically into the mice. Unfortunately, we did not detect expression of LIF into the tumor, and in agreement with this, the treatment with antiLIF neutralizing antibody had no effect in the tumor growth (fig. 18a,b). This result suggests that in GL261 model the activation of JAK/STAT3 pathway is not regulated by LIF but by other factors.

After the result with GL261 cells, we decided to use another GBM syngeneic model, the SMA560 cell line (Oh, Fakurnejad et al. 2014). It has been shown that treatment with a TGFBRI inhibitor increases the disease-free survival in $25 \%$ of mice by the reversion of the immune suppression, allowing tumor rejection (Tran, Uhl et al. 2007). Previous work from our lab has 
shown that TGF $\beta$ induces the self-renewal capacity of cancer-initiating cells (CICs) through the induction of LIF (Penuelas, Anido et al. 2009). We hypothesized that the immune-regulator effect of TGF $\beta$ could also occur, at least partially, through LIF. So, LIF may have a double role in tumor growth: increasing CICs self-renewal and facilitating an immune-suppressor environment. Therefore, we thought that if SMA560 is a useful model to demonstrate an effect of a TGF $\beta$ pathway inhibitor, it could be useful for our project. In order to assess whether SMA560 were sensitive to the LIF pathway, we performed an immunoblotting after recombinant LIF or anti-LIF antibody treatments. We observed only a slight decrease of $p$ STAT3 after LIF inhibition (fig. 17a).

Ovarian cancer is the deadliest of all female reproductive cancer worldwide. Unlike other epithelial tumors, peritoneal dissemination is the most common mechanism of the disease progression. This feature is preserved in some mouse models of ovarian cancer: ID8 and HM1 formed cancerous ascites and massive peritoneal dissemination after intraperitoneal injection into syngeneic mice (Abiko, Mandai et al. 2013). In order to study the relevance of the LIF signaling, we tested the sensitivity to LIF treatments in vitro. The results showed large differences between both cell lines. While HM1 did not show detectable levels of p-STAT3 even after the treatment with recombinant LIF, ID8 experimented a dramatic increase of $p$ STAT3 after exposition to recombinant LIF and a clear decrease when treated with anti-LIF, showing the sensitivity of this cell line (fig. 17a). However, when we checked the levels of secreted LIF in vitro, we observed that ID8 secreted very low levels (fig. 17b). Based on previous works in which the authors showed the immunogenicity of ID8 model (Duraiswamy, Freeman et al. 2013), we decided to inoculate ID8 cells intraperitoneally into mice. When we analyzed the tumors, we observed expression of LIF in vivo (fig. 18a), indicating that ID8 syngeneic model could be a useful tool to study the LIF contribution to tumor development in vivo.

Lung cancer is the one of most common and aggressive type of cancer worldwide and it is the main cause of cancer deaths (Domagala-Kulawik 2015). Recent work has shown that NSCLC patients with tumors expressing high levels of LIF exhibited a shorter overall survival (Albrengues, Bourget et al. 2014). We tested the sensitivity to LIF treatments using the NSCLC cell line KLN205. Although p-STAT3 was not detected by immunoblotting at basal levels nor after LIF treatment, KLN205 expressed high levels of LIF (fig. 17a,b). We inoculated orthotopically KLN205 into mice, and we observed that the generated tumors displayed high levels of LIF (fig. 18a). 
CRC remains one of the major causes of death worldwide, despite steady improvement in early detection and overall survival over the past decade. Immunotherapy has shown considerable clinical benefit in various cancers, including CRC (Singh, Sharma et al. 2015). Recently, it has been published that LIF up-regulation correlates with significantly poor clinical outcome in patients with CRC (Yu, Yue et al. 2014). Based on the immunogenicity of CT26 model (Duraiswamy, Kaluza et al. 2013), we checked this syngeneic CRC cell line. Although there was no regulation of p-STAT3 after the LIF pathway-targeting treatments, CT26 secreted moderate levels of LIF (fig. 17a,b). We inoculated CT26 cells subcutaneously into mice, and we performed an IHC against LIF in the tumors. We observed that CT26 tumors expressed high levels of LIF (fig. 18a).

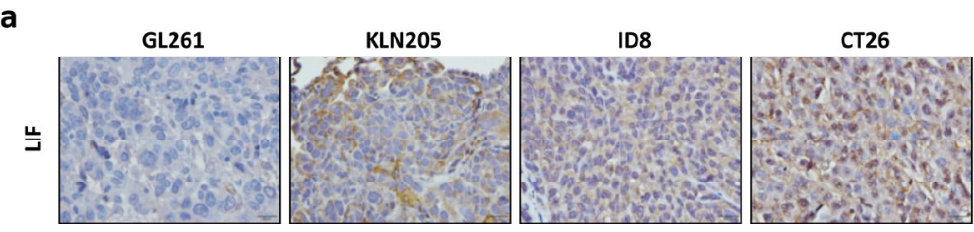

b - GL261 - GBM
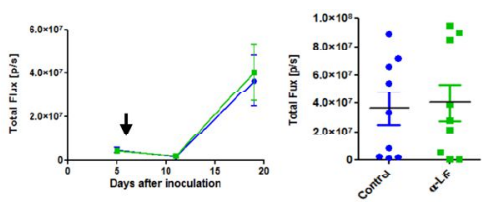

d - ID8 - Ovarian cancer
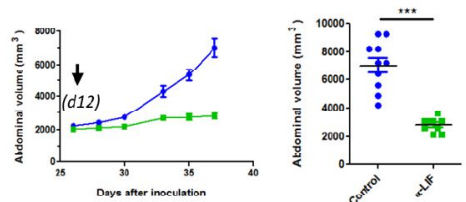

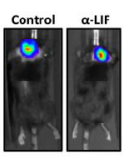

C - KLN205 - NSCLC
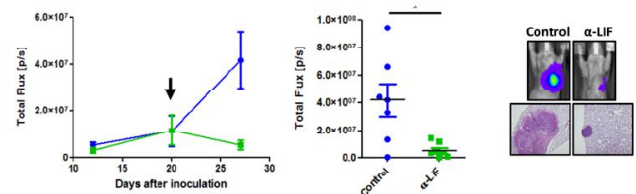

e - CT26-CRC

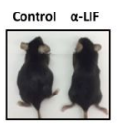

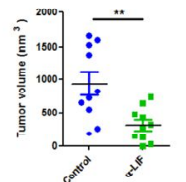

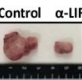

Figure 18. LIF blockade by a neutralizing antibody decreases in vivo tumor growth in syngeneic models that express high levels of LIF. (a) LIF IHC was performed in tumors generated from GL261, KLN205, ID8 and CT26 cells. Representative images are shown. Scale

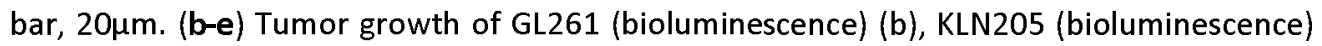
(c), ID8 (abdominal volume) (d) and CT26 (tumor volume) (e) models is shown. Arrows indicate the start of anti-LIF treatment, and scatter plots on the right represents the endpoint. Data are presented as mean \pm SEM.

\subsection{Characterization of the response to LIF blockade in vivo}

To sum up, we have identified three cancer cell lines from different tumor types (ovarian cancer, NSCLC and CRC) that are able to generate syngeneic tumors in mice and express high levels of LIF (fig. 18a). Next, we decided to suppress LIF signaling in these syngeneic models using two independent approaches: a) by preventing the interaction of LIF with its receptor 
using a neutralizing antibody against LIF, and b) by knocking down the expression of LIF by RNA interference using two independent shRNAs. Prior to inoculate infected cells, LIF transcript levels were determined by qRT-PCR, and the secreted LIF protein by ELISA (fig. 19a,d). In order to verify LIF knock-down, we performed an IHC for LIF in lungs (fig. 19c) and in diaphragm tumors (fig. 19f) in KLN205 and ID8 models respectively.

a - KLN205- NSCLC
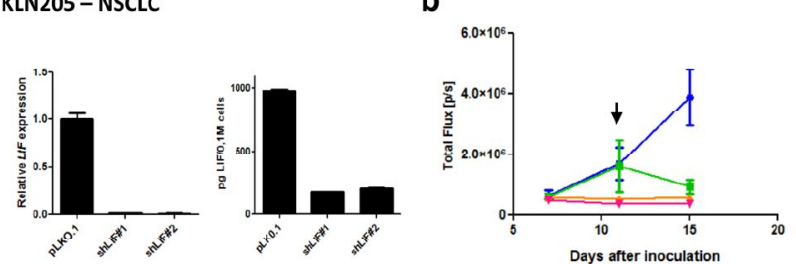

d - ID8 - Ovarian cancer
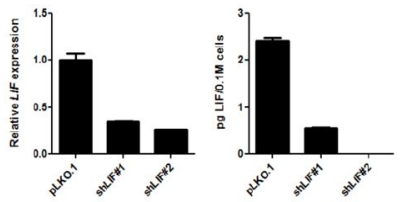

e

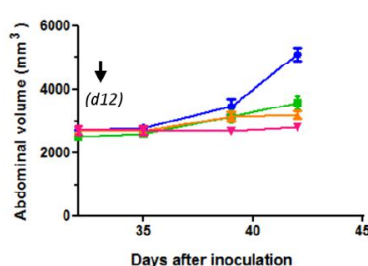

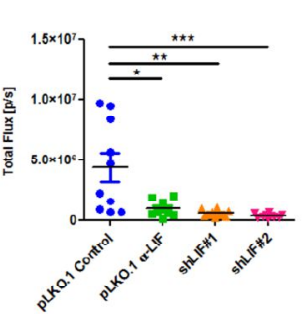
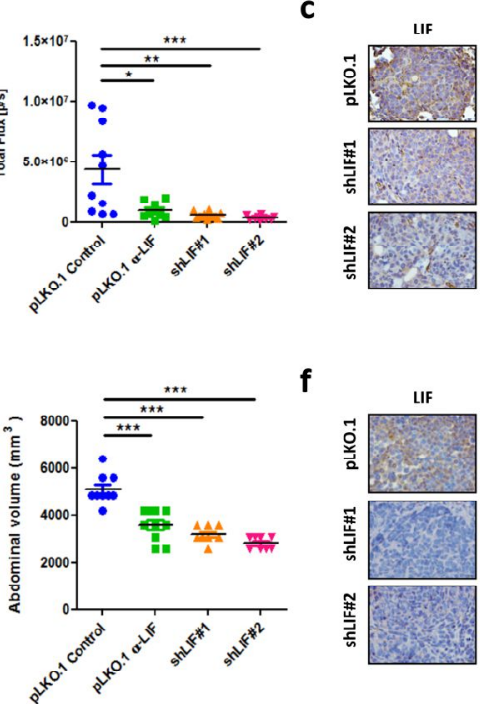

Figure 19. LIF blockade by RNA interference decreases in vivo tumor growth. (a,d) KLN205 (a) and ID8 (d) cells were infected with the indicated lentivirus. Previously to inoculate cells into mice, LIF transcript levels were determined by qRT-PCR analysis (left panels) and secreted LIF protein levels were determined by ELISA (right panels). Data are presented as mean \pm SD. (b,e) KLN205 (b) or ID8 (e) cells infected with the indicated lentivirus were inoculated. Tumor growth of KLN205 (bioluminescence) and ID8 (abdominal volume) models is shown. Arrows indicate the start of anti-LIF treatment, and scatter plots on the right represents the endpoint. Data are presented as mean \pm SEM. (c,f) IHC for LIF was performed in lung (c) and diaphragm tumors (f). Representative images are shown. Scale bar, $20 \mu \mathrm{m}$.

In the three models, the blockade of LIF via neutralizing antibody (fig. 18c-e) or RNA interference (fig. 19b,e), leads to a decrease of tumor growth. In particular, we observed a regression in established tumors in response to anti-LIF treatment in KLN205 tumors. In all these models we observed a marked decrease in p-STAT3 levels in response to the anti-LIF treatment (fig. 20a-c), showing that LIF was the main cytokine inducing the JAK/STAT3 pathway. Moreover, we did not observe a significant decrease in Ki67 positive cells in tumors from treated animals, but there was an increase in cleaved caspase 3 (CC3), indicating that the blockade of LIF induced tumor cell death (fig. 20a-c). 


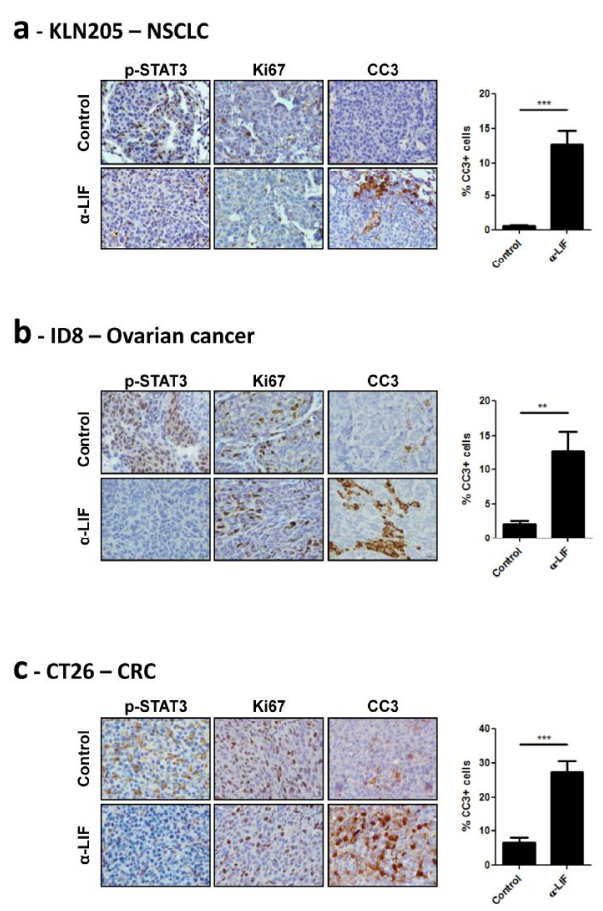

Figure 20. LIF blockade characterization in tumor-bearing mice. (a-c) p-STAT3, Ki67 and CC3 IHC were performed in KLN205 (a), ID8 (b) and CT26 (c) models treated or not with anti-LIF. Representative images are shown. Scale bar, 20 $\mu \mathrm{m}$. Percentage of $\mathrm{CC}^{+}$cells was calculated. Data are presented as mean \pm SEM.

\section{LIF regulates tumor-associated myeloid cells (TAMCs) polarization}

\subsection{PBMCs from healthy volunteers}

We then decided to study the molecular mechanisms involved in the anti-tumor response. We hypothesized that the oncogenic effect of LIF could be mediated by the microenvironment and, in particular, by the regulation of TAMCs. In order to assess this hypothesis, we decided to determine the effect of LIF on isolated monocytes from healthy human donors. Instead of using recombinant LIF, we opted to study the effect of endogenous LIF secreted by the tumor cells. We first performed a screening of five different human glioma cell lines. Four out of five showed a p-STAT3 increase after LIF treatment, and all five cell lines showed a decrease in pSTAT3 when were treated with anti-LIF neutralizing antibody (fig. 21a). For the next experiments, we chose U251 cells since they show high levels of secreted LIF (fig. 21b,c). 


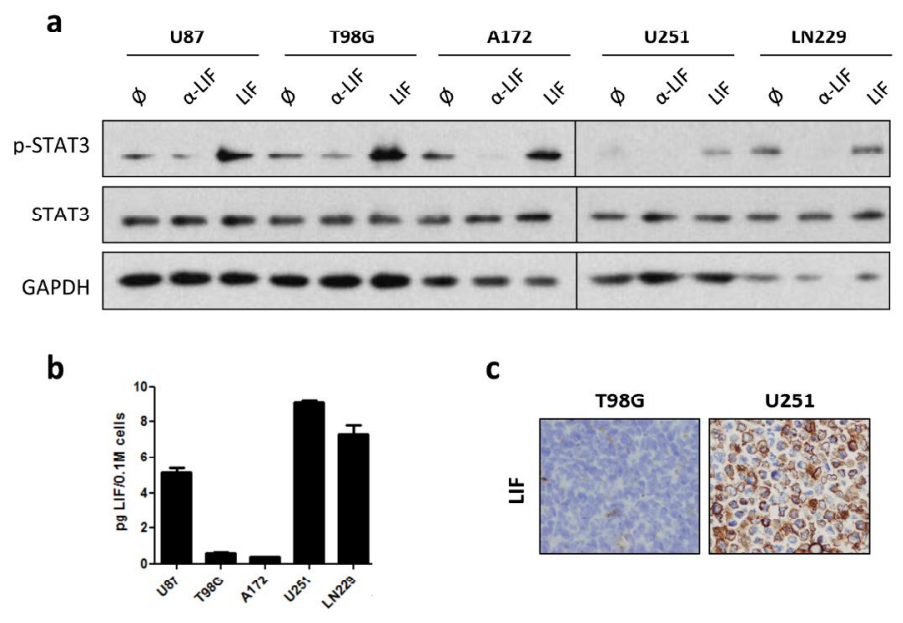

Figure 21. LIF pathway characterization in human glioma cell lines. (a) A battery of human glioma cell lines were treated with anti-LIF for $16 \mathrm{~h}$ or recombinant LIF for $4 \mathrm{~h}$. The levels of p-STAT3, STAT3 and GAPDH were determined by immunoblotting. (b) Secreted LIF protein basal levels were determined by ELISA after $72 \mathrm{~h}$. Data are presented as mean \pm SD. (c) LIF IHC was performed in pellets of T98G and U251 cells. Representative images are shown. Scale bar, $20 \mu \mathrm{m}$.

In order to knock-down LIF expression and secretion, we used shRNAs. The conditioned media from control and shLIF U251 was collected to incubate human monocytes, CD14 ${ }^{+}$cells isolated from PBMCs from healthy volunteers. After five days, we performed a transcriptomic analysis to determine the gene expression impact in the monocytes (fig. 22a). The results revealed several genes up-regulated or down-regulated in monocytes incubated with conditioned media devoid of LIF (table 17). In particular, we observed a down-regulation of genes related to the oncogenic M2 phenotype in myeloid cells, such as CCL22, CCL1, MRC1 and CTSK (fig. 22b). It is well known that CCL22 and CCL1 are secreted chemokines that induce immunosuppression acting as chemoattractants of Tregs (Curiel, Coukos et al. 2004, Hoelzinger, Smith et al. 2010); MRC1 is a broadly used M2 marker (Biswas and Mantovani 2010); and, finally, CTSK is an oncogenic cathepsin involved in tumor invasion and metastasis (Herroon, Rajagurubandara et al. 2013). We validated the transcriptomic results by qRT-PCR (fig. 22c) as well as the down-regulation of CCL22 through ELISA (fig. 22d). We also performed an ELISA from the conditioned media of U251 to ensure that CCL22 came from CD14 ${ }^{+}$cells and not from U251. As expected, we did not detect CCL22 in the media (data not shown). 
a

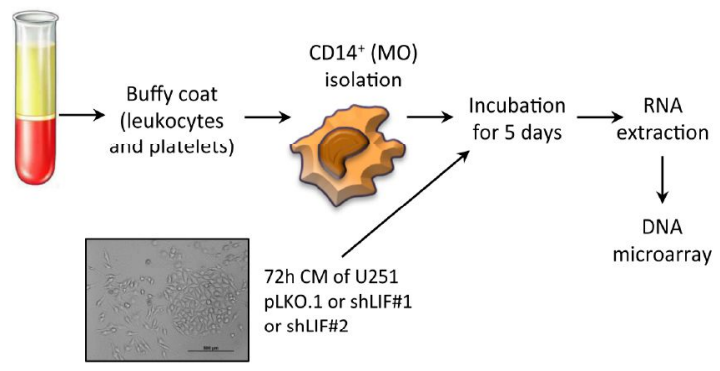

b
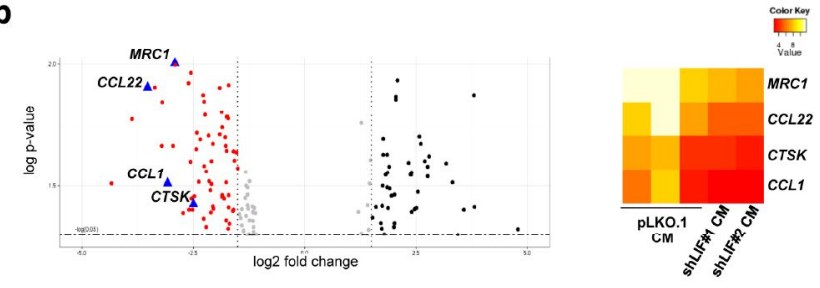

C

d
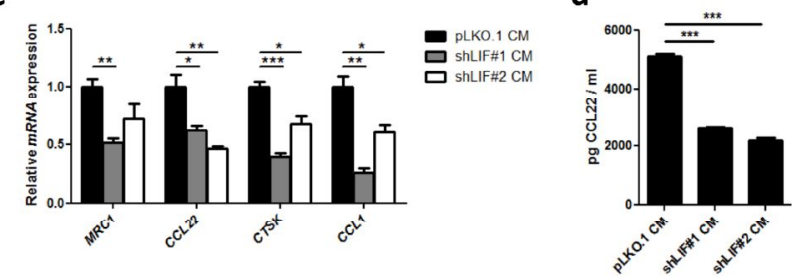

Figure 22. Blockade of LIF decreases M2-like polarization of monocytes (MO) from healthy donors. (a) Scheme representing the experimental procedure is shown. (b) Volcano plot and heatmap of differentially expressed genes in monocytes from healthy donors cultured with conditioned media (CM) from U251 pLKO.1 (control) or shLIF were determined by transcriptomic analysis. See also Table 17. (c,d) MRC1, CCL22, CTSK and CCL1 transcript levels were determined by GRT-PCR analysis (c) and CCL22 secreted protein levels by ELISA (d). Data are presented as mean \pm SEM.

Following another approach, we determined the phagocytic capacity of isolated CD $14^{+}$cells once exposed to conditioned media from U251 in presence or absence of anti-LIF neutralizing antibody. After five days of treatment, we added Zymosan A Bioparticles labeled with fluorescein, and after 1 hour incubation, cells were fixed and the percentage of phagocytic capacity was calculated by cell counting (fig. 23a). The results showed that conditioned media from U251 treated with the anti-LIF antibody leads to a significant increase of CD14 ${ }^{+}$cells phagocytic capacity (fig. 23b). 

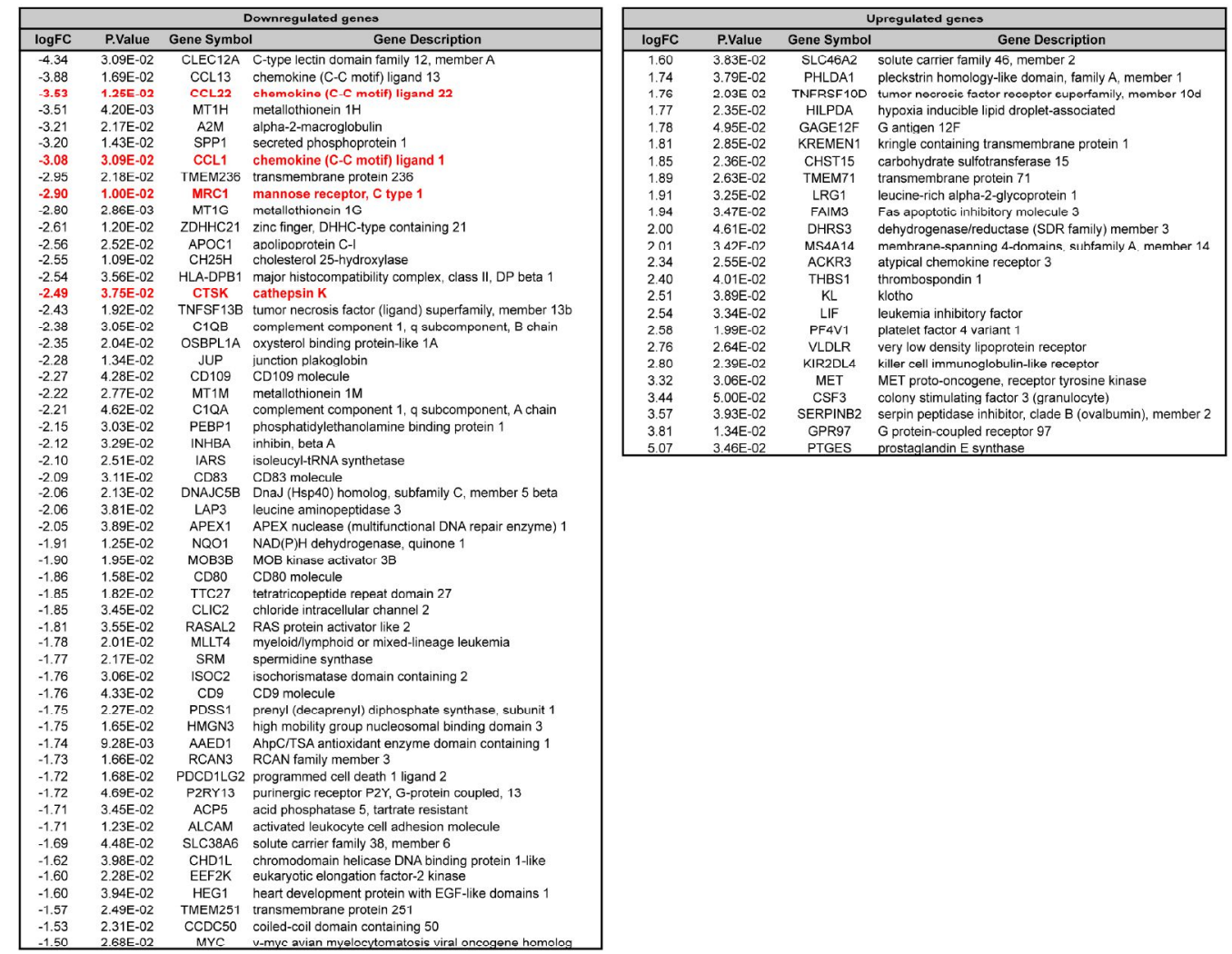

Table 17. LIF-responsive genes in monocytes from healthy donors. Table of differentially expressed genes in monocytes from healthy volunteers cultured with conditioned media from U251 shLIF or U251 pLKO.1 (control) determined by Human Gene 2.1 ST Affymetrix Microarray with significative \pm 1.50 fold change value.

a

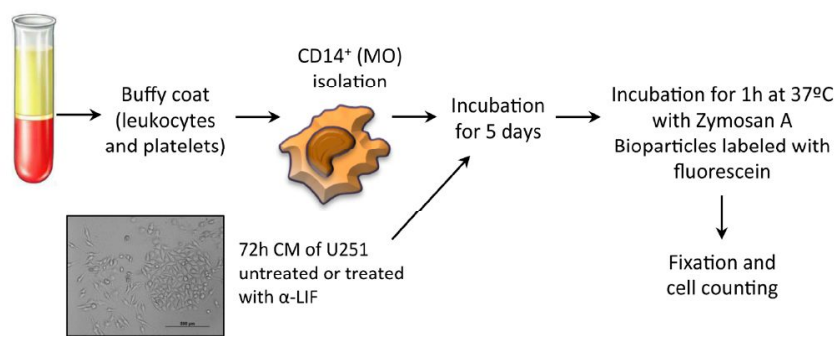

b

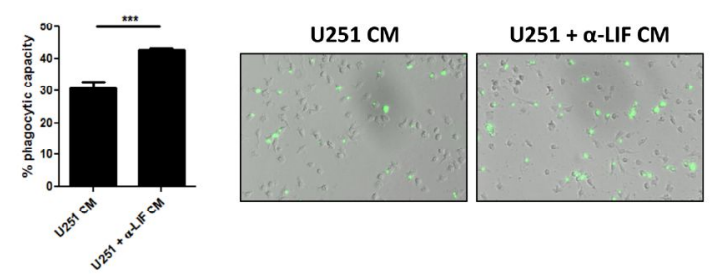

Figure 23. Blockade of LIF leads to an increase of monocytes (MO) phagocytic capacity. (a) Scheme representing the experimental procedure is shown. (b) Percentage of cells with a phagocytic capacity was calculated by cell counting (6 fields/condition). Data correspond to 6 independent experiments and are presented as mean \pm SEM. Representative images are shown. 


\subsection{Syngeneic models: ovarian cancer, NSCLC and CRC}

In order to determine whether the effect of LIF on normal human monocytes was also relevant in the context of TAMCs, we went back to the syngeneic tumor models described previously. We isolated $\mathrm{CD} 11 \mathrm{~b}^{+}$cells from the ascites of the ID8 tumor-bearing mice, treated or not with the anti-LIF antibody. Then, RNA was extracted from the $\mathrm{CD}_{11} \mathrm{~b}^{+}$cells and a transcriptomic analysis was performed (fig. 24a, table 18). As in the case of the human monocytes, we found several genes related to the M2 phenotype down-regulated (i.e. PF4, CCL7, CCL3, CTSK, MRC1, CD163, CCL2) (fig. 24b). Interestingly, down-regulation of MRC1 and CTSK was also spotted in the analysis of human monocytes. The results were validated by qRT-PCR (fig. 24c).

\section{a}

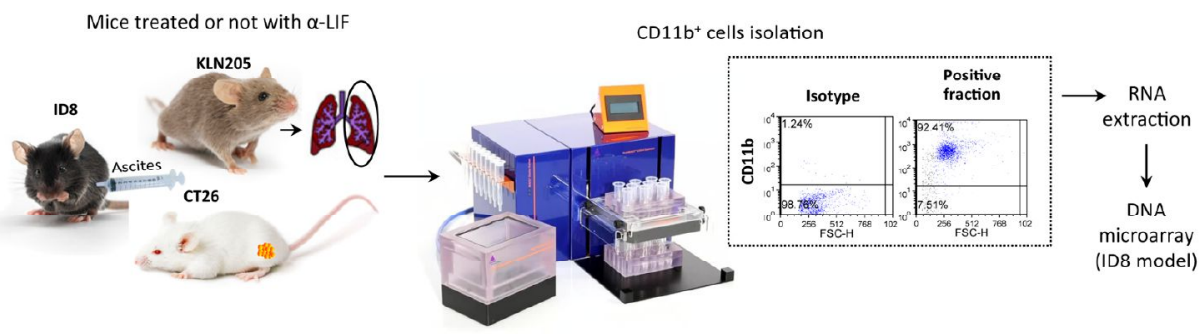

b - ID8 - Ovarian cancer
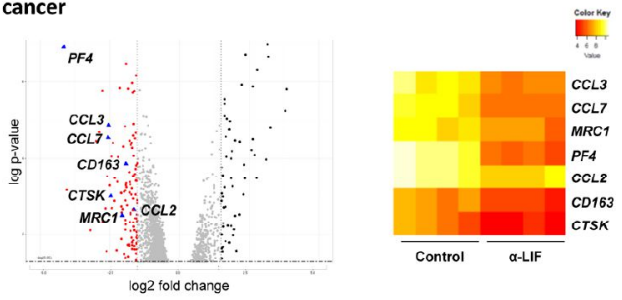

c
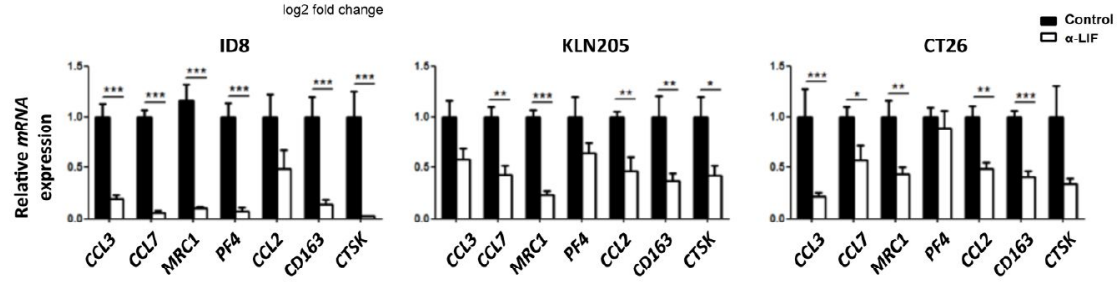

Figure 24. Blockade of LIF decreases the expression of M2-like genes on TAMCs from tumor-bearing mice. (a) Scheme representing the experimental procedure is shown. (b) Volcano plot and heatmap of differentially expressed genes in $\mathrm{CD}_{11} \mathrm{~b}^{+}$cells from ascitic fluid of ID8 treated with anti-LIF mice determined by transcriptomic analysis. See also Table 18. (c) CD11 $\mathrm{b}^{+}$cells from ascitic fluid of ID8, and KLN205 and CT26 tumors treated or not with anti-LIF were isolated ( $\mathrm{n}=4 \mathrm{mice} / \mathrm{group}$ ). CCL3, CCL7, MRC1, PF4, CCL2, CD163 and CTSK transcript levels were determined by qRT-PCR analysis. Data are presented as mean \pm SEM. 


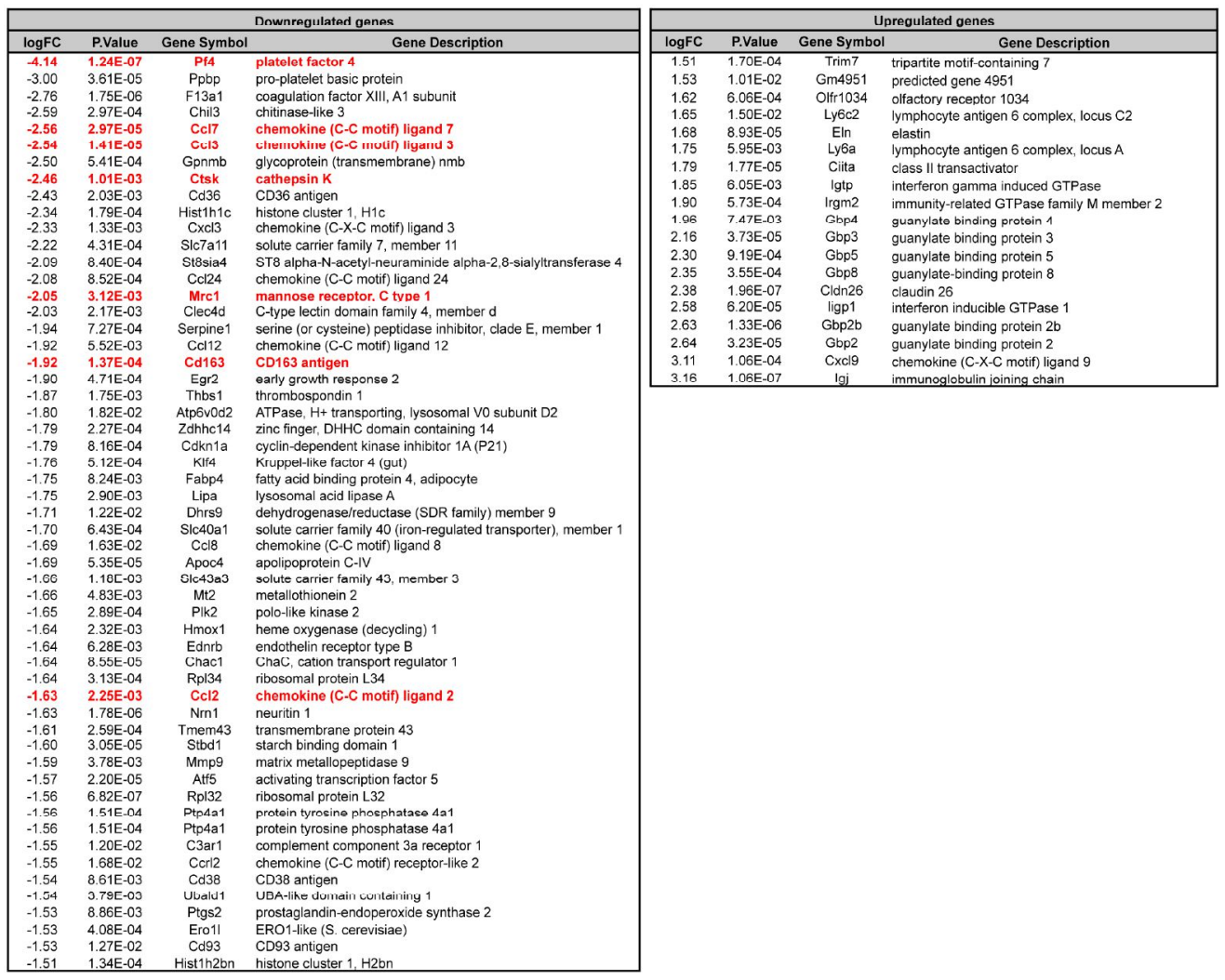

Table 18. LIF-responsive genes in TAMC from ascitic fluid of ID8 model. Table of differentially expressed genes in $\mathrm{CD} 1 \mathrm{~b}^{+}$cells isolated from ascitic fluid of mice bearing tumors generated by ID8 cells treated or not with anti-LIF antibody determined by Mouse Gene 2.1 ST Affymetrix Microarray with significative \pm 1.50 fold change value.

We then decided to assess whether the effect on TAMCs could be extrapolated to other tumor types. Besides the ovarian cancer ID8 model, we treated the NSCLC KLN205 and CRC CT26 models with anti-LIF antibody. We isolated $\mathrm{CD} 11 \mathrm{~b}^{+}$cells from the tumors and we analyzed the expression levels of the identified genes in the previous transcriptomic analysis (fig. 24a,b). Consistently, we observed a down-regulation of M2 phenotype related genes in all models (fig. 24c). These results indicated that the TAMC response to LIF might be transversal across tumor types. Furthermore, we performed an IF analysis of the expression of CCL22 in CD11 b ${ }^{+}$cells in sections of ID8 diaphragm tumors (fig. 25a) and CT26 subcutaneous tumors (fig. 25b). We observed that in untreated tumors, the majority of $C D 11 b^{+}$cells expressed CCL22, indicating that most of the CD11 $b^{+}$cells were polarized towards an M2-like phenotype. Moreover, in both cases, the levels of CCL22 were strongly down-regulated in $\operatorname{CD} 11 b^{+}$cells by the neutralization of LIF. The expression of MRC1 in TAMCs was also decreased in response to the anti-LIF treatment corroborating the previous transcriptomic analysis (fig. 25c). Our results showed that the blockade of LIF decreased the M2-like polarization of the tumor-infiltrated CD11b cells. 


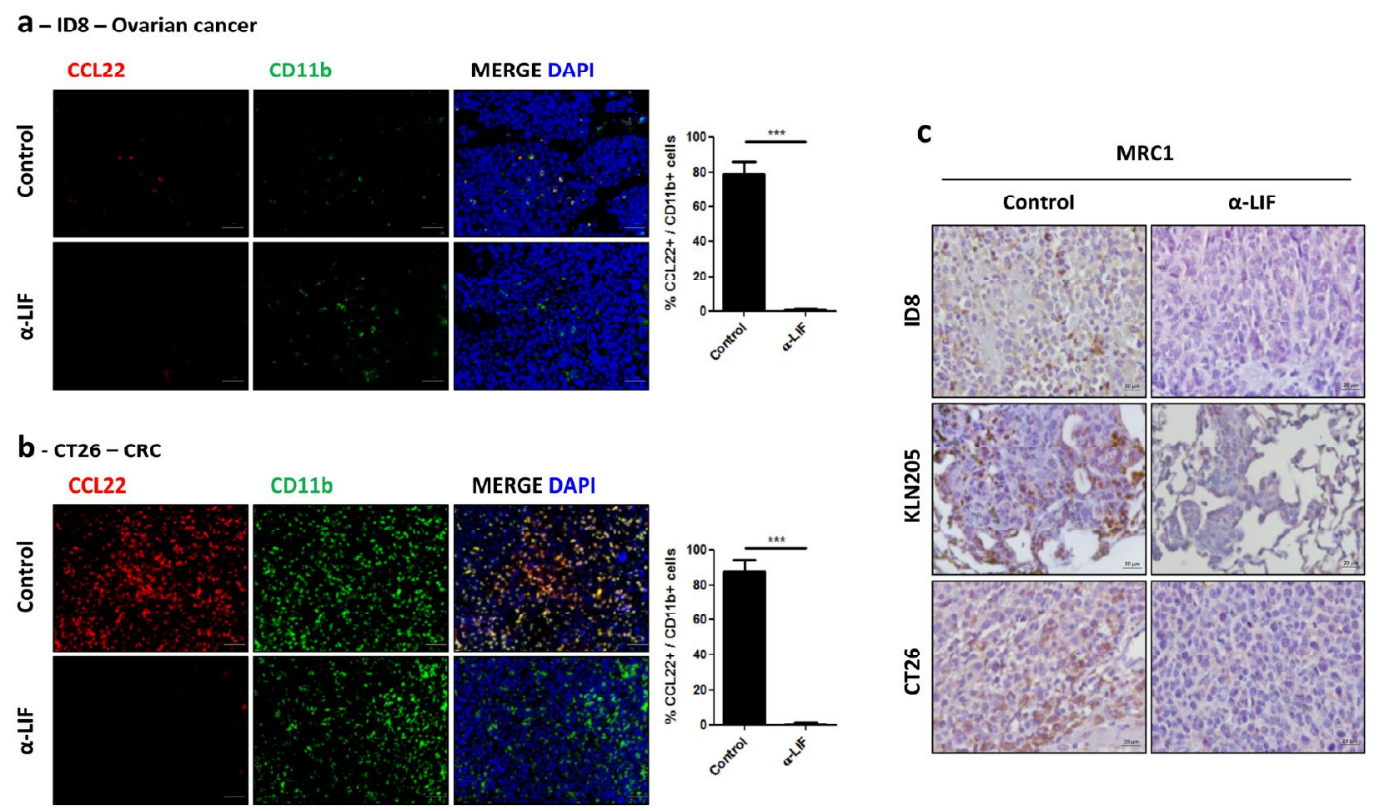

Figure 25. Blockade of LIF decreases M2-like polarization of TAMCs from tumorbearing mice. (a,b) Double IF for CCL22 and CD11b was performed in ID8 (a) and CT26 (b) tumors treated or not with anti-LIF neutralizing antibody. Scale bar, $50 \mu \mathrm{m}$. Representative images are shown and CCL22/CD11b expression ratio was calculated. Data are presented as mean \pm SEM. (c) MRC1 IHC was performed in the tumors of indicated models. Representative images are shown. Scale bar, $20 \mu \mathrm{m}$.

\subsection{Human xenograft GBM model: U251 cell line}

Based on the results shown above, we aimed to address whether this phenomenon was also taking place in GBM. Since immunocompromised mice (BALB/c nude mice) maintain the myeloid lineage, we studied the effect of the blockade of LIF in a human cell line xenograft model of GBM. Following the previous strategy, we selected the U251 cell line (fig. 21a-c). We treated the U251 xenograft orthotopic model with the anti-LIF antibody and, in parallel, we knocked down LIF using two independent shRNAs (fig. 26b,d). The results showed that LIF blockade either using a neutralizing antibody or RNA interference, prevented tumor growth (fig. 26a,c). There was also a noticeable infiltration of IBA-1 $1^{+}$microglia/TAMCs, as previously described (Pyonteck, Akkari et al. 2013). Importantly, all IBA-1 ${ }^{+}$cells were CCL22 positive in the untreated mice and showed a marked decrease in CCL22 expression in response to the LIF blockade (fig. 26e,f), recapitulating what we observed in the CRC and ovarian cancer models. 


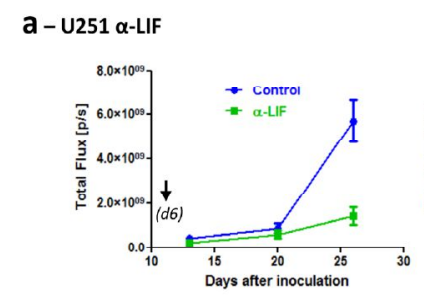

b - U251 shLIF
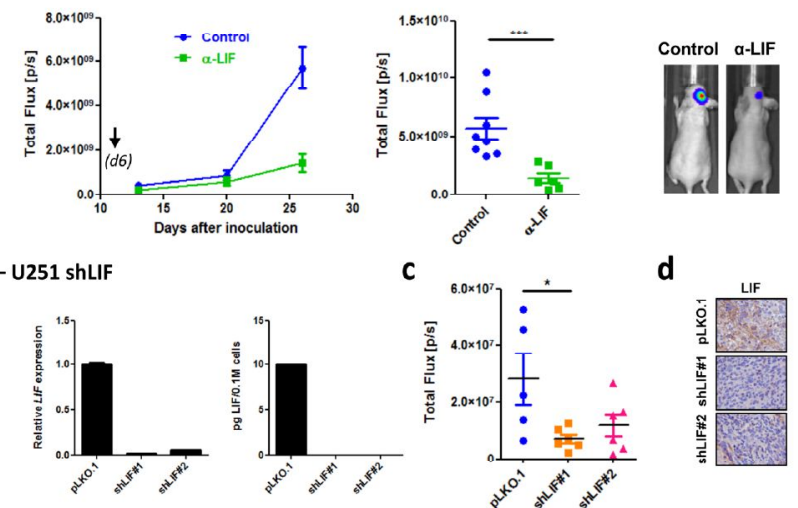

c

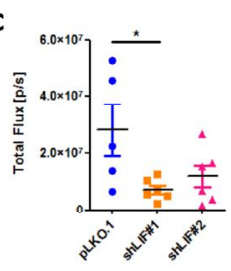

d
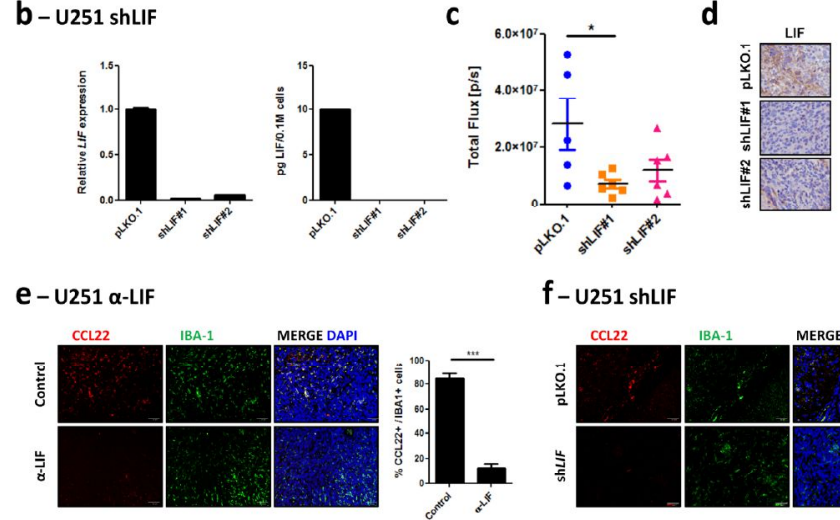

f - U251 shLIF

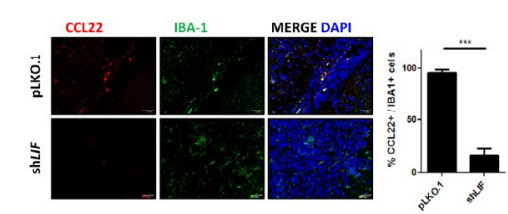

Figure 26. LIF blockade decreases M2-like polarization and inhibits tumor growth in U251 GBM model. (a) Tumor growth of the U251 orthotopic xenograft model measured by bioluminescence is shown. The anti-LIF treatment started on day 6 after inoculation. Data are presented as mean \pm SEM. (b-d) U251 cells were infected with the indicated lentivirus. Previously to inoculate cells into mice, LIF transcript levels were determined by qRT-PCR analysis (left panel) and secreted LIF protein levels were determined by ELISA (right panel). Data are presented as mean \pm SD (b). U251 cells infected with the indicated lentivirus were inoculated. 7 days after surgery, tumor size was determined by bioluminescence. Data are presented as mean \pm SEM (c). IHC for LIF was performed in brain tumors. Representative images are shown. Scale bar, $20 \mu \mathrm{m}(\mathrm{d})$. (e,f) Double IF for CCL22 and IBA-1 was performed in U251 tumors treated with anti-LIF (e) and infected with

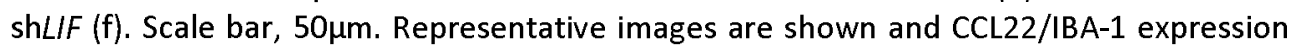
ratio was calculated. Data are presented as mean \pm SEM.

\subsection{PDX models for GBM}

It is well known that established tumor cell lines tend to differ from the characteristics of tumor cells in patients due to their adaptation to grow in artificial conditions (Lee, Kotliarova et al. 2006). To circumvent these limitations, we generated patient-derived xenograft (PDX) models by inoculating dissociated freshly obtained human tumor specimens in the brain of immunodeficient mice (Penuelas, Anido et al. 2009, Anido, Saez-Borderias et al. 2010). PDX models faithfully recapitulate the characteristics of tumors in patients and constitute extremely useful tools for preclinical experiments and for the study of the molecular mechanisms involved in cancer (Hidalgo, Amant et al. 2014). 

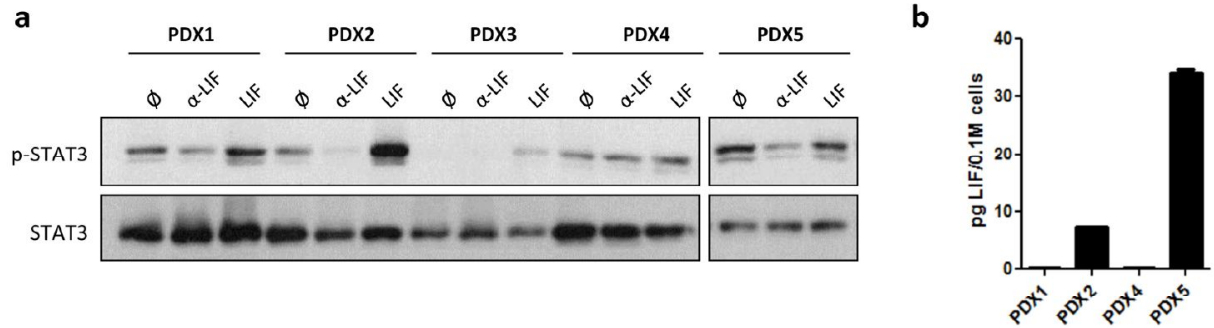

Figure 27. LIF pathway characterization in GBM patient-derived cells. (a) A battery of patient-derived GBM cells were treated with anti-LIF for $16 \mathrm{~h}$ or LIF for $4 \mathrm{~h}$. The levels of $\mathrm{p}$ STAT3 and STAT3 were determined by immunoblotting. (b) Secreted LIF protein basal levels were determined by ELISA after $72 \mathrm{~h}$. Data are presented as mean \pm SD.

a
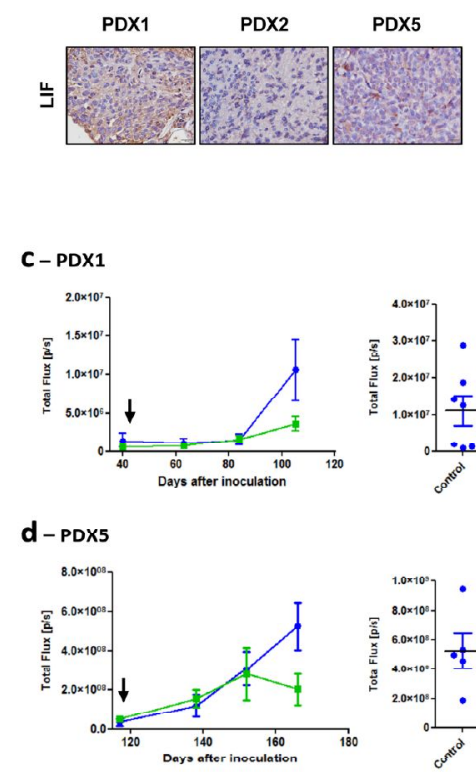
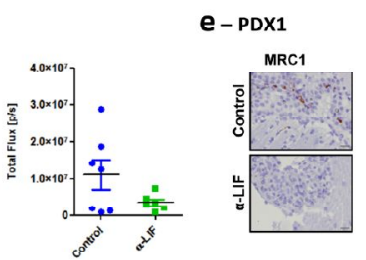

f-PDX5
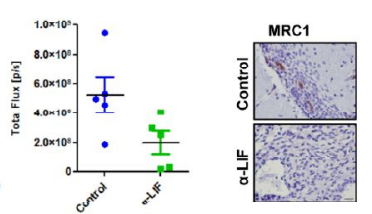
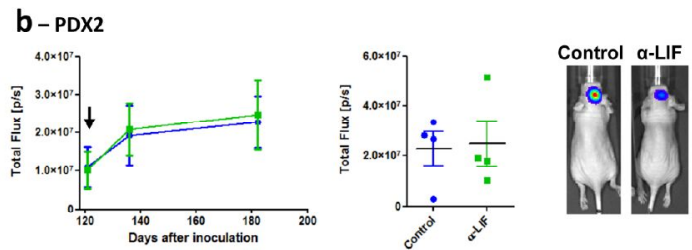

g-PDX1

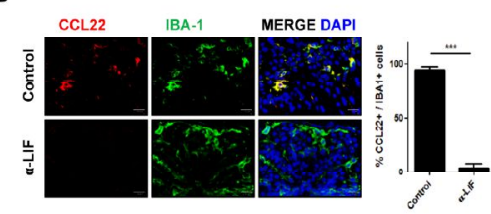

h - PDX5

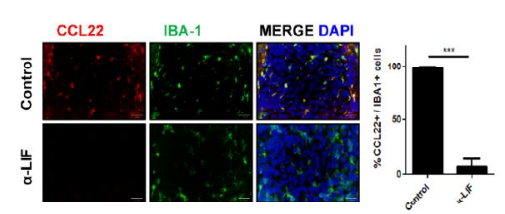

Figure 28. LIF blockade decreases M2-like polarization and inhibits tumor growth in PDX GBM models that express high levels of LIF. (a) LIF IHC was performed in tumors generated orthotopically in mice from PDX1, PDX2 and PDX5 patient-derived cells. Representative images are shown. Scale bar, 20 $\mu \mathrm{m}$. (b-d) Three different GBM PDX were inoculated. 17 weeks after surgery, PDX2 mice were treated with anti-LIF for 9 weeks and tumor size was determined by bioluminescence (b). 6 weeks after surgery, PDX1 mice were treated with anti-LIF for 9 weeks and tumor size was determined by bioluminescence (c). 17 weeks after surgery, PDX5 mice were treated with anti-LIF for 7 weeks and tumor size was determined by bioluminescence (d). Data are presented as mean \pm SEM. (e-h)

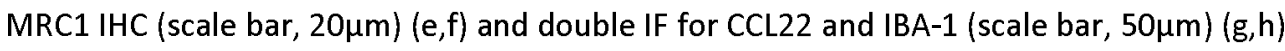
were performed in tumors generated by PDX1 and PDX5 treated or not with anti-LIF. Representative images are shown and CCL22/IBA-1 expression ratio was calculated. Data are presented as mean \pm SEM. 
In a similar way that we did previously, we performed a screening of several PDXs models. Four out of five showed an increase in p-STAT3 levels after recombinant LIF treatment, and three out of four (among those ones that expressed p-STAT3 at basal conditions) showed a decrease after anti-LIF antibody treatment (fig. 27a). We checked the secreted levels of LIF by ELISA in vitro (fig. 27b), and by IHC in vivo in the orthotopic tumors from those PDXs that better responded to anti-LIF antibody at p-STAT3 level (fig. 28a). The results showed that PDX1 cells secreted low levels of LIF in vitro, but they showed higher levels in vivo compared to PDX2, which, on the contrary, secreted moderate levels in vitro but no detectable levels in vivo (fig. 27b and fig. 28a). As expected, PDX2 did not response to anti-LIF treatment (fig. 28b). Thus, with the aim to study TAMCs, we selected PDX1 and PDX5 as PDX models that expressed high levels of LIF in vivo. In both cases we observed a decrease in tumor growth in response to treatment (fig. $28 \mathrm{c}, \mathrm{d}$ ), and when we analyzed the TAMCs, we observed a strong downregulation of MRC1 (fig. 28e,f) and CCL22 (fig. 28g,h) expression, reproducing the phenomenon observed in the other tumor models.

\subsection{TAMC depletion}

We next decided to evaluate whether the effect on TAMCs was responsible for the anti-tumor response to the blockade of LIF. To this aim, we used the KLN205 immunocompetent model and we depleted macrophages by treating the animals with clodronate liposomes (Weisser, van Rooijen et al. 2012). Since the clodronate treatment induced some toxicity in mice, we performed a short experiment of 11 days treatment, combining clodronate with the neutralizing antibody against LIF. As expected, the blockade of LIF prevented tumor growth but this response was prevented in mice treated with clodronate (fig. 29a). These results showed that large part of the anti-cancer effect of the inhibition of LIF is mediated by macrophages. The blockade of LIF decreased p-STAT3 in the tumors of both clodronate treated and untreated mice and, as expected, clodronate eliminated the presence of macrophages as measured by the decrease in $\mathrm{CD}^{+} 8^{+}$cells (fig. 29b). 

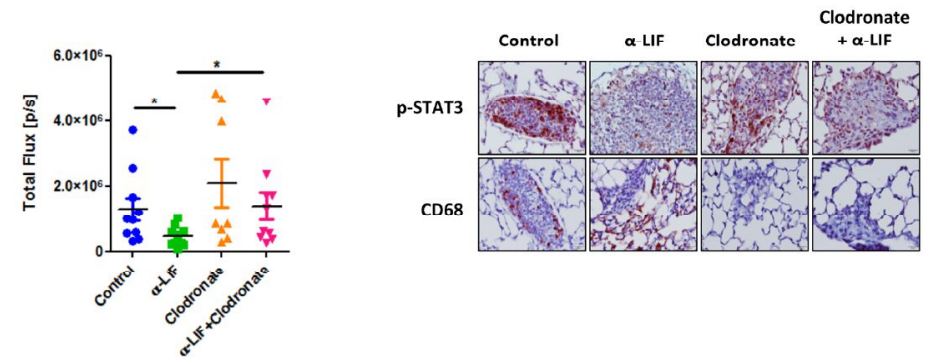

Figure 29. Anti-tumor effect of LIF blockade is mediated largely by macrophages. (a) KLN205 cells were inoculated in control mice or in mice pre-treated with a single dose of clodronate 4 days before the surgery. After inoculation, tumor-bearing mice were treated with clodronate and anti-LIF for 11 days and tumor size was determined by bioluminescence. Data are presented as mean \pm SEM. (b) CD68 and p-STAT3 IHC were performed. Representative images are shown. Scale bar, $20 \mu \mathrm{m}$.

\section{4. ㄴF blockade prevents Treg and facilitates effector T and NK cell tumor infiltration}

As we mentioned above, Tregs have a key role in cancer immunosuppression. Among the chemokines inhibited by the blockade of LIF in TAMCs, CCL22, CCL1, CCL2 and CCL3 are well described inducers and/or recruiters of Tregs (Curiel, Coukos et al. 2004, Fridlender, Buchlis et al. 2010, Hoelzinger, Smith et al. 2010, Schlecker, Stojanovic et al. 2012). So, we speculated that the treatment with the anti-LIF antibody might impact on Treg infiltration. Using the three syngeneic models, we determined the effect of anti-LIF on the Tregs population by flow cytometry analysis (fig. 30a). Interestingly, we observed a marked decrease in $\mathrm{CD}^{+} \mathrm{CD} 25^{+} \mathrm{FoxP}^{+}$Tregs in KLN205 (fig. 30b) and CT26 models (fig. 30c), but we did not see this effect on ID8 model, although we checked the Treg presence among the tumor cells attached to the diaphragm and in the ascites (data not shown). We also checked $\mathrm{CD}^{+}$Tregs in all models, since they have been related to the tumor immune escape in CRC and prostate tumors (Kiniwa, Miyahara et al. 2007, Chaput, Louafi et al. 2009). However, the percentages in our models were so small that we could not extract any conclusion (data not shown). 

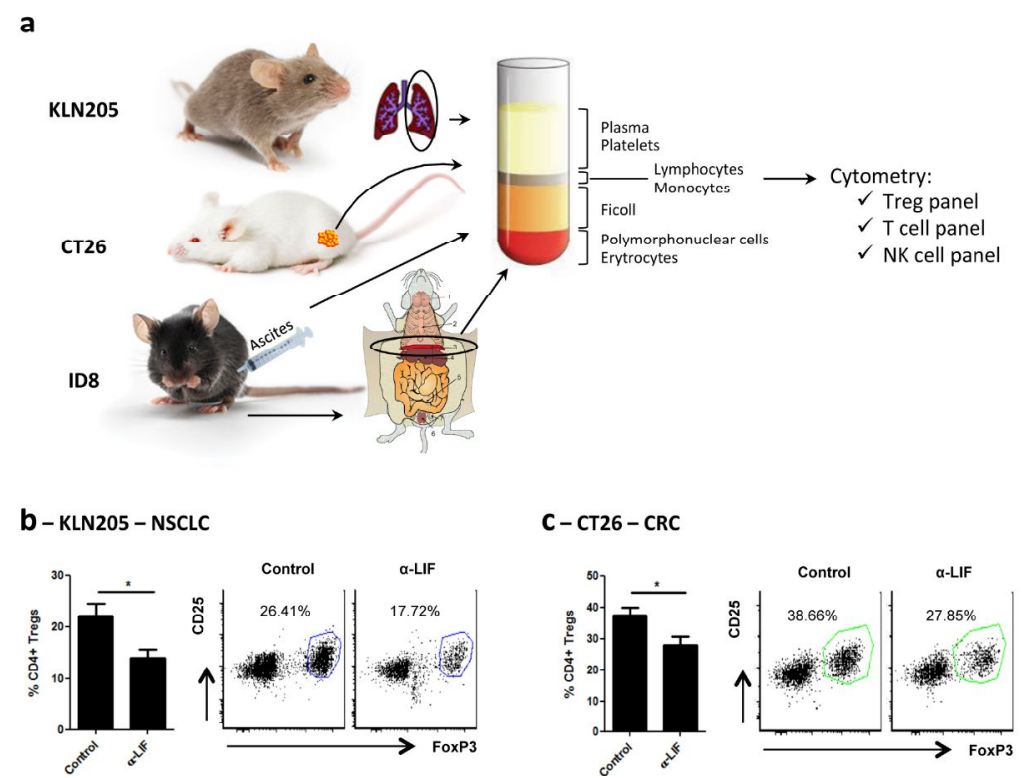

\begin{abstract}
Figure 30. LIF blockade decreases Tregs recruitment. (a) Scheme representing the experimental procedure is shown. $(\mathbf{b}, \mathbf{c}) 10$ or 18 days after the start of the anti-LIF treatment, tumor leukocytes were isolated from KLN205 (b) and CT26 (c) tumors respectively. Percentages of Tregs $\left(\mathrm{CD} 25^{+} \mathrm{FoxP}^{+}\right)$among $\mathrm{CD}^{+}{ }^{+}$cells were determined by flow cytometry. The results are the mean of 6 mice/group. Data are presented as mean \pm SEM. Representative plots are shown.
\end{abstract}

TAMCs and Tregs express an array of effector molecules (cell surface receptors, cytokines, chemokines and enzymes) that suppress cytotoxic functions of effector T and NK cells, leading to the inhibition of the anti-tumor immune response (Noy and Pollard 2014). Thus, we assessed the T and NK cell populations in our models by flow cytometry analysis (fig. 30a). Upon the treatment with the anti-LIF antibody in CT26 and ID8 models, we observed an increased tumor infiltration of $\mathrm{CD}^{+} \mathrm{CD}^{+}$cells (helper T cells), $\mathrm{CD}^{+} \mathrm{CD}^{+}$cells (cytotoxic $\mathrm{T}$ cells) and $\mathrm{CD}^{-} \mathrm{CD} 49 \mathrm{~b}^{+}$cells (NK cells) (fig. 31a,c). The results were verified by IHC (fig. 31b,d). However, in the KLN205 NSCLC orthotopic model, we did not observe any increase in those immune populations after the treatment (fig. 31e). We hypothesized that the reason could be that KLN205 is defined as a poorly immunogenic squamous cell carcinoma model (Labeur, Roters et al. 1999). In order to validate the hypothesis that anti-LIF antibody was having an effect on immune cells, we decided to check the spleen. We realized that the percentages of $\mathrm{CD}^{+} \mathrm{CD}^{+}$and $\mathrm{CD}^{+} \mathrm{CD}^{+}$cells were significantly higher in treated mice (fig. 31f), corroborating the anti-LIF antibody effect seen in the other two models. 
a - CT26-CRC

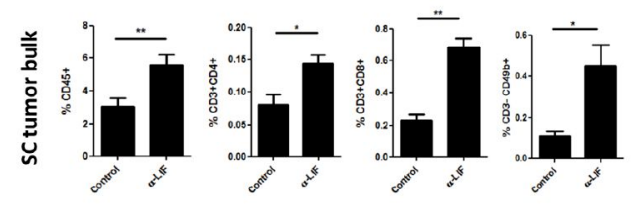

C - ID8 - Ovarian cancer

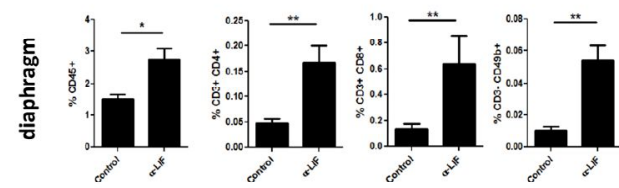

e - KLN205 - NSCLC

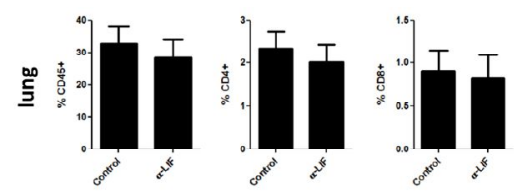

b - CT26 - CRC

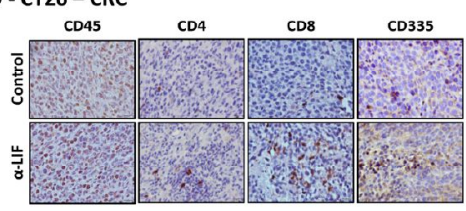

d - ID8 - Ovarian cancer

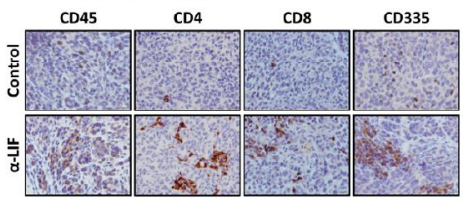

f - KLN205 - NSCLC

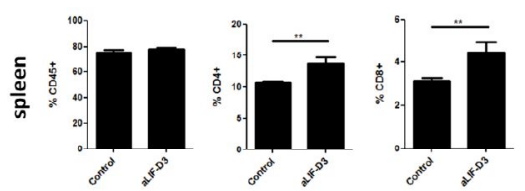

Figure 31. LIF blockade enhances T and NK cell infiltration. (a,c) 18 days or 27 days after the start of anti-LIF treatment, tumor leukocytes were isolated from CT26 (a) and ID8 (c) tumors respectively. Percentages of helper $\mathrm{T}\left(\mathrm{CD}^{+} \mathrm{CD} 4^{+}\right)$, cytotoxic $\mathrm{T}\left(\mathrm{CD} 3^{+} \mathrm{CD} 8^{+}\right)$and $\mathrm{NK}$ $\left(\mathrm{CD}^{-} \mathrm{CD}^{-} 9 \mathrm{~b}^{+}\right)$cells were determined by flow cytometry. The results are the mean of 8 to 10 mice/group. Data are presented as mean \pm SEM. (b,d) CD45, CD4, CD8 and CD335 IHC were performed in CT26 (b) and ID8 (d) tumors. Representative images are shown. Scale bar, $20 \mu \mathrm{m}$. (e,f) 10 days after the start of anti-LIF treatment, tumor leukocytes were isolated from KLN205 lungs (e) or spleens (f) tumors. Percentages of helper T $\left(\mathrm{CD}^{+} \mathrm{CD}^{+}\right)$ and cytotoxic $\mathrm{T}\left(\mathrm{CD}^{+} \mathrm{CD}^{+}\right)$cells were determined by flow cytometry. The results are the mean of 8 to 10 mice/group. Data are presented as mean \pm SEM.

Overall, our data indicated that anti-LIF neutralizing antibody promotes a reduction in the expression of CCL22 and related chemokines secreted by TAMCs, which leads to a decrease in Treg infiltration, and to an increase of helper T, cytotoxic T and NK cells within the tumor mass. It has been well described that Tregs have an impact on other immune cells (Shevach 2009). Thus, the increased presence of effector T and NK cells after LIF blockade might be due to the decreased number of TAMCs and also Tregs. This scenario indicated a crosstalk between innate and adaptive immunity.

To corroborate our hypothesis, we decided to assess how the downregulation of the CCL22 expression observed in TAMCs might impact on the effect of LIF blockade on tumor growth. Treatment with blocking antibodies against LIF and CCL22 (Jakubzick, Wen et al. 2004, Dogan, Long et al. 2011) and combinatory treatments with both antibodies in CT26 mouse models, showed that the neutralization of CCL22 decreased tumor growth at a similar level as the blockade of LIF, and that the combined treatment with anti-LIF and anti-CCL22 antibodies were 
not inducing an additive anti-tumor response (fig. 32a). T cell populations were analyzed in all animals (fig. 32b). This indicated that the anti-tumor effect of the neutralization of LIF was in large part mediated by the regulation of CCL22 expression.

a

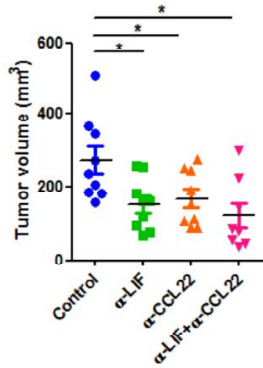

b

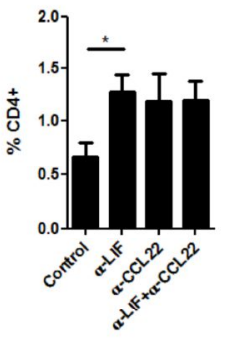

Figure 32. Anti-tumor effect of LIF blockade is mediated through the engagement of effector T cells. (a) CT26 cells were inoculated in mice. 3 days after inoculation, tumorbearing mice were treated with anti-LIF and/or anti-CCL22 twice a week for 15 days, and tumor volume was determined. Data are presented as mean \pm SEM. (b) Tumor leukocytes were isolated from $\mathrm{CT} 26$ tumors. Percentages of helper $\mathrm{T}\left(\mathrm{CD}^{+} \mathrm{CD4}^{+}\right)$and cytotoxic $\mathrm{T}$ $\left(\mathrm{CD}^{+} \mathrm{CD}^{+}\right)$cells were determined by flow cytometry. The results are the mean of 8 to 10 mice/group. Data are presented as mean \pm SEM.

Finally, we decided to validate the crosstalk between the native and the adaptive immune response and show that the anti-tumor response to anti-LIF agents is mediated by the engagement of effector T cells via the regulation of TAMCs, CCL22 and Tregs. We therefore treated the CT26 mouse model with anti-LIF antibody and concomitantly depleted the CD4 ${ }^{+}$ and $C D 8^{+} T$ cells using neutralizing antibodies against CD4 and CD8 (Jing, Gershan et al. 2009, Andreasson, Eriksson et al. 2010). Treatment with anti-CD4 and anti-CD8 antibodies led to an increase in tumor growth indicating that the effector T cells were partially preventing tumor growth in the CT26 tumor model (fig. 33a). Importantly, the depletion of the effector T cells impaired the anti-tumor effect of anti-LIF antibody showing that the oncogenic response to LIF is in part mediated by the regulation of the cytotoxic $T$ and helper $T$ compartments. The depletion of $\mathrm{T}$ cells by the CD4 and CD8 neutralizing antibodies was confirmed by flow cytometry (fig. 33b) and IHC (fig. 33c). 


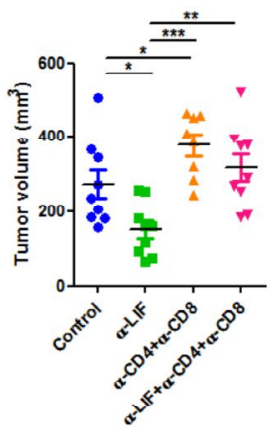

b
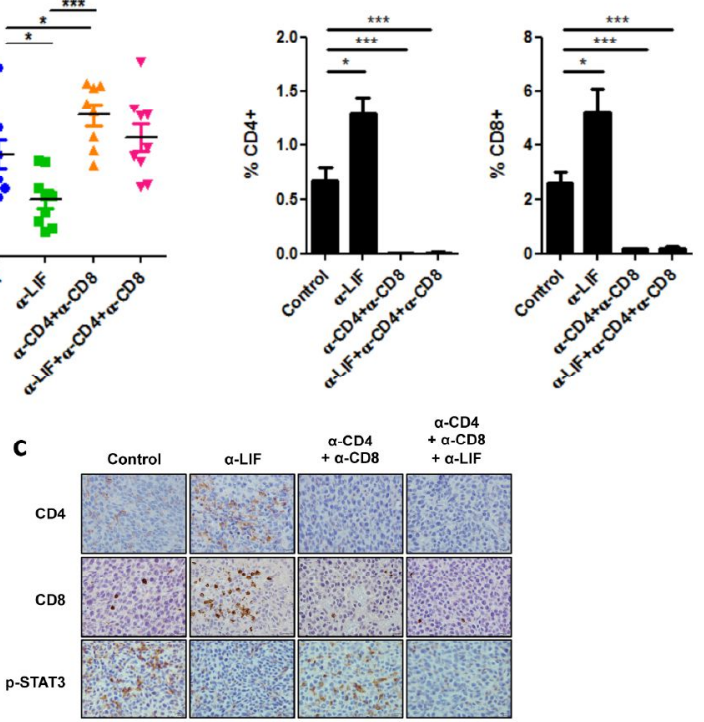

Figure 33. Anti-tumor effect of LIF blockade is mediated through the engagement of effector T cells. (a) CT26 cells were inoculated in control mice or in mice pre-treated with a single dose of anti-CD4 and anti-CD 2 days before the surgery. 3 days after inoculation, tumor-bearing mice were treated with anti-LIF and/or anti-CD4/CD8 twice a week for 15 days, and tumor volume was determined. Data are presented as mean \pm SEM. (b) Tumor leukocytes were isolated from CT26 tumors. Percentages of helper $\mathrm{T}\left(\mathrm{CD}^{+} \mathrm{CD}^{+}\right)$and cytotoxic $\mathrm{T}\left(\mathrm{CD}^{+} \mathrm{CD} 8^{+}\right)$cells were determined by flow cytometry. The results are the mean of 8 to 10 mice/group. Data are presented as mean \pm SEM. (c) CD4, CD8 and p-STAT3 IHC were performed. Representative images are shown. Scale bar, $20 \mu \mathrm{m}$.

\section{LIF is responsible for the M2-like phenotype of TAMCs in human GBM and confers}

\section{poor prognosis: organotypic model}

Until this point, the study was based on the use of syngeneic mouse models, human cell line xenograft models (U251), PDX models and PBMCs from healthy donors. Each of these models presents some advantages and disadvantages. The syngeneic mouse model allows the study of the effect of the neutralization of LIF in the context of a fully immunocompetent animal. However, the tumors are generated by mouse cancer cell lines that could have limited resemblance to real human cancer cells. The PDX models fully recapitulate the characteristics of the tumor of the patient but they are generated in immunodeficient mouse models. In order to circumvent these limitations, we decided to study the phenomenon of the modulation of the TAMC phenotype using organotypic tissue cultures of GBM specimens freshly obtained from patients. The organotypic models allow the short-term culture of sections of tumors that maintain the tissue architecture and stroma (immune and endothelial cells) from the tumor of the patient, which bypasses some of the limitations described for the other models (Merz, Gaunitz et al. 2013) (fig. 34a). Thus, these are optimal models for the study of the immune cell 
tumor infiltrates in the context of the actual tumor of the patient. We obtained organotypic cultures from three patients, and in all three cultures a large infiltration of TAMCs was present as detected by the IBA-1 marker, that co-expressed with CCL22, MRC1 and CD163. Interestingly, a three day treatment of the organotypic culture with the neutralizing antibody against LIF promoted a decrease in CCL22, MRC1 and CD163 expression in agreement with the previous results using the syngeneic and PDX tumor models (fig. 34b). These results further demonstrate that LIF is crucial for the maintenance of an oncogenic M2-like phenotype in TAMCs.

a
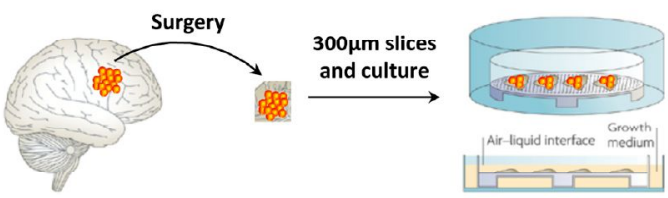

b
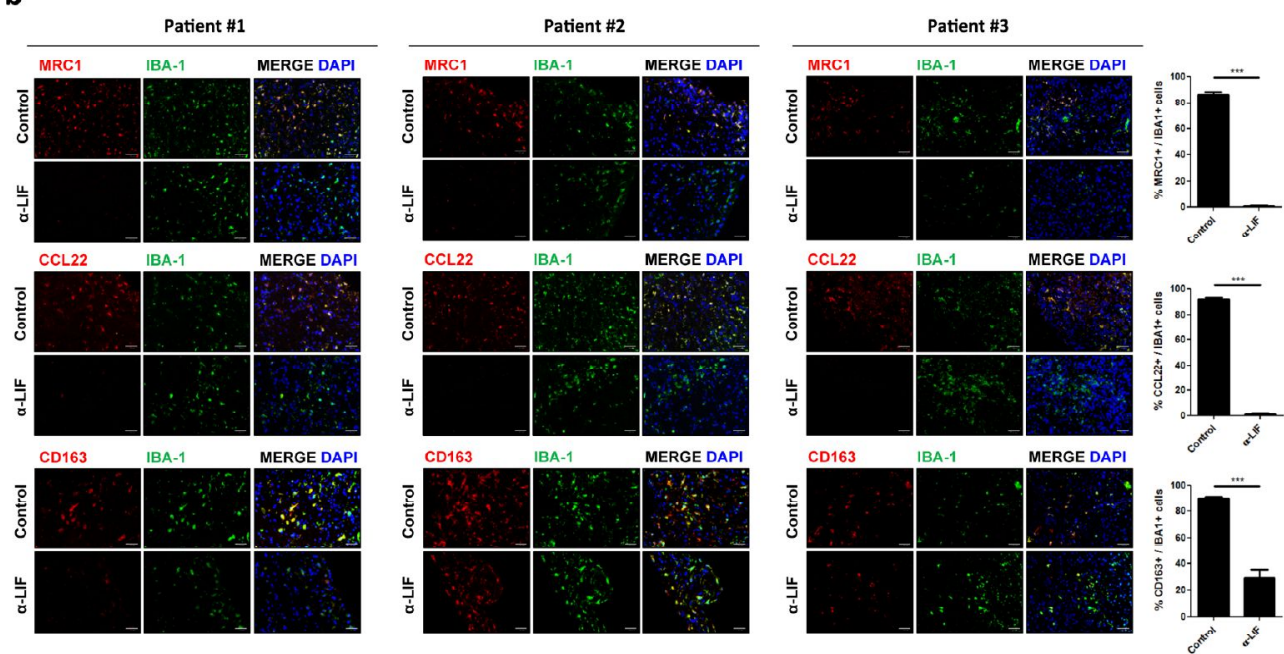

Figure 34. LIF regulates M2-like TAMCs in human GBM (a) Scheme representing the experimental procedure is shown (adapted from (Pampaloni, Reynaud et al. 2007)). (b) Human GBM organotypic slices were incubated with anti-LIF for 3 days ( 3 slices for each condition) from 3 different patients and double IF for MRC1, CCL22 and CD163 with IBA-1 were performed. Scale bar, $50 \mu \mathrm{m}$. Representative images are shown and MRC1/IBA-1, CCL22/IBA-1 and CD163/MRC1 expression ratios were calculated. The results are the mean of all patients. Data are presented as mean \pm SEM.

Next, we speculated that if LIF was required for the expression of M2-like factors in TAMCs, LIF expression should correlate with the presence of M2-like TAMCs in tumors. Through the analysis of the TCGA database, we analyzed the expression of LIF, MRC1 and CD163 in a cohort of 147 GBM patients. We observed a correlation between MRC1 and CD163 expression with LIF and, as expected, between MRC1 and CD163 (fig. 35a). Interestingly, patients with tumors expressing high levels of LIF, MRC1 and CD163 showed a shorter overall survival and time-to- 
progression (fig. 35b), and matched with patients diagnosed with the mesenchymal subtype (10 out of 11), the most aggressive subtype of GBM (fig. 35c). These results indicate that tumors expressing high levels of LIF, and consequently infiltrated with M2-like TAMCs, exhibit a worse prognosis, suggesting that in this particular group of patients LIF could be a good therapeutic target.

a
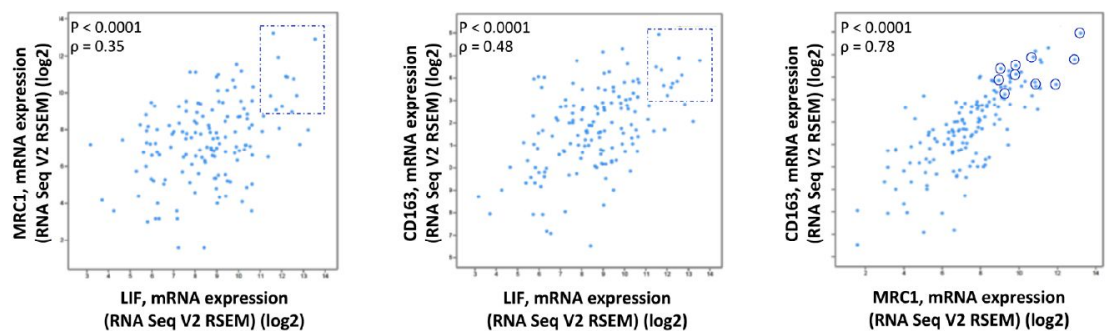

b
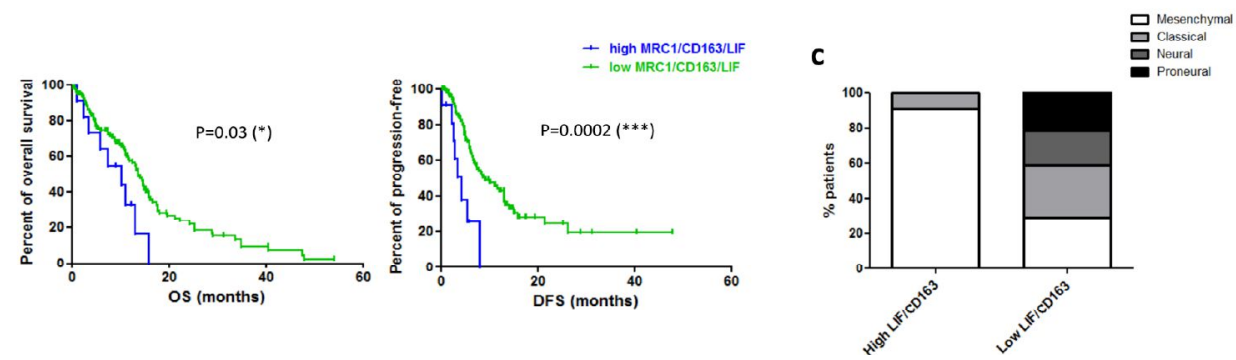

Figure 35. LIF correlates with M2-like genes in human GBM and confers poor prognosis. (a) Correlations between LIF and MRC1, LIF and CD163, and MRC1 and CD163 mRNA levels are shown. Spearman's rank correlation coefficient $(\rho)$ with two-tailed significance (P) was calculated. (b) Kaplan-Meier curves representing the overall survival (OS) and the diseasefree survival (DFS) of patients with LIF mRNA levels up-regulated $>11$ fold, MRC1 mRNA levels up-regulated $>9$ fold and $C D 163$ mRNA levels up-regulated $>13$ fold are shown. $P$ values (P) were calculated. (c) Percentage of GBM subtypes in patients with $L I F, M R C 1$ and $C D 163$ mRNA levels up-regulated as described in (b) are shown. Data were obtained from the cBioPortal database (GBM TCGA 2013, $n=147$ ).

\section{LIF blockade inhibits PDL1 expression}

It is well established that tumors exploit the PD-1/PDL1 pathway to evade eradication by the immune system: PDL1 expression on tumor cells or on APCs inhibits T cell activation, prevents the lysis of tumor cells and, in some cases, increases death of effector T cells (Wolchok and Chan 2014). It has been published that PDL1 is regulated in a STAT3-dependent manner, and that the blockade of STAT3 activation prevents PDL1 expression (Sumpter and Thomson 2011, Wolfle, Strebovsky et al. 2011). 


\subsection{Syngeneic models: ovarian cancer, NSCLC and CRC}

In order to assess if LIF was controlling PDL1 expression, we decided to use the syngeneic immunocompetent mouse models. We assessed the levels of PDL1 in different cell lines by flow cytometry (fig. 36a) and, in some cases, also by IHC (fig. 36b). Since ID8 cells did no express PDL1, we decided to focus on KLN205 and CT26.

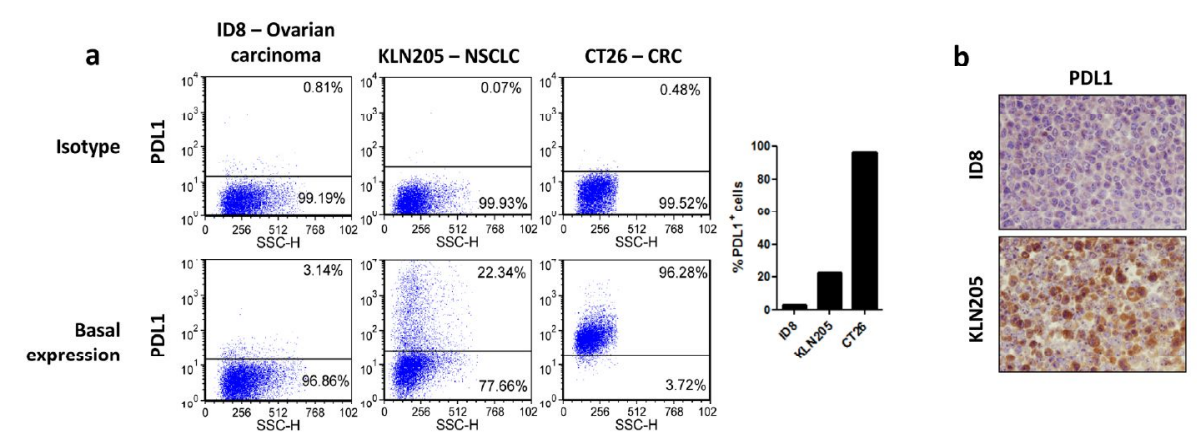

Figure 36. PDL1 expression in mouse tumor cell lines. (a) PDL1 basal levels were determined on ID8, KLN205 and CT26 cells by flow cytometry. A graph representing the percentages is shown. (b) PDL1 IHC was performed in pellets of ID8 and KLN205 cells. Representative images are shown. Scale bar, $20 \mu \mathrm{m}$.

In order to study the relevance of LIF in PDL1 expression, we decided to block LIF function in KLN205 and CT26 using two independent approaches: a) a neutralizing antibody, and b) two independent shRNAs targeting LIF. LIF and PDL1 transcript levels of infected cells were determined by qRT-PCR analysis. There was no effect in PDL1 expression at mRNA level neither in KLN205 (fig. 37a) nor in CT26 (data not shown). By contrast, we got a decrease in PDL1 protein levels in those cells infected with the shLIF and after anti-LIF treatment by both immunoblotting (fig. 37c) and cytometry (fig. 37b,d) in KLN205, but not in CT26 (data not shown). Thus, our data suggest that LIF modulates PDL1 expression at post-transcriptional level in KLN205 in vitro. 


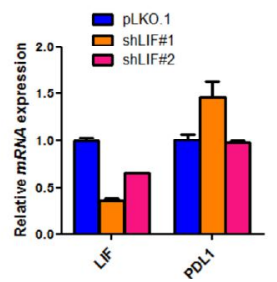

C

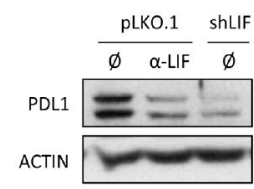

b

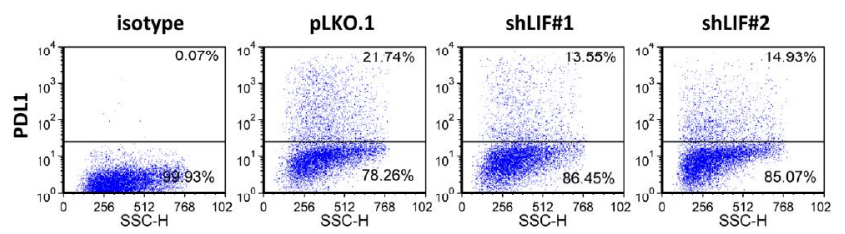

d

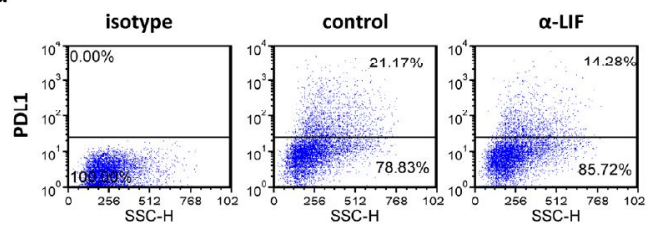

Figure 37. LIF regulates PDL1 in KLN205 cell line. (a,b) KLN205 cells were infected with the indicated lentivirus. $L I F$ and $P D L 1$ transcript levels were determined by qRT-PCR analysis (a) and PDL1 protein levels were also determined by flow cytometry (b). Data are presented as mean \pm SD. (c,d) KLN205 cells control were treated with anti-LIF for $16 \mathrm{~h}$. The levels of PDL1 and ACTIN were determined by immunoblotting (c) and by flow cytometry (d). The levels of PDL1 in KLN205 shLIF were also determined by immunoblotting (c).

Based on these results, we were willing to address whether this phenomenon was also taking place in vivo. It has been described that PDL1 expression on tumor cell lines is generally lower in vitro, and its expression is increased upon adoptive transfer into animals (Keir, Butte et al. 2008). We decided to check PDL1 levels by IHC in all syngeneic models that responded to antiLIF treatment. Surprisingly, we observed a down-regulation of PDL1 in response to the treatment in KLN205, CT26 and also ID8, despite of the low levels expressed in vitro (fig. 38a).

Besides being produced in large amounts by cancer cells, PDL1 is also expressed on certain immune cells, such as macrophages (Keir, Butte et al. 2008). Indeed, when we recovered the mRNA from CD11b ${ }^{+}$cells isolated from tumors (KLN205, CT26) or from ascitic fluid (ID8) (fig. 24a), we observed lower levels of PDL1 in those cells derived from anti-LIF treated mice in both KLN205 and CT26, but not in ID8 (fig. 38b). Thus, in our models LIF may regulate, at least partially, PDL1 expression in tumor and in CD11 $\mathrm{b}^{+}$cells.

\subsection{Human xenograft GBM model: U251 cell line}

Based on these data, we went on to address whether this regulation was also taking place in GBM. We analyzed PDL1 expression of five glioma human cell lines by cytometry assay (fig. 39a), and we verified this result by IHC in some of them (fig. 39b). The U251 cell line showed the highest levels of PDL1 expression and, interestingly, showed high levels of LIF secretion (fig. 21b). 
a

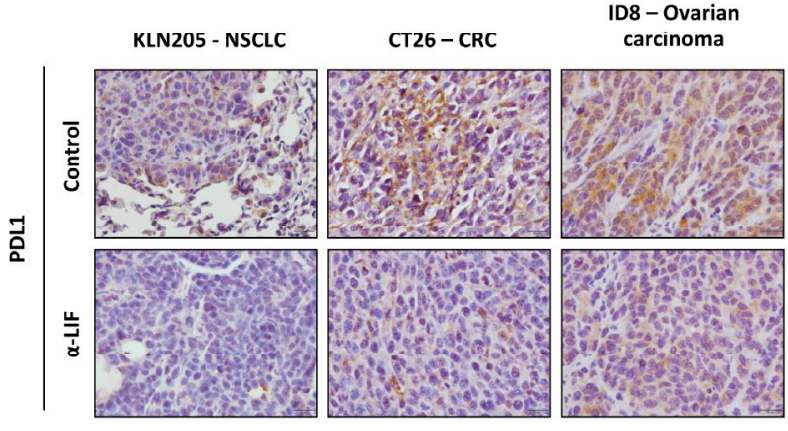

b
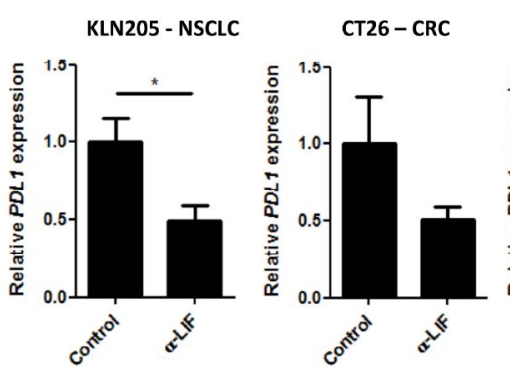

ID8 - Ovarian

carcinoma

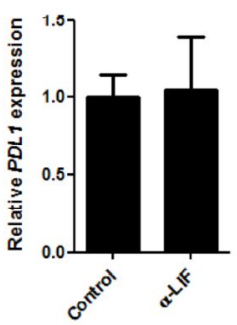

Figure 38. Blockade of LIF decreases PDL1 expression in tumors from syngeneic models. (a) PDL1 IHC was performed in KLN205, CT26 and ID8 tumor-bearing mice treated or not with anti-LIF. Representative images are shown. Scale bar, $20 \mu \mathrm{m}$. (b) $\mathrm{CD}_{11 \mathrm{~b}^{+}}$cells from KLN205 and CT26 tumors, and from ascitic fluid of ID8 mice treated or not with anti-LIF were isolated ( $\mathrm{n}=4 \mathrm{mice} / \mathrm{group}$ ) as shown in fig. 24a. $P D L 1$ transcript levels were determined by $q R T-P C R$ analysis. Data are presented as mean \pm SEM.

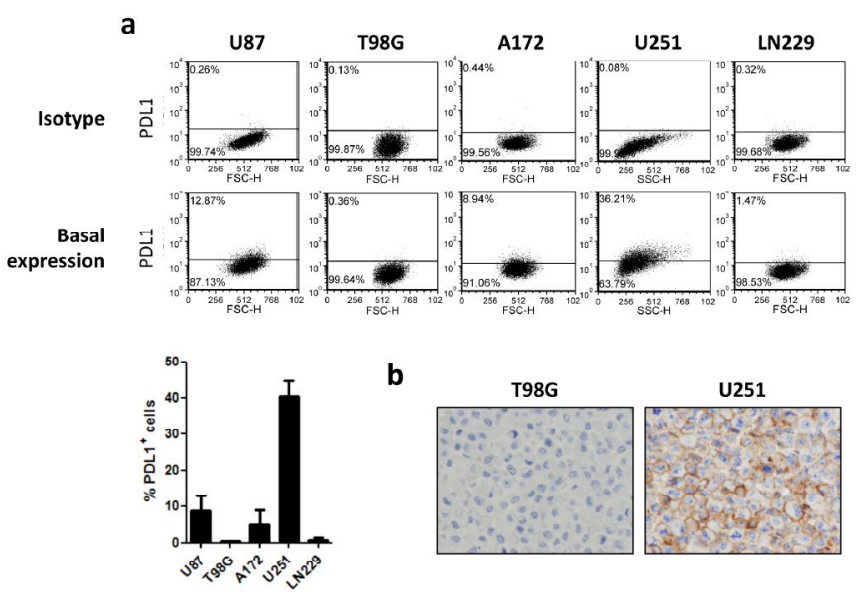

Figure 39. PDL1 expression in human glioma cell lines. (a) PDL1 basal levels were determined in a battery of human glioma cell lines by flow cytometry. A graph representing the mean of two independent experiments is shown. Data are presented as mean \pm SD. (b) PDL1 IHC was performed in pellets of T98G and U251 cells. Representative images are shown. Scale bar, $20 \mu \mathrm{m}$. 
Next, we decided to block LIF using the two independent approaches used before: a) a neutralizing antibody, and b) two independent shRNAs targeting LIF. We observed a decrease in PDL1 both at mRNA and protein level in those cells infected with the LIF shRNAs (fig. 40a,b), and at protein level after anti-LIF treatment (fig. 40c,d). Thus, the result suggests that in U251 the regulation of PDL1 by LIF is not only at post-transcriptional level, as in KLN205.

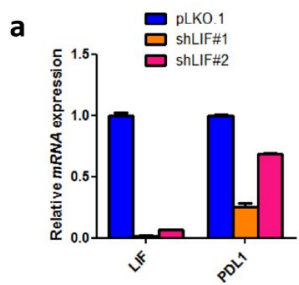

b
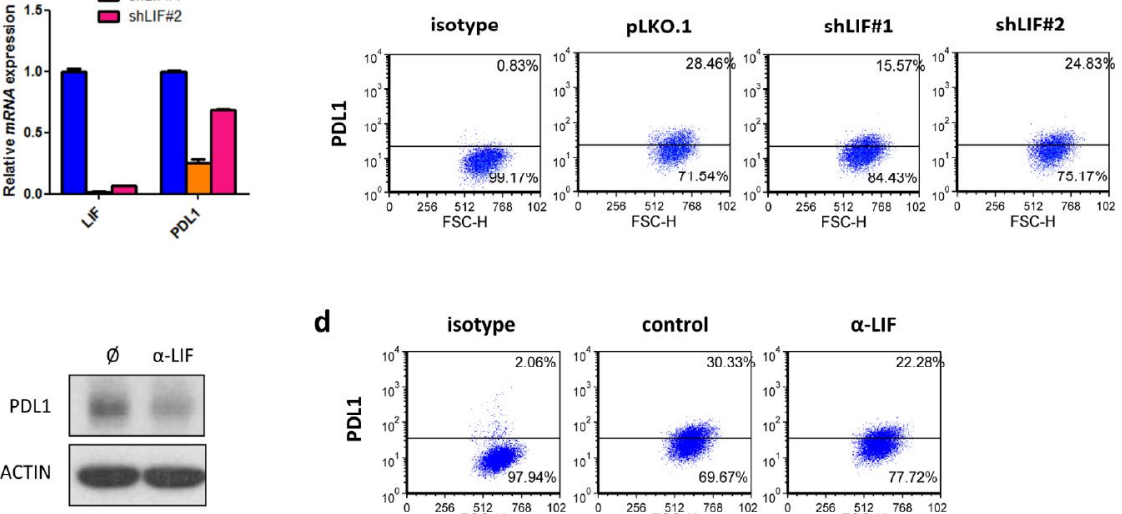

d

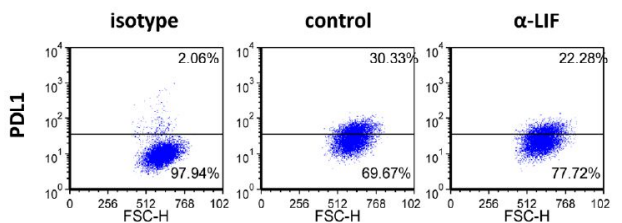

Figure 40. LIF regulates PDL1 in U251 cell line. (a,b) U251 cells were infected with the indicated lentivirus. $L I F$ and $P D L 1$ transcript levels were determined by qRT-PCR analysis (a) and PDL1 protein levels were also determined by flow cytometry (b). Data are presented as mean \pm SD. (c,d) U251 cells were treated with anti-LIF for $16 \mathrm{~h}$. The levels of PDL1 and ACTIN were determined by immunoblotting (c) and by flow cytometry (d).

\subsection{PDX models for GBM}

We performed a screening of several PDXs that we have established in our lab to analyze PDL1 expression by cytometry analysis (fig. 41). PDX5 stood out among all PDXs, which interestingly was the same PDX that secreted the highest levels of LIF (fig. 27b). Thus, we selected PDX5, and also PDX1 because we saw that in vivo expressed high levels of LIF (fig. 28a), and we knocked-down LIF through RNA interference. Then, we checked LIF and PDL1 expression by qRT-PCR (fig. 42a,b). In both cases, we observed a clear decrease in PDL1 transcription. 

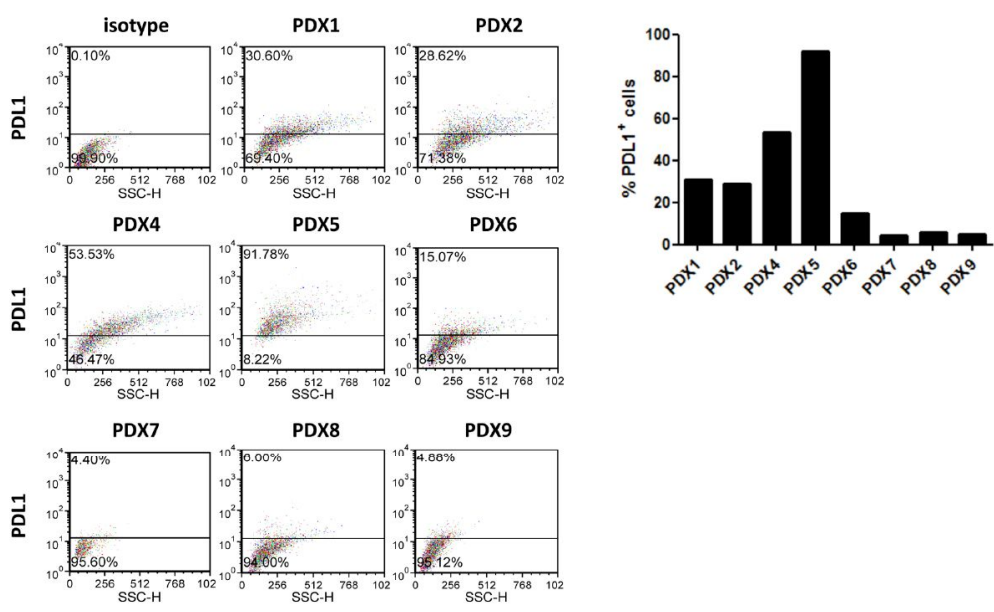

Figure 41. PDL1 expression in GBM patient-derived cells. PDL1 basal levels were determined in a battery of GBM patient-derived cells by flow cytometry. A graph representing the percentages is shown.
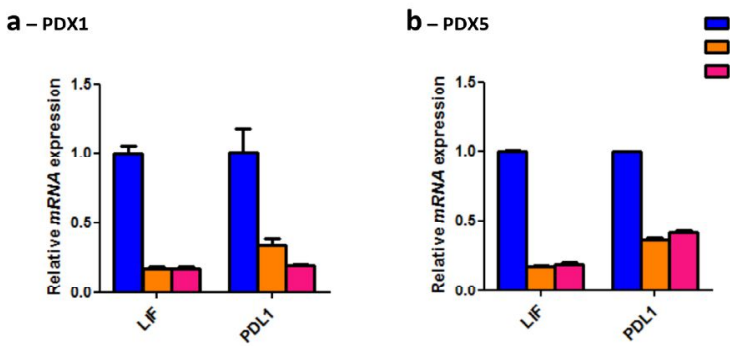

Figure 42. LIF regulates PDL1 in GBM patient-derived cells. (a,b) PDX1 (a) and PDX5 (b) cells were infected with the indicated lentivirus. LIF and PDL1 transcript levels were determined by qRT-PCR analysis. Data are presented as mean \pm SD.

\subsection{PDL1 promoter: a possible molecular mechanism}

In order to study the molecular mechanism by which LIF induces PDL1 transcription, we studied the PDL1 promoter. PDL1 promoter has a few regulatory elements, including the ISRE/IRF1 module of the JAK/STAT-responsive promoter, and the predicted enhancer element containing dual AP-1 binding sites (fig. 43a) (Green, Rodig et al. 2012). AP-1 DNA binding complex is a dimer consisting of members of Fos and Jun families, such as cJun and FosL2, and it has been described that other proteins, such as CREB/ATF, can interact with AP-1 components (Kaminska, Pyrzynska et al. 2000). We performed an immunoblotting with tumor cells from several PDXs and interestingly, we observed a regulation of FosL2 and p-cJun, and also p-CREB (fig. 43b). This result suggests that although JAK/STAT3 pathway is the main known pathway through which LIF signals, there exist other pathways to consider in the study of the molecular mechanism. 
a

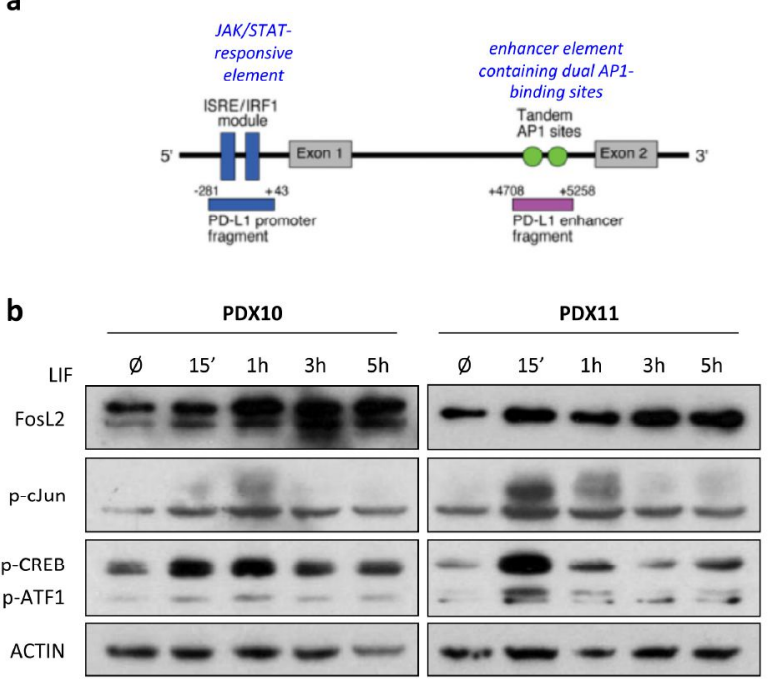

Figure 43. LIF may regulate PDL1 expression through AP-1. (a) Diagram representation of the PDL1 regulatory elements (adapted from (Green, Rodig et al. 2012)). (b) Patientderived cells were treated with recombinant LIF at different time points. The levels of FosL2, p-cJun, p-CREB/p-ATF1 and ACTIN were determined by immunoblotting.

\section{Correlation of PDL1, LIF and CD44}

It has been described that, within the heterogeneous tumor mass, cells with characteristics of stem cells are responsible for tumor initiation, recurrence, and resistance to therapy. Our lab has identified CD44 as a cell surface marker expressed by a population enriched for CICs (Anido, Saez-Borderias et al. 2010). We wondered whether this population was also involved in the immunosuppression caused by LIF, and if those cells showed a greater ability to immunosuppress the environment.

First, we verified the role of LIF on the CIC population. So we treated different patient-derived cells with recombinant LIF (fig. 44a) or with the antibody against LIF (fig. 44b) during 7 days and we checked CD44 population. Interestingly, we saw, to a greater or lesser extent, an increase in CD44 high population in all cells treated with recombinant LIF and a decrease after LIF inhibition.

Next, we wanted to examine if there was a correlation between CD44 and PDL1, and we checked the expression of both proteins in tumor cells from several PDXs by cytometry (fig. 41 and fig. 45a). We observed a significant positive correlation between them (fig. 45b), indicating that it was a really interesting line to explore. Furthermore, we checked TCGA database and we also saw a positive correlation in a cohort of 147 GBM patients (fig. 45c). 


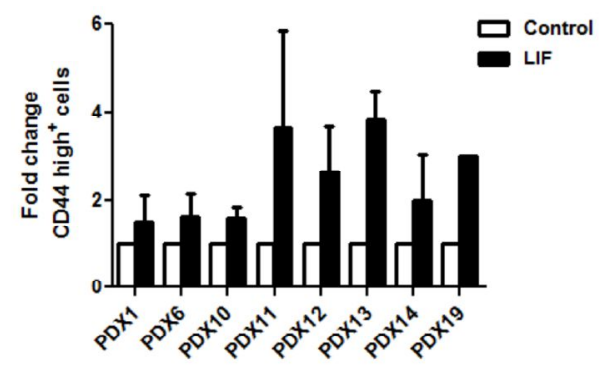

b

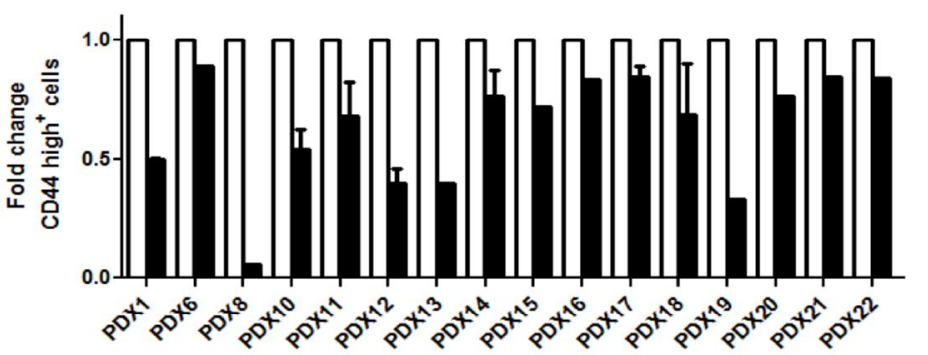

Figure 44. LIF induces an increase of CD44 high population in GBM patient-derived cells. $(a, b)$ Patient-derived cells were treated with recombinant LIF (a) or anti-LIF (b) for 7 days. The percentage of CD44 high population was determined by flow cytometry. Data correspond to 1 to 4 independent experiments. Data are presented as mean \pm SD.

a

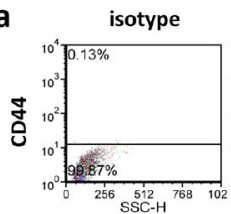

PDX4

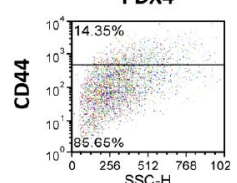

PDX7
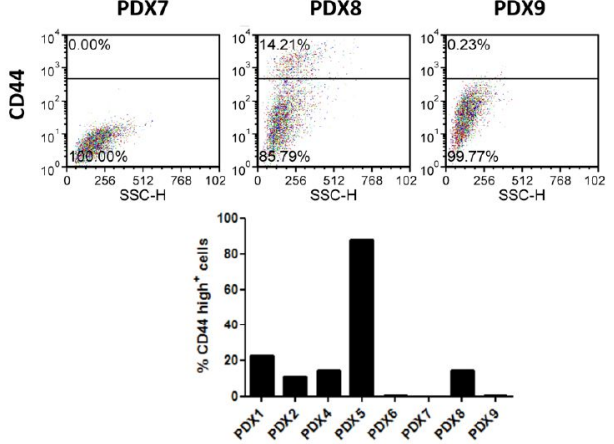

b
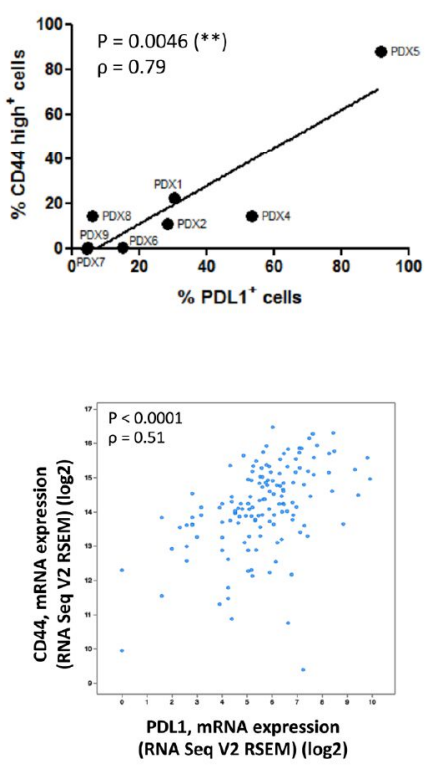

Figure 45. PDL1 expression correlates with CD44 in GBM patient-derived cells. (a) CD44 basal levels were determined in a battery of GBM patient-derived cells by flow cytometry. A graph representing the percentage is shown (lower panel). (b) Correlation between CD44 and PDL1 (fig. 41) protein expression levels determined by flow cytometry is shown. Spearman's rank correlation coefficient $(\rho)$ with two-tailed significance $(P)$ was calculated. (c) Correlation between CD44 and PDL1 mRNA levels is shown. Spearman's rank correlation coefficient $(\rho)$ with two-tailed significance $(P)$ was calculated. Data were obtained from the cBioPortal database (GBM TCGA 2013, n=147). 
Next, we decided to sort two different PDXs according to CD44 expression (fig. 46a), and check PDL1 and LIF transcript levels in CD44 high and low populations (fig. 46b). In agreement with our hypothesis, CD44 high population, a population enriched for CICs, showed higher levels of both LIF and PDL1 transcripts.

a

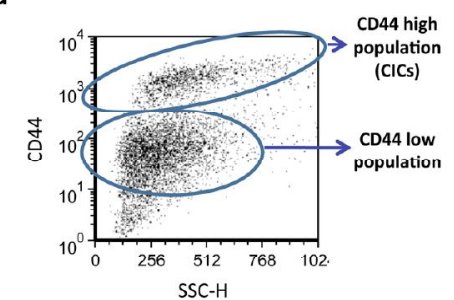

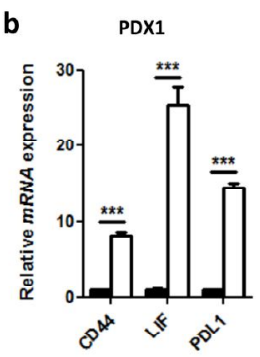

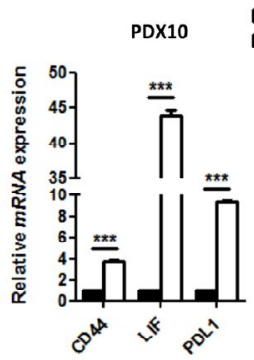

Figure 46. CD44 high population express high levels of LIF and PDL1 transcripts. (a) Scheme representing the experimental procedure is shown. (b) Patient-derived cells were sorted depending on the CD44 levels. CD44, LIF and PDL1 transcript levels were determined by qRT-PCR analysis. Data are presented as mean \pm SD.

Finally, we checked the correlation between the three proteins in TCGA database, in a cohort of 147 GBM patients (fig. 47a), and we corroborated the results obtained in vitro with cells from patients. Interestingly, patients with tumors expressing high levels of $L I F, P D L 1$ and $C D 44$ showed a shorter overall survival and time-to-progression (fig. 47b), and matched with patients diagnosed with the mesenchymal subtype (14 out of 15), the most aggressive subtype of GBM (fig. 47c). 


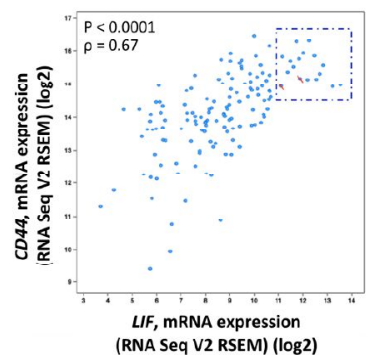

b

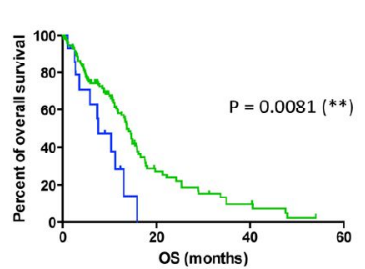

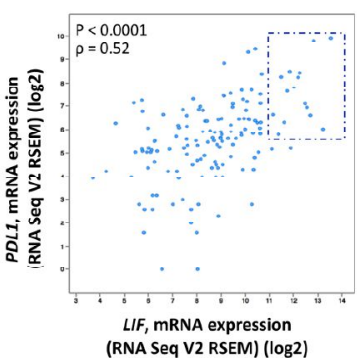

(RNA Seq V2 RSEM) (log2

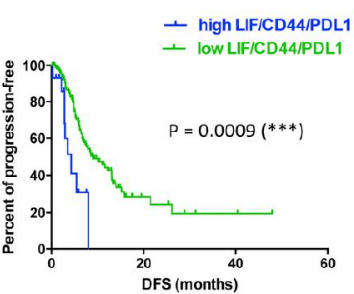

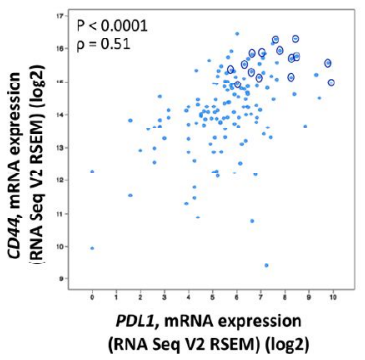

C

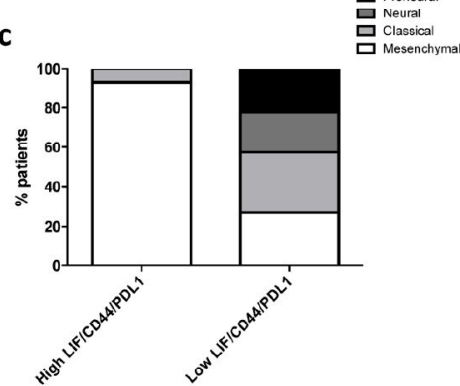

Figure 47. LIF correlates with CD44 and PDL1 in human GBM and confers poor prognosis. (a) Correlations between $L I F$ and $C D 44, L I F$ and $P D L 1$, and $P D L 1$ and $C D 44$ mRNA levels are shown. Spearman's rank correlation coefficient $(\rho)$ with two-tailed significance (P) was calculated. (b) Kaplan-Meier curves representing the overall survival (OS) and the diseasefree survival (DFS) of patients with LIF mRNA levels up-regulated >11 fold, CD44 mRNA levels up-regulated $>14,5$ fold and $P D L 1$ mRNA levels up-regulated $>5,5$ fold are shown. $P$ values (P) were calculated. (c) Percentage of GBM subtypes in patients with LIF,CD44 and LIF mRNA levels up-regulated as described in (b) are shown. Data were obtained from the cBioPortal database (GBM TCGA 2013, n=147). 


\section{DISCUSSION}




\section{LIF blockade prevents TAMCs and Tregs immunosuppression and promotes the infiltration of effector T and NK cells}

The wide inter-tumor heterogeneity in LIF expression, where some tumors express aberrantly high levels of LIF, together with the fact that high LIF expression in the tumor confers poor prognosis, suggests that LIF might be positively selected during oncogenesis providing a competitive advantage to the tumor. Indeed, we have observed that LIF acts as an oncogenic factor through the regulation of the tumor-related immune-response, and the blockade of LIF inhibits tumor growth and induces, in some cases, tumor regression.

The immunosuppression observed in tumors is mediated by the accumulation of different cell types. TAMCs include all those immune cells derived from myeloid precursors which maintain $\mathrm{CD} 11 \mathrm{~b}$ expression (tumor-associated macrophages and MDSCs mainly, but also a subset of immature DCs, called tolerogenic DCs, which have an immunosuppressive role in cancer) (Ma, Shurin et al. 2013, Burkholder, Huang et al. 2014, Okita, Tanaka et al. 2014). TAMCs are mainly M2-polarized cells, and exert anti-inflammatory and pro-tumorigenic activities (Roszer 2015). We have reported that LIF blockade inhibits the expression of M2-like factors in normal human monocytes and TAMCs using various models of different tumor types, as well as in human organotypic cultures from freshly isolated human GBM tumors. Importantly, since there were no differences in $\mathrm{CD}_{11} \mathrm{~b}^{+}$infiltrating cells, we speculate that LIF does not promote the recruitment of myeloid cells into the tumor area.

Among the M2-like factors regulated by LIF that we identified, we found different genes that produce Tregs chemoattractants, such as CCL1, CCL2, CCL3 and CCL22 (Curiel, Coukos et al. 2004, Fridlender, Buchlis et al. 2010, Hoelzinger, Smith et al. 2010, Schlecker, Stojanovic et al. 2012, Anz, Rapp et al. 2015). Among these chemotactic factors, CCL22 is one of the best characterized and effectively, Tregs constitutively express high levels of its cognate receptor CCR4 (Iellem, Mariani et al. 2001). In vivo experiments have shown that inhibition of CCL22 prevents the migration of human Tregs into the tumor area and it decreases tumor growth (Curiel, Coukos et al. 2004, Anz, Rapp et al. 2015). Some authors have reported that some tumor cells secrete CCL22 (Curiel, Coukos et al. 2004). However, a recent work by Anz and collaborators did not find detectable levels of secreted CCL22 when they analyzed a cohort of murine and human cell lines, including the colon cancer cell line CT26 used in the present work (Anz, Rapp et al. 2015). Although those experiments were done in vitro, which may differ significantly from the in vivo situation, when we checked the presence of CCL22 in our in vivo models, we found that the majority of CCL22 positive cells were also positive for CD11b, indicating that, at least in our models, TAMCs were the main source of CCL22. In agreement 
with these observations, we were not able to detect CCL22 in the conditioned media from the GBM cell line U251 when we performed the experiments with monocytes from healthy donors. Thus, we hypothesized that the down-regulation of CCL22 in TAMCs after LIF neutralization is the responsible for the decrease of the intra-tumor Tregs and, in turn, this reduction leads to an intra-tumor increase of effector T and NK cells. Besides the Tregs effect on anti-tumor immune cell population (Shevach 2009), it has been described that TAMCs can also directly regulate T and NK cells infiltration (Noy and Pollard 2014) (fig. 48). This increase in T and NK cells promoted an increase in tumor cell death, as observed in tumors treated with the anti-LIF antibody. In agreement with these results, when we depleted the macrophages in mice, we lost the effect on the tumor growth in response to LIF blockade, suggesting that the effect of anti-LIF on macrophages was the main responsible of the anti-tumor outcome. Surprisingly, we observed an increase in tumor growth when the animals were treated with clodronate alone. An important consideration in interpretation of data when depleting macrophages with clodronate-containing liposomes is that all professional phagocytes are depleted, including M2-like macrophages but also some types of immune cells such as mature DCs and M1-like macrophages (Sunderkotter, Nikolic et al. 2004, Tacke, Ginhoux et al. 2006, van Rooijen and Hendrikx 2010, Weisser, van Rooijen et al. 2012). Thus, a possible explanation for that increase in the tumor growth is that clodronate-containing liposomes eliminate, besides TAMCs, other phagocytes with an immune-suppressor role, impairing its function and enhancing the tumor progression.

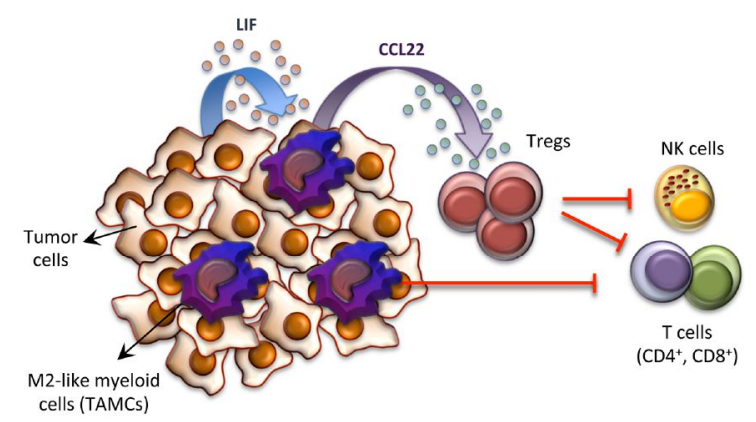

Figure 48. The LIF-TAMCs-CCL22-Treg axis. Tumor cells secrete LIF that promotes TAMC polarization into an M2-like phenotype inducing the expression of CCL22. In turn, CCL22 secreted by TAMCs recruits Tregs that inhibit effector T and NK cell tumor infiltration. TAMC can also directly inhibit effector T and NK cells.

Following this rationale about the regulation of CCL22 by LIF, we blocked CCL22 in mice in combination with the anti-LIF antibody. As we expected, since both treatments target redundantly CCL22, those mice treated with both antibodies showed a reduction in tumor growth in the same extend as the animals treated with each antibody alone. Thus, we 
demonstrated that LIF immunosuppressive effect was mainly executed through the regulation of CCL22 secretion by TAMCs.

Tregs inhibit the proliferation and activation of T lymphocytes by tumor antigens (Shevach 2004). As a consequence, a decrease in Tregs in the anti-LIF treated mice would lead to an increase of effector $\mathrm{T}$ cells in the tumor tissues. We saw an increase in $\mathrm{CD} 4^{+}$and $\mathrm{CD} 8^{+} \mathrm{T}$ cell infiltration in CT26 and ID8 models, but not in KLN205. As we mentioned above, KLN205 is defined as a poorly immunogenic model (Labeur, Roters et al. 1999). Furthermore, tumor nodules showed a spread distribution throughout the lung, so we digested the entire lung. We observed that the basal percentage of $\mathrm{T}$ cells was higher than in tumors from the other models, probably, because lung is an organ continuously exposed to exogenous agents, so little (but effective) changes in TME may be masked. Due to the fact that the activation of T cells happens into spleen, among other lymphoid organs (Banchereau and Steinman 1998), we assessed whether the differences in T cell populations were more evident in splenic cells. As expected, we observed a significant increase in $\mathrm{CD}^{+}$and $\mathrm{CD} 8^{+} \mathrm{T}$ cell populations in treated mice. In the case of Tregs, we obtained significant differences in the lung and not in the spleen because this cell population is significantly increased in tumor conditions (Ganesan, Johansson et al. 2013).

To corroborate the final role of adaptive immunity after LIF blockade, we depleted $\mathrm{CD}^{+}$and $\mathrm{CD}^{+} \mathrm{T}$ cells in the mice. The animals depleted of effector $\mathrm{T}$ cells showed a significant increase in tumor growth when compared to control mice, and those animals treated with the combined therapy did not present any effect in response to LIF blockade. Thus, as we expected, although anti-LIF decreased TAMCs CCL22 secretion, and consequently, the infiltration of Tregs, without the effector $\mathrm{T}$ cells we did not observe a reduction in tumor growth.

As mentioned before, TAMCs are immune cells with high phenotypic heterogeneity. A large number of M2-like markers have been identified, including transmembrane glycoproteins, scavenger receptors, enzymes, growth factors, hormones, cytokines, and cytokines receptors (Mantovani, Sozzani et al. 2002, Roszer 2015). Due to TAMCs heterogeneity, we decided to check in parallel different markers. Besides CCL22, MRC1/CD206 (a transmembrane glycoprotein) and CD163 (a scavenger receptor) were also regulated by LIF. In agreement with the fundamental role of LIF in maintaining the M2-like phenotype of TAMCs, a correlation between the expression of the M2-like markers in TAMCs and LIF was observed in GBM patients. As we predicted, GBM patients with tumors exhibiting high M2-like markers and high levels of LIF exhibit worse prognosis, being diagnosed most of them with the mesenchymal 
subtype, the most aggressive subtype of GBM (Doucette, Rao et al. 2013).

Back to the analysis of the TAMC microarrays and qRT-PCR validation in other models, we also highlighted other interesting genes: CCL7, CTSK and PF4 genes. CCL7, also known as monocyte chemotactic protein 3 (MCP3), is a secreted chemokine that, as its name suggests, attracts monocytes to tumor tissue. It is secreted by the M2-phenotype cells, promotes invasion and migration, and its overexpression is associated with poor prognosis (Martinez, Helming et al. 2009, Cho, Lee et al. 2012, Hwang, Lee et al. 2012). CTSK is a lysosomal protease that plays a key role in protein turnover and degradation of the extracellular matrix (Christensen and Shastri 2015). High CTSK expression has been found in osteoclasts and synovial fibroblasts, where it is responsible for the degradation of bone and articular cartilage respectively, and in macrophages associated with bone metastatic lesions in breast and prostate cancer. Herroon and collaborators demonstrated a critical involvement of CTSK in osteoclast, macrophage and tumor cell interactions, which collectively contribute to colonization and growth of metastasis in the bone (Herroon, Rajagurubandara et al. 2013). Finally, although PF4 has been described as a platelet-specific molecule, it has been showed that it may be expressed in activated T cells (Shi, Field et al. 2014), and we have showed that also TAMCs are able to express it. PF4 has been better characterized in the platelets context, the main transporters of several angiogenesis regulators, among which PF4 is included (Peterson, Zurakowski et al. 2012, Han, Cao et al. 2014). Besides its angiogenic role, PF4 has been linked to the regulation of T cell development, to the transplantation tolerance, and to monocyte survival and differentiation (Scheuerer, Ernst et al. 2000, Gleissner, Shaked et al. 2010, Shi, Field et al. 2014).

Thus, in addition to the LIF role in the maintenance of TAMCs M2-like phenotype, LIF also plays a role in the ability of those myeloid cells to degrade the extracellular matrix enhancing metastasis, and its role in angiogenic processes.

To sum up, our results could be an example of crosstalk between the innate and the adaptive immune response, since LIF regulates the M2-like phenotype of TAMCs that, in turn, through CCL22, control Treg tumor infiltration and the effector T and NK cells anti-tumor response (fig. 48).

\section{LIF blockade inhibits PDL1 expression}

Trying to shed light on the mechanism by which LIF is able to inhibit cells from adaptive immunity, we explored one of the most studied mechanisms used by the tumor to evade the immune system, PD-1/PDL1 pathway. Through this mechanism, the tumor impairs the TCRmediated activation of lymphocytes by the binding of PDL1 expressed in tumor cells and 
TAMCs with its receptor, PD-1, on lymphocytes. Importantly, it has been described a p-STAT3 binding site in PDL1 promoter, the main readout of LIF pathway (Marzec, Zhang et al. 2008, Wolfle, Strebovsky et al. 2011, Fujita, Yagishita et al. 2015, Wang, Yen et al. 2015, Chen, Jiang et al. 2016). It has been reported high levels of PDL1 on CT26 and ID8 tumor cells in vivo but not in vitro without stimulation (ID8), as well as on macrophages, DCs, and MDSCs derived from those tumors (Abiko, Mandai et al. 2013, Duraiswamy, Freeman et al. 2013, Duraiswamy, Kaluza et al. 2013). In fact, Abiko and collaborators described 3 types of cells with regards to PDL1 expression: type A cells always express PDL1 (CT26 and KLN205 in our work); type B cells do not express PDL1 at baseline but express PDL1 when are stimulated (ID8); and type C cells never express PDL1 (Abiko, Mandai et al. 2013).

Our in vitro data showed a partial decrease, about 30-35\%, of PDL1 after LIF blockade in tumor cells. These results suggested that LIF regulates partially PDL1 expression, probably in collaboration with other factors from the TME. In vivo data showed a decrease in PDL1 expression on tumor cells and also on isolated TAMCs from KLN205 and CT26 syngeneic models after anti-LIF treatment, but not on TAMCs isolated from ID8 ascites at mRNA level. We propose different possible explanations for this: a) the regulation of PDL1 by LIF on TAMCS from C57BL6 (ID8 mouse strain) is only at post-translational level; b) PDL1 on TAMCs in that model is not regulated by LIF; c) TAMCs require to be embedded in the tumor mass in order to have PDL1 regulation, with a direct cell-to-cell contact with tumor cells.

Interestingly, our results in PDL1 mRNA expression from shLIF infected tumor cells indicate that in KLN205 murine cell line the regulation of PDL1 by LIF, at least in vitro, is posttranslational, and in human cells (U251 and GBM PDXs) the regulation is at transcriptional level, suggesting a PDL1 regulation by LIF at different levels depending on the cell type.

Thus, we have seen that the effect of LIF blockade in tumor progression could be mediated, at least partially, by PDL1 regulation. It has been described that in PDL1 promoter, besides STAT3 binding site, there is an AP-1-responsive enhancer (Green, Monti et al. 2010). AP-1 DNA binding complex is a dimer consisting in members of Fos and Jun families, such as cJun and FosL2, and it has been described that other proteins, such as CREB/ATF, can interact with AP-1 components (Kaminska, Pyrzynska et al. 2000). We checked those factors after LIF treatment, and interestingly cJun, FosL2 and CREB/ATF were increased. These results suggest another molecular mechanism by which LIF could induce PDL1 transcription besides p-STAT3.

Clinical trials with anti-PD-1/PDL1 treatments show encouraging results in different types of cancer, demonstrating the importance of target this pathway to unmask the tumor in front of 
patient's immune system. However, only a fraction of the total number of treated patients remains free from disease progression for many years (Kim and Eder 2014, Wolchok and Chan 2014). In pre-clinical assays performed by Duraiswamy and colleagues, it was found that treatment with anti-PD-1 or anti-PDL1 antibodies showed CT26 tumor regression in $25 \%$ and $33 \%$ of the mice respectively, and ID8-VEGF tumor regression in $25 \%$ and $37,5 \%$ of the mice respectively (Duraiswamy, Kaluza et al. 2013). They also demonstrated that PD-1/PDL1 pathway blockade restored the immune system suppression and led to expansion of effector $T$ cells, which is associated with the clinical response (Duraiswamy, Freeman et al. 2013). As we commented above, our results suggested that LIF is not the only responsible for PDL1 expression, thus with anti-LIF antibody we did not deplete completely PDL1 expression. Moreover, LIF is regulating other pathways, besides PD-1/PDL1, that lead to TAMCs, Tregs, effector T and NK cells modulation. Thus, we hypothesized that there could be a synergism with the concomitant treatment with antibodies against LIF and PD-1/PDL1 pathway. Importantly, in response to LIF blockade, the self-renewal of CICs will also be affected (Penuelas, Anido et al. 2009), defining anti-LIF neutralizing antibody as a dual therapy: genomically targeted therapy and immune checkpoint therapy.

GBM are classified as classical, proneural, neural and mesenchymal subtypes according to its genetic and chromosomic alterations, being the mesenchymal subtype the most aggressive (Verhaak, Hoadley et al. 2010). Among other aspects, it is the most immunosuppressive version of GBM, and shows an enrichment of CD44 and PDL1 in addition to other immunosuppressive genes (Doucette, Rao et al. 2013). Previous work in our lab showed a positive correlation between the CD44 positivity and the CIC population (Anido, Saez-Borderias et al. 2010). It has been described the contribution of CICs to tumor evasion of the immunosurvillance. Wei and colleagues demonstrated that CICs inhibit T cell proliferation and induce its apoptosis, and promote Treg expansion, at least, partially through PDL1 (Wei, Barr et al. 2010). In this study, we reported a positive correlation between CD44, LIF and PDL1 expression in tumor cells derived from GBM patients, showing a higher expression of LIF and PDL1 in the CD44 high population. We validated our results with data from a large cohort of GBM patients from TCGA 2013. Furthermore, those patients with high expression of CD44/LIF/PDL1 belonged to mesenchymal subset and showed a poorer survival.

Thus, CICs mediate immunosuppression by several redundant mechanisms such as PDL1, as previously described (Wei, Barr et al. 2010). Summarizing, we contribute with new data showing a positive correlation between LIF, CD44 and PDL1 expression, presenting them as biomarkers of poor prognosis. A possible link between them is that LIF increases the CIC 
population and promotes PDL1 expression on them, making the tumors less immunogenics. Thus, we think that LIF blockade targets the tumors by two different ways: a) impairing CICs self-renewal, and b) exposing the tumor to the host immune system.

\section{Final remarks}

Our work shows that LIF protects the tumor from the host immune system through the reeducation of TAMCs. Interestingly, the immunosuppressive response to LIF is not specific from tumors. It has been reported that constitutive LIF expression is rarely observed except in the uterus and airway epithelia. In both of these tissues, the immune system is tightly regulated to avoid excessive responses to continuous exposition to exogenous agents in lung, or to maintain the maternal tolerance in the case of embryos. Moreover, decidual and alveolar monocytes are immunosuppressive. During blastocyst implantation, LIF has been shown to inhibit the immune response through the regulation of macrophages, NK and T cells, in organ transplantation and autoimmune diseases (Metcalfe, Watson et al. 2005, Schofield and Kimber 2005, Duluc, Delneste et al. 2007, Trouillas, Saucourt et al. 2009, Janssens, Van den Haute et al. 2015). As in many other cases, cancer highjacks a normal developmental program for its own benefit. LIF has emerged during the evolution to protect the embryo from the immune system of the mother during implantation. In a similar way, tumors abduce this function by secreting aberrantly high levels of LIF in order to be able to thrive independently of the immune reaction from the host.

Moreover, LIF has a crucial role during embryogenesis by inducing ESC self-renewal. Analogous to the ESCs, LIF promotes the self-renewal of CICs (Penuelas, Anido et al. 2009). As in the case of the embryo, LIF acts in cancer through a dual mechanism of action, by protecting the tumor from the immune system and by inducing $\mathrm{CIC}$ self-renewal.

Our results have been obtained using models of different tumor types (GBM, NSCLC, ovarian cancer and CRC) selected by their expression of LIF and showing that the role of LIF might be transversal across cancer. Moreover, we developed our research as close as possible to the real tumor using PDX and organotypic models. Of note, the organotypic model has allowed us to discern the molecular response to LIF in the context of the tumor and immune system of the patient.

Through this work, we have discerned a role of LIF in the cancer immune response and, remarkably, we have uncovered an immunomodulatory therapeutic target. We have open a potential therapeutic possibility based on the development of anti-cancer agents based on the inhibition of LIF. 


\section{CONCLUSIONS}


Aberrant LIF expression tends to be present in the most aggressive tumors.

LIF blockade leads to a decrease in tumor growth by inducing tumor cell apoptosis in murine syngeneic models of ovarian cancer, NSCLC and CRC, and in human GBM models using a cell line and cells derived from patients, demonstrating that its role is transversal across different tumor types.

LIF protects the tumor from the immune system of the host through the re-education of tumor-associated myeloid cells (TAMCs).

LIF blockade down-regulates CCL22 and related chemokines secretion by TAMCs preventing regulatory $T$ cell (Treg) infiltration, and leading to the increase of effector $T$ and NK cells within the tumor mass.

$>$ LIF expression correlates with the infiltration of M2-like TAMCs in tumors. GBM patients whose tumors express high levels of LIF, MRC1 and CD163 belong to mesenchymal subtype and exhibit a worse prognosis.

$>$ LIF blockade reduces PDL1 expression in cancer cells and in TAMCs, facilitating the effector T cells activation.

Cancer-initiating cells (CICs) show a positive correlation of CD44, LIF and PDL1 expression in GBM patients. Those patients with high expression of the three proteins belong to the mesenchymal subtype and exhibit a worse prognosis. 
RESUMEN 


\section{Introducción y Objetivos}

LIF es una citoquina que regula los procesos celulares para mantener la auto-renovación y la pluripotencia de las células madre embrionarias. En nuestro laboratorio, hemos identificado LIF como inductor de la capacidad de auto-renovación de las CICs (Cancer Initiating Cells) y como promotor de la oncogénesis in vivo (Penuelas, Anido et al. 2009). Sin embargo, su función celular en cáncer sigue siendo poco clara.

En los últimos tiempos, se está invirtiendo mucho esfuerzo en estudiar el microambiente tumoral, y se ha descubierto que tiene un papel clave en el desarrollo del cáncer. Los tumores se componen de células malignas rodeadas por una gran variedad de poblaciones celulares como células inmunes, fibroblastos y células de vasos sanguíneos y linfáticos. Se cree que la falta de una respuesta inmune eficiente se debe a que este microambiente tumoral está dominado por células inmunosupresoras que favorecen que el tumor escape de la vigilancia inmunológica. Para erradicar tumores mediante inmunoterapia es indispensable superar esta respuesta inmunosupresora. La identificación de las moléculas que determinan el microambiente inmunosupresor del tumor es crucial para descubrir nuevas dianas para la aplicación clínica de nuevas estrategias terapéuticas.

La inflamación tumoral es debida a un conjunto de citoquinas producidas por las células inmunes, las células del estroma y las células tumorales. Estos factores pueden actuar de manera autocrina o paracrina para asegurar el reclutamiento de células inmunes hacia el tumor. Los macrófagos asociados al tumor (con un fenotipo M2), las células mieloides supresoras (MDSCs) y las células T reguladoras (Tregs) son los tipos celulares responsables de la supresión de las respuestas inmunitarias innata y adaptativa, y son considerados marcadores de mal pronóstico (Grivennikov, Greten et al. 2010). Por otro lado, la respuesta inmune anti-tumoral está compuesta básicamente por células T CD8 ${ }^{+}$, natural killers (NKs) y células dendríticas maduras, asociadas a un pronóstico favorable (Joyce and Pollard 2009). La interacción entre estas células, su jerarquía, y si pueden ser consideradas dianas terapéuticas son grandes incógnitas que se están intentando desvelar.

Varios estudios muestran que LIF juega un papel clave como inmunosupresor en distintos procesos, como en la implantación del embrión en el útero materno, la tolerancia en trasplantes, y en enfermedades autoinmunes como la esclerosis múltiple (Metcalfe, Watson et al. 2005, Salleh and Giribabu 2014, Janssens, Van den Haute et al. 2015). Sin embargo, aunque ya se han relacionado altos niveles de LIF con una mayor agresividad del tumor, se sabe muy 
poco acerca del papel que puede cumplir esta citoquina durante la inmunosupresión que tiene lugar en el desarrollo tumoral.

Así, el objetivo de este trabajo es caracterizar el papel de LIF en la regulación de la inmunosupresión en el microambiente tumoral, y averiguar si podría convertirse en una nueva diana terapéutica para el tratamiento del cáncer.

\section{Resultados y Discusión}

Con el fin de evaluar la expresión de LIF en tumores, realizamos inmunohistoquímicas (IHC) en tejidos de diversos tipos tumorales. Observamos una gran heterogeneidad en la expresión de LIF. Aquellos tumores que mostraban una expresión aberrantemente alta tendían a ser más agresivos, traduciéndose en un promedio de vida más corto. Estos resultados nos sugirieron que LIF podría estar confiriendo una ventaja selectiva al tumor y actuar como factor oncogénico.

Para estudiar el efecto oncogénico de LIF en el sistema inmune, decidimos usar modelos murinos inmunocompetentes singénicos, que escogimos en base a una alta expresión de LIF en los tumores in vivo. Seguimos dos aproximaciones distintas: por un lado tratamos a los ratones con un anticuerpo contra LIF, y por el otro inoculamos células previamente infectadas con virus expresando shRNA contra LIF. En ambos casos, vimos que en modelos de cáncer de pulmón de células no pequeñas (NSCLC), de carcinoma de ovario, y de cáncer de colon (CRC), el bloqueo de LIF conducía a una disminución del crecimiento tumoral. En los 3 modelos observamos una disminución de la presencia de cleaved caspase 3 (CC3), un marcador de apoptosis, que nos indicó que con el bloqueo de LIF se estaba induciendo la muerte de las células tumorales.

Basándonos en un trabajo previo en el que se mostraba el efecto de LIF in vitro en la polarización de los macrófagos asociados al tumor en cáncer de ovario (Duluc, Delneste et al. 2007), estudiamos el efecto de LIF en nuestros modelos singénicos. Aislamos las células mieloides $\mathrm{CD}_{11} \mathrm{~b}^{+}$asociadas al tumor (TAMCS), y realizamos un análisis transcriptómico. Diversos genes relacionados con un fenotipo M2 tenían una expresión disminuida en las células $\mathrm{CD} 11 \mathrm{~b}^{+}$que provenían de ratones tratados con el anticuerpo contra LIF, como por ejemplo MRC1 y CD163 (marcadores de superficie de TAMCs), y CCL22 (factor relacionado con el reclutamiento de Tregs), entre otros. Verificamos estos resultados mediante inmunofluorescencia e inmunohistoquímica en los tejidos tumorales. Además, también confirmamos la infiltración de Tregs mediante citometría, viéndose una disminución en los animales tratados. Los datos sugerían que LIF podría estar actuando básicamente a través de 
los macrófagos, incrementando la secreción de CCL22 y aumentando así el reclutamiento de Tregs al tumor. Tanto la presencia de TAMCs, como la presencia de Tregs se han asociado a un peor pronóstico (Grivennikov, Greten et al. 2010, Quail and Joyce 2013). Para confirmar nuestra hipótesis, usamos el modelo de NSCLC y deplecionamos los macrófagos mediante el tratamiento con liposomas de clodronato (Weisser, van Rooijen et al. 2012). Como esperábamos, el efecto en la disminución del crecimiento tumoral del anticuerpo contra LIF se vio disminuida en aquellos animales sin macrófagos. Llegados a este punto, con el fin de confirmar la importancia de CCL22 en el escenario que describimos, combinamos el tratamiento con un anticuerpo anti-CCL22 (Jakubzick, Wen et al. 2004, Dogan, Long et al. 2011) con el anticuerpo anti-LIF, y observamos una reducción del tamaño tumoral similar en el grupo de la combinación con respecto a los dos grupos tratados con cada uno de los anticuerpos por separado.

Se ha descrito que las Tregs inhiben la proliferación y activación de las células T (Shevach 2004). Así que nuestro siguiente paso fue estudiar el sistema inmunológico adaptativo, evaluando el efecto del anticuerpo anti-LIF en la infiltración de las células T y de las células NKs. Efectivamente, cuando analizamos la infiltración de estas poblaciones celulares antitumorales mediante citometría e IHC, vimos que estaban significativamente aumentadas en los ratones tratados. Para corroborar el papel final de la inmunidad adaptativa después del bloqueo de LIF, deplecionamos los ratones de células T con anticuerpos anti-CD4 y anti-CD8 (Jing, Gershan et al. 2009, Andreasson, Eriksson et al. 2010), y combinamos ese tratamiento con el anti-LIF. Aquellos animales deplecionados de células T mostraron unos tumores más grandes incluso que los controles y no mostraron respuesta al anti-LIF. Según nuestra hipótesis, la falta de respuesta a LIF fue debida a que, a pesar de que el anti-LIF bloqueara la secreción de CCL22 por los TAMCs, no había células T efectoras que pudieran prevenir el crecimiento tumoral.

En base a los resultados obtenidos hasta el momento, nos propusimos estudiar si este fenómeno también se daba en glioblastoma (GBM). Debido a que no encontramos un modelo singénico adecuado de GBM, y dado que los ratones inmunodeprimidos Balb/c nude mantenían el linaje mieloide, estudiamos el efecto del bloqueo de LIF usando la línea celular humana U251. Sin embargo, debido a que las líneas celulares se han cultivado durante años en condiciones artificiales y pueden no ser representativas del comportamiento de los tumores en pacientes, también estudiamos el efecto del anticuerpo en modelos xenograft derivados de biopsias de pacientes (patient-drived xenografts, PDXs). Previamente, nos cercioramos que todas las células (U251 y PDXs) expresaran altos niveles de LIF una vez inoculadas 
ortotópicamente en los ratones. En todos los casos, vimos una disminución del crecimiento tumoral que iba acompañada de una disminución en la expresión de marcadores de TAMCsM2 (CCL22 y MRC1).

Cada uno de los modelos usados hasta este momento tiene sus ventajas e inconvenientes. Por ejemplo, los modelos singénicos de ratón permiten el estudio de la neutralización de LIF en un contexto de un animal completamente inmunocompetente. Sin embargo, los tumores generados por líneas celulares de ratón pueden diferir de las células tumorales humanas. Los modelos PDXs recapitulan las características del tumor del paciente (Anido, Saez-Borderias et al. 2010), pero se tienen que generar en ratones inmunodeficientes. Así que para intentar superar estas limitaciones, decidimos estudiar el fenómeno de la modulación del fenotipo de los TAMCs en cultivos de tejido organotípicos recién obtenidos de pacientes con GBM (Merz, Gaunitz et al. 2013). Estos modelos permiten un cultivo a corto plazo de secciones de tumor que mantienen la arquitectura del tejido y del estroma (células inmunes y células endoteliales) del tumor del paciente. Obtuvimos cultivos organtípicos de tres pacientes distintos que incubamos con el anticuerpo anti-LIF durante 3 días, y posteriormente verificamos la expresión de los marcadores de TAMCs usados anteriormente, MRC1, CD163 y CCL22. La expresión de estos marcadores en todos los pacientes, disminuyó demostrando una vez más que LIF es crucial para el mantenimiento de un fenotipo tipo M2. Finalmente, comprobamos en una cohorte de 147 pacientes de GBM que había una correlación positiva en la expresión de estos tres factores, y que aquellos pacientes con una alta expresión mostraban tumores más agresivos y una esperanza de vida más corta. Estos resultados indicaron que LIF podría ser una buena diana terapéutica.

Realizamos una aproximación más estudiando el efecto de LIF en monocitos aislados de sangre de donantes sanos. Mediante un análisis transcriptómico de monocitos incubados con medios condicionados de células U251 infectadas con shLIF RNA, vimos una disminución en la expresión de varios genes relacionados con un fenotipo $\mathrm{M} 2$, coincidiendo algunos de ellos con los resultados obtenidos en los modelos singénicos. Además, también verificamos el efecto de la inhibición de LIF en la capacidad de fagocitosis de los macrófagos, viendo un claro aumento en respuesta al tratamiento tal como esperábamos.

Como he comentado anteriormente, LIF tiene un efecto sobre la inmunidad adaptativa, siendo responsable, al menos en parte, de la inactivación de los linfocitos T citotóxicos. Uno de los mecanismos para la inhibición de los linfocitos T es mediante la vía de PD-1/PDL1. PDL1 se une a su receptor PD-1 que se encuentra en los linfocitos $\mathrm{T}$, el cual previene una activación exacerbada del sistema inmune. Este mecanismo es aprovechado por el tumor. Así, la unión 
del PDL1 presente en las células tumorales y en las TAMCs activa la vía de PD-1 y evita que los linfocitos T detecten el tumor. Se ha visto que la expresión de PDL1 se correlaciona con un pronóstico desfavorable (Keir, Butte et al. 2008, Duraiswamy, Freeman et al. 2013, Burkholder, Huang et al. 2014). Con el propósito de evaluar el posible efecto de LIF en la regulación de PDL1, estudiamos su expresión en nuestros modelos después del tratamiento con el anticuerpo anti-LIF. Vimos una disminución de su expresión en todos nuestros modelos singénicos, tanto en las células tumorales (por IHC) como en las células CD11 $\mathrm{b}^{+}$aisladas del tumor de los modelos singéncos de NSCLC y CRC (por qRT-PCR).

Finalmente, nos preguntamos si las CICs definidas anteriormente en el laboratorio como células que expresan altos niveles de CD44 y responsables de la iniciación tumoral, de la recurrencia y de la resistencia a la terapia (Anido, Saez-Borderias et al. 2010), podrían tener un papel importante en la inmunosupresión. Así, verificamos la expresión de PDL1 y LIF en células CD44 positivas y observamos una correlación entre las tres proteínas. Además, consultamos la expresión de los tres genes en una cohorte de 147 pacientes de GBM, lo que corroboró nuestros resultados, y nos mostró que aquellos pacientes con altos niveles de expresión pertenecían al subtipo mesenquimal dentro de los GBM, los cuales presentaban un peor pronóstico.

Así pues, este trabajo define LIF como inductor de una respuesta inmunosupresora pleiotrópica en procesos tumorales, y lo identifica como diana terapéutica. Con el bloqueo de LIF permitiremos al sistema inmunológico del huésped detectar el tumor y atacarlo, y por otro lado, prevendremos la auto-renovación y proliferación de las CICs, responsables de la iniciación tumoral, de la recurrencia y de la resistencia a la terapia.

\section{Conclusiones}

El bloqueo de LIF reduce el crecimiento tumoral en modelos murinos singénicos de cáncer de ovario, pulmón y colon, y en modelos de GBM humano generados a partir de una línea celular y de células que provienen de pacientes. Así, demostramos que el efecto de LIF es transversal en distintos tipos de cáncer.

El bloqueo de LIF promueve la polarización de las células mieloides asociadas al tumor (TAMCs) disminuyendo la expresión de marcadores de M2, MRC1, CD163 y CCL22 entre otros.

El bloqueo de LIF disminuye la secreción de CCL22 de las TAMCs, reduciendo la infiltración de células $T$ reguladoras (Tregs) e incrementando la presencia de células del sistema inmunológico adaptativo, las células Ty las natural killer (NKs). 
La expresión de LIF correlaciona con una mayor expresión de los marcadores de M2, CD163 y MRC1, en pacientes con GBM, los cuales muestran un bajo índice de supervivencia.

- El bloqueo de LIF reduce la expresión de PDL1 tanto en células tumorales como en las TAMCs, permitiendo así la activación de las células T efectoras.

Las cancer initiating cells (CICs) muestran una correlación positiva de CD44, LIF y PDL1. Aquellos pacientes que muestran altos niveles de expresión pertenecen al subtipo de GBM más agresivo denominado mesenquimal, y muestran un bajo índice de supervivencia. 


\section{REFERENCES}


Abiko, K., M. Mandai, J. Hamanishi, Y. Yoshioka, N. Matsumura, T. Baba, K. Yamaguchi, R. Murakami, A. Yamamoto, B. Kharma, K. Kosaka and I. Konishi (2013). "PD-L1 on tumor cells is induced in ascites and promotes peritoneal dissemination of ovarian cancer through CTL dysfunction." Clin Cancer Res 19(6): 1363-1374.

Albrengues, J., I. Bourget, C. Pons, V. Butet, P. Hofman, S. Tartare-Deckert, C. C. Feral, G. Meneguzzi and C. Gaggioli (2014). "LIF mediates proinvasive activation of stromal fibroblasts in cancer." Cell Rep 7(5): 1664-1678.

Andreasson, K., M. Eriksson, K. Tegerstedt, T. Ramqvist and T. Dalianis (2010). "CD4+ and CD8+ T cells can act separately in tumour rejection after immunization with murine pneumotropic virus chimeric Her2/neu virus-like particles." PLoS One 5(7): e11580.

Anido, J., A. Saez-Borderias, A. Gonzalez-Junca, L. Rodon, G. Folch, M. A. Carmona, R. M. Prieto-Sanchez, I. Barba, E. Martinez-Saez, L. Prudkin, I. Cuartas, C. Raventos, F. Martinez-Ricarte, M. A. Poca, D. Garcia-Dorado, M. M. Lahn, J. M. Yingling, J. Rodon, J. Sahuquillo, J. Baselga and J. Seoane (2010). "TGF-beta Receptor Inhibitors Target the CD44(high)/Id1(high) Glioma-Initiating Cell Population in Human Glioblastoma." Cancer Cell 18(6): 655-668. Anz, D., M. Rapp, S. Eiber, V. H. Koelzer, R. Thaler, S. Haubner, M. Knott, S. Nagel, M. Golic, G. M. Wiedemann, F. Bauernfeind, C. Wurzenberger, V. Hornung, C. Scholz, D. Mayr, S. Rothenfusser, S. Endres and C. Bourquin (2015). "Suppression of Intratumoral CCL22 by Type I Interferon Inhibits Migration of Regulatory T Cells and Blocks Cancer Progression." Cancer Res 75(21): 4483-4493.

Balkwill, F. and A. Mantovani (2001). "Inflammation and cancer: back to Virchow?" Lancet 357(9255): 539-545. Banchereau, J. and R. M. Steinman (1998). "Dendritic cells and the control of immunity." Nature 392(6673): 245252.

Bauer, S., B. J. Kerr and P. H. Patterson (2007). "The neuropoietic cytokine family in development, plasticity, disease and injury." Nat Rev Neurosci 8(3): 221-232.

Beyer, M. and J. L. Schultze (2006). "Regulatory T cells in cancer." Blood 108(3): 804-811.

Bingle, L., N. J. Brown and C. E. Lewis (2002). "The role of tumour-associated macrophages in tumour progression: implications for new anticancer therapies." J Pathol 196(3): 254-265.

Biswas, S. K. and A. Mantovani (2010). "Macrophage plasticity and interaction with lymphocyte subsets: cancer as a paradigm." Nat Immunol 11(10): 889-896.

Blank, C., I. Brown, R. Marks, H. Nishimura, T. Honjo and T. F. Gajewski (2003). "Absence of programmed death receptor 1 alters thymic development and enhances generation of CD4/CD8 double-negative TCR-transgenic $T$ cells." J Immunol 171(9): 4574-4581.

Bruce, J. N., B. Kennedy, F. Talavera, J. E. Harris and R. C. Shepard (2015). "Glioblastoma Multiforme." Medscape, News \& Perspective http://emedicine.medscape.com/article/283252-overview.

Burkholder, B., R. Y. Huang, R. Burgess, S. Luo, V. S. Jones, W. Zhang, Z. Q. Lv, C. Y. Gao, B. L. Wang, Y. M. Zhang and R. P. Huang (2014). "Tumor-induced perturbations of cytokines and immune cell networks." Biochim Biophys Acta 1845(2): 182-201.

Butte, M. J., M. E. Keir, T. B. Phamduy, A. H. Sharpe and G. J. Freeman (2007). "Programmed death-1 ligand 1 interacts specifically with the B7-1 costimulatory molecule to inhibit T cell responses." Immunity 27(1): 111-122. Butzkueven, H., J. G. Zhang, M. Soilu-Hanninen, H. Hochrein, F. Chionh, K. A. Shipham, B. Emery, A. M. Turnley, S. Petratos, M. Ernst, P. F. Bartlett and T. J. Kilpatrick (2002). "LIF receptor signaling limits immune-mediated demyelination by enhancing oligodendrocyte survival." Nat Med 8(6): 613-619.

Carro, M. S., W. K. Lim, M. J. Alvarez, R. J. Bollo, X. Zhao, E. Y. Snyder, E. P. Sulman, S. L. Anne, F. Doetsch, H. Colman, A. Lasorella, K. Aldape, A. Califano and A. lavarone (2010). "The transcriptional network for mesenchymal transformation of brain tumours." Nature 463(7279): 318-325.

Chaput, N., S. Louafi, A. Bardier, F. Charlotte, J. C. Vaillant, F. Menegaux, M. Rosenzwajg, F. Lemoine, D. Klatzmann and J. Taieb (2009). "Identification of CD8+CD25+Foxp3+ suppressive T cells in colorectal cancer tissue." Gut 58(4): 520-529.

Chen, J., C. C. Jiang, L. Jin and X. D. Zhang (2016). "Regulation of PD-L1: a novel role of pro-survival signalling in cancer." Ann Oncol 27(3): 409-416.

Cho, Y. B., W. Y. Lee, S. J. Choi, J. Kim, H. K. Hong, S. H. Kim, Y. L. Choi, H. C. Kim, S. H. Yun, H. K. Chun and K. U. Lee (2012). "CC chemokine ligand 7 expression in liver metastasis of colorectal cancer." Oncol Rep 28(2): 689-694. Choi, S., H. R. Kim, L. Leng, I. Kang, W. L. Jorgensen, C. S. Cho, R. Bucala and W. U. Kim (2012). "Role of macrophage migration inhibitory factor in the regulatory T cell response of tumor-bearing mice." J Immunol 189(8): 3905-3913. Christensen, J. and V. P. Shastri (2015). "Matrix-metalloproteinase-9 is cleaved and activated by cathepsin K." BMC Res Notes 8: 322.

Churlaud, G., F. Pitoiset, F. Jebbawi, R. Lorenzon, B. Bellier, M. Rosenzwajg and D. Klatzmann (2015). "Human and Mouse CD8(+)CD25(+)FOXP3(+) Regulatory T Cells at Steady State and during Interleukin-2 Therapy." Front Immunol 6: 171.

Crane, C. A., B. J. Ahn, S. J. Han and A. T. Parsa (2012). "Soluble factors secreted by glioblastoma cell lines facilitate recruitment, survival, and expansion of regulatory T cells: implications for immunotherapy." Neuro Oncol 14(5): 584-595.

Curiel, T. J., G. Coukos, L. Zou, X. Alvarez, P. Cheng, P. Mottram, M. Evdemon-Hogan, J. R. Conejo-Garcia, L. Zhang, M. Burow, Y. Zhu, S. Wei, I. Kryczek, B. Daniel, A. Gordon, L. Myers, A. Lackner, M. L. Disis, K. L. Knutson, L. Chen and W. Zou (2004). "Specific recruitment of regulatory T cells in ovarian carcinoma fosters immune privilege and predicts reduced survival." Nat Med 10(9): 942-949. 
Dogan, R. N., N. Long, E. Forde, K. Dennis, A. P. Kohm, S. D. Miller and W. J. Karpus (2011). "CCL22 regulates experimental autoimmune encephalomyelitis by controlling inflammatory macrophage accumulation and effector function." J Leukoc Biol 89(1): 93-104.

Domagala-Kulawik, J. (2015). "The role of the immune system in non-small cell lung carcinoma and potential for therapeutic intervention." Transl Lung Cancer Res 4(2): 177-190.

Dong, H., S. E. Strome, D. R. Salomao, H. Tamura, F. Hirano, D. B. Flies, P. C. Roche, J. Lu, G. Zhu, K. Tamada, V. A. Lennon, E. Celis and L. Chen (2002). "Tumor-associated B7-H1 promotes T-cell apoptosis: a potential mechanism of immune evasion." Nat Med 8(8): 793-800.

Doucette, T., G. Rao, A. Rao, L. Shen, K. Aldape, J. Wei, K. Dziurzynski, M. Gilbert and A. B. Heimberger (2013). "Immune heterogeneity of glioblastoma subtypes: extrapolation from the cancer genome atlas." Cancer Immunol Res 1(2): 112-122.

Duluc, D., M. Corvaisier, S. Blanchard, L. Catala, P. Descamps, E. Gamelin, S. Ponsoda, Y. Delneste, M. Hebbar and P. Jeannin (2009). "Interferon-gamma reverses the immunosuppressive and protumoral properties and prevents the generation of human tumor-associated macrophages." Int J Cancer 125(2): 367-373.

Duluc, D., Y. Delneste, F. Tan, M. P. Moles, L. Grimaud, J. Lenoir, L. Preisser, I. Anegon, L. Catala, N. Ifrah, P. Descamps, E. Gamelin, H. Gascan, M. Hebbar and P. Jeannin (2007). "Tumor-associated leukemia inhibitory factor and IL-6 skew monocyte differentiation into tumor-associated macrophage-like cells." Blood 110(13): 4319-4330. Duraiswamy, J., G. J. Freeman and G. Coukos (2013). "Therapeutic PD-1 pathway blockade augments with other modalities of immunotherapy T-cell function to prevent immune decline in ovarian cancer." Cancer Res 73(23): 6900-6912.

Duraiswamy, J., K. M. Kaluza, G. J. Freeman and G. Coukos (2013). "Dual blockade of PD-1 and CTLA-4 combined with tumor vaccine effectively restores T-cell rejection function in tumors." Cancer Res 73(12): 3591-3603.

El Andaloussi, A. and M. S. Lesniak (2006). "An increase in CD4+CD25+FOXP3+ regulatory T cells in tumor-infiltrating lymphocytes of human glioblastoma multiforme." Neuro Oncol 8(3): 234-243.

Freeman, G. J. (2008). "Structures of PD-1 with its ligands: sideways and dancing cheek to cheek." Proc Natl Acad Sci U S A 105(30): 10275-10276.

Freeman, G. J., A. J. Long, Y. Iwai, K. Bourque, T. Chernova, H. Nishimura, L. J. Fitz, N. Malenkovich, T. Okazaki, M. C. Byrne, H. F. Horton, L. Fouser, L. Carter, V. Ling, M. R. Bowman, B. M. Carreno, M. Collins, C. R. Wood and T. Honjo (2000). "Engagement of the PD-1 immunoinhibitory receptor by a novel $B 7$ family member leads to negative regulation of lymphocyte activation." J Exp Med 192(7): 1027-1034.

Fridlender, Z. G., G. Buchlis, V. Kapoor, G. Cheng, J. Sun, S. Singhal, M. C. Crisanti, L. C. Wang, D. Heitjan, L. A. Snyder and S. M. Albelda (2010). "CCL2 blockade augments cancer immunotherapy." Cancer Res 70(1): 109-118.

Fujita, Y., S. Yagishita, K. Hagiwara, Y. Yoshioka, N. Kosaka, F. Takeshita, T. Fujiwara, K. Tsuta, H. Nokihara, T. Tamura, H. Asamura, M. Kawaishi, K. Kuwano and T. Ochiya (2015). "The clinical relevance of the miR197/CKS1B/STAT3-mediated PD-L1 network in chemoresistant non-small-cell lung cancer." Mol Ther 23(4): 717-727. Furnari, F. B., T. Fenton, R. M. Bachoo, A. Mukasa, J. M. Stommel, A. Stegh, W. C. Hahn, K. L. Ligon, D. N. Louis, C. Brennan, L. Chin, R. A. DePinho and W. K. Cavenee (2007). "Malignant astrocytic glioma: genetics, biology, and paths to treatment." Genes Dev 21(21): 2683-2710.

Gabrilovich, D. I. and S. Nagaraj (2009). "Myeloid-derived suppressor cells as regulators of the immune system." Nat Rev Immunol 9(3): 162-174.

Ganesan, A. P., M. Johansson, B. Ruffell, A. Yagui-Beltran, J. Lau, D. M. Jablons and L. M. Coussens (2013). "Tumorinfiltrating regulatory $T$ cells inhibit endogenous cytotoxic $T$ cell responses to lung adenocarcinoma." J Immunol 191(4): 2009-2017.

Gao, W., L. Thompson, Q. Zhou, P. Putheti, T. M. Fahmy, T. B. Strom and S. M. Metcalfe (2009). "Treg versus Th17 lymphocyte lineages are cross-regulated by LIF versus IL-6." Cell Cycle 8(9): 1444-1450.

Garbers, C., H. M. Hermanns, F. Schaper, G. Muller-Newen, J. Grotzinger, S. Rose-John and J. Scheller (2012).

"Plasticity and cross-talk of interleukin 6-type cytokines." Cytokine Growth Factor Rev 23(3): 85-97.

Gearing, D. P., N. M. Gough, J. A. King, D. J. Hilton, N. A. Nicola, R. J. Simpson, E. C. Nice, A. Kelso and D. Metcalf (1987). "Molecular cloning and expression of cDNA encoding a murine myeloid leukaemia inhibitory factor (LIF)." EMBO J 6(13): 3995-4002.

Gleissner, C. A., I. Shaked, C. Erbel, D. Bockler, H. A. Katus and K. Ley (2010). "CXCL4 downregulates the atheroprotective hemoglobin receptor CD163 in human macrophages." Circ Res 106(1): 203-211.

Gobert, M., I. Treilleux, N. Bendriss-Vermare, T. Bachelot, S. Goddard-Leon, V. Arfi, C. Biota, A. C. Doffin, I. Durand, D. Olive, S. Perez, N. Pasqual, C. Faure, I. Ray-Coquard, A. Puisieux, C. Caux, J. Y. Blay and C. Menetrier-Caux (2009). "Regulatory $T$ cells recruited through CCL22/CCR4 are selectively activated in lymphoid infiltrates surrounding primary breast tumors and lead to an adverse clinical outcome." Cancer Res 69(5): 2000-2009.

Graf, U., E. A. Casanova and P. Cinelli (2011). "The Role of the Leukemia Inhibitory Factor (LIF) - Pathway in Derivation and Maintenance of Murine Pluripotent Stem Cells." Genes (Basel) 2(1): 280-297.

Green, M. R., S. Monti, S. J. Rodig, P. Juszczynski, T. Currie, E. O'Donnell, B. Chapuy, K. Takeyama, D. Neuberg, T. R. Golub, J. L. Kutok and M. A. Shipp (2010). "Integrative analysis reveals selective 9p24.1 amplification, increased PD-1 ligand expression, and further induction via JAK2 in nodular sclerosing Hodgkin lymphoma and primary mediastinal large B-cell lymphoma." Blood 116(17): 3268-3277. 
Green, M. R., S. Rodig, P. Juszczynski, J. Ouyang, P. Sinha, E. O'Donnell, D. Neuberg and M. A. Shipp (2012). "Constitutive AP-1 activity and EBV infection induce PD-L1 in Hodgkin lymphomas and posttransplant lymphoproliferative disorders: implications for targeted therapy." Clin Cancer Res 18(6): 1611-1618.

Gresle, M. M., E. Alexandrou, Q. Wu, G. Egan, V. Jokubaitis, M. Ayers, A. Jonas, W. Doherty, A. Friedhuber, G. Shaw, M. Sendtner, B. Emery, T. Kilpatrick and H. Butzkueven (2012). "Leukemia inhibitory factor protects axons in experimental autoimmune encephalomyelitis via an oligodendrocyte-independent mechanism." PLoS One $7(10)$ : e47379.

Grivennikov, S. I., F. R. Greten and M. Karin (2010). "Immunity, inflammation, and cancer." Cell 140(6): 883-899. Haines, B. P., R. B. Voyle, T. A. Pelton, R. Forrest and P. D. Rathjen (1999). "Complex conserved organization of the mammalian leukemia inhibitory factor gene: regulated expression of intracellular and extracellular cytokines." $\underline{J}$ Immunol 162(8): 4637-4646.

Han, H., F. L. Cao, B. Z. Wang, X. R. Mu, G. Y. Li and X. W. Wang (2014). "Expression of angiogenesis regulatory proteins and epithelial-mesenchymal transition factors in platelets of the breast cancer patients."

ScientificWorldJournal 2014: 878209.

Hanahan, D. and R. A. Weinberg (2011). "Hallmarks of cancer: the next generation." Cell 144(5): 646-674. He, Z., J. J. Li, C. H. Zhen, L. Y. Feng and X. Y. Ding (2006). "Effect of leukemia inhibitory factor on embryonic stem cell differentiation: implications for supporting neuronal differentiation." Acta Pharmacol Sin 27(1): 80-90. Heimberger, A. B., M. Abou-Ghazal, C. Reina-Ortiz, D. S. Yang, W. Sun, W. Qiao, N. Hiraoka and G. N. Fuller (2008). "Incidence and prognostic impact of FoxP3+ regulatory T cells in human gliomas." Clin Cancer Res 14(16): 51665172.

Hendriks, J. J., H. Slaets, S. Carmans, H. E. de Vries, C. D. Dijkstra, P. Stinissen and N. Hellings (2008). "Leukemia inhibitory factor modulates production of inflammatory mediators and myelin phagocytosis by macrophages." $\underline{\mathrm{J}}$ Neuroimmunol 204(1-2): 52-57.

Herroon, M. K., E. Rajagurubandara, D. L. Rudy, A. Chalasani, A. L. Hardaway and I. Podgorski (2013). "Macrophage cathepsin K promotes prostate tumor progression in bone." Oncogene 32(12): 1580-1593.

Hidalgo, M., F. Amant, A. V. Biankin, E. Budinska, A. T. Byrne, C. Caldas, R. B. Clarke, S. de Jong, J. Jonkers, G. M. Maelandsmo, S. Roman-Roman, J. Seoane, L. Trusolino and A. Villanueva (2014). "Patient-derived xenograft models: an emerging platform for translational cancer research." Cancer Discov 4(9): 998-1013.

Hirai, H., P. Karian and N. Kikyo (2011). "Regulation of embryonic stem cell self-renewal and pluripotency by leukaemia inhibitory factor." Biochem J 438(1): 11-23.

Hirano, F., K. Kaneko, H. Tamura, H. Dong, S. Wang, M. Ichikawa, C. Rietz, D. B. Flies, J. S. Lau, G. Zhu, K. Tamada and L. Chen (2005). "Blockade of B7-H1 and PD-1 by monoclonal antibodies potentiates cancer therapeutic immunity." Cancer Res 65(3): 1089-1096.

Hoelzinger, D. B., S. E. Smith, N. Mirza, A. L. Dominguez, S. Z. Manrique and J. Lustgarten (2010). "Blockade of CCL1 inhibits T regulatory cell suppressive function enhancing tumor immunity without affecting T effector responses." J Immunol 184(12): 6833-6842.

Horita, H., E. Kuroda, T. Hachisuga, M. Kashimura and U. Yamashita (2007). "Induction of prostaglandin E2 production by leukemia inhibitory factor promotes migration of first trimester extravillous trophoblast cell line, HTR-8/SVneo." Hum Reprod 22(7): 1801-1809.

Hughes, R., B. Z. Qian, C. Rowan, M. Muthana, I. Keklikoglou, O. C. Olson, S. Tazzyman, S. Danson, C. Addison, M. Clemons, A. M. Gonzalez-Angulo, J. A. Joyce, M. De Palma, J. W. Pollard and C. E. Lewis (2015). "Perivascular M2 Macrophages Stimulate Tumor Relapse after Chemotherapy." Cancer Res 75(17): 3479-3491.

Hussain, S. F., D. Yang, D. Suki, K. Aldape, E. Grimm and A. B. Heimberger (2006). "The role of human gliomainfiltrating microglia/macrophages in mediating antitumor immune responses." Neuro Oncol 8(3): 261-279. Hwang, T. L., L. Y. Lee, C. C. Wang, Y. Liang, S. F. Huang and C. M. Wu (2012). "CCL7 and CCL21 overexpression in gastric cancer is associated with lymph node metastasis and poor prognosis." World J Gastroenterol 18(11): 12491256.

lellem, A., M. Mariani, R. Lang, H. Recalde, P. Panina-Bordignon, F. Sinigaglia and D. D'Ambrosio (2001). "Unique chemotactic response profile and specific expression of chemokine receptors CCR4 and CCR8 by CD4(+)CD25(+) regulatory T cells." J Exp Med 194(6): 847-853.

Ishibashi, H., T. Suzuki, S. Suzuki, T. Moriya, C. Kaneko, T. Takizawa, M. Sunamori, M. Handa, T. Kondo and H. Sasano (2003). "Sex steroid hormone receptors in human thymoma." J Clin Endocrinol Metab 88(5): 2309-2317.

Jacobs, V. L., P. A. Valdes, W. F. Hickey and J. A. De Leo (2011). "Current review of in vivo GBM rodent models: emphasis on the CNS-1 tumour model." ASN Neuro 3(3): e00063.

Jakubzick, C., H. Wen, A. Matsukawa, M. Keller, S. L. Kunkel and C. M. Hogaboam (2004). "Role of CCR4 ligands, CCL17 and CCL22, during Schistosoma mansoni egg-induced pulmonary granuloma formation in mice." Am J Pathol 165(4): 1211-1221.

Janssens, K., C. Van den Haute, V. Baekelandt, S. Lucas, J. van Horssen, V. Somers, B. Van Wijmeersch, P. Stinissen, J. J. Hendriks, H. Slaets and N. Hellings (2015). "Leukemia inhibitory factor tips the immune balance towards regulatory T cells in multiple sclerosis." Brain Behav Immun 45: 180-188.

Jing, W., J. A. Gershan and B. D. Johnson (2009). "Depletion of CD4 T cells enhances immunotherapy for neuroblastoma after syngeneic HSCT but compromises development of antitumor immune memory." Blood 113(18): 4449-4457. 
Joyce, J. A. (2005). "Therapeutic targeting of the tumor microenvironment." Cancer Cell 7(6): 513-520.

Joyce, J. A. and J. W. Pollard (2009). "Microenvironmental regulation of metastasis." Nat Rev Cancer 9(4): 239-252.

Kaminska, B., B. Pyrzynska, I. Ciechomska and M. Wisniewska (2000). "Modulation of the composition of AP-1

complex and its impact on transcriptional activity." Acta Neurobiol Exp (Wars) 60(3): 395-402.

Keir, M. E., M. J. Butte, G. J. Freeman and A. H. Sharpe (2008). "PD-1 and its ligands in tolerance and immunity." Annu Rev Immunol 26: 677-704.

Kim, J. W. and J. P. Eder (2014). "Prospects for targeting PD-1 and PD-L1 in various tumor types." Oncology (Williston Park) 28 Suppl 3: 15-28.

Kiniwa, Y., Y. Miyahara, H. Y. Wang, W. Peng, G. Peng, T. M. Wheeler, T. C. Thompson, L. J. Old and R. F. Wang (2007). "CD8+ Foxp3+ regulatory T cells mediate immunosuppression in prostate cancer." Clin Cancer Res 13(23): 6947-6958.

Komohara, Y., M. Jinushi and M. Takeya (2014). "Clinical significance of macrophage heterogeneity in human malignant tumors." Cancer Sci 105(1): 1-8.

Kritikou, E. A., A. Sharkey, K. Abell, P. J. Came, E. Anderson, R. W. Clarkson and C. J. Watson (2003). "A dual, nonredundant, role for LIF as a regulator of development and STAT3-mediated cell death in mammary gland." Development 130(15): 3459-3468.

Labeur, M. S., B. Roters, B. Pers, A. Mehling, T. A. Luger, T. Schwarz and S. Grabbe (1999). "Generation of tumor immunity by bone marrow-derived dendritic cells correlates with dendritic cell maturation stage." J Immunol 162(1): 168-175.

Latchman, Y. E., S. C. Liang, Y. Wu, T. Chernova, R. A. Sobel, M. Klemm, V. K. Kuchroo, G. J. Freeman and A. H. Sharpe (2004). "PD-L1-deficient mice show that PD-L1 on T cells, antigen-presenting cells, and host tissues negatively regulates T cells." Proc Nat| Acad Sci U S A 101(29): 10691-10696.

Lee, J., S. Kotliarova, Y. Kotliarov, A. Li, Q. Su, N. M. Donin, S. Pastorino, B. W. Purow, N. Christopher, W. Zhang, J. K. Park and H. A. Fine (2006). "Tumor stem cells derived from glioblastomas cultured in bFGF and EGF more closely mirror the phenotype and genotype of primary tumors than do serum-cultured cell lines." Cancer Cell 9(5): 391-403. Levy, Y. A., K. Mausner-Fainberg, A. Vaknin-Dembinsky, T. Amidror, K. Regev and A. Karni (2015). "Dysregulated production of leukemia inhibitory factor in immune cells of relapsing remitting multiple sclerosis patients." $\underline{J}$ Neuroimmunol 278: 85-89.

Li, X., Q. Yang, H. Yu, L. Wu, Y. Zhao, C. Zhang, X. Yue, Z. Liu, H. Wu, B. G. Haffty, Z. Feng and W. Hu (2014). "LIF promotes tumorigenesis and metastasis of breast cancer through the AKT-mTOR pathway." Oncotarget 5(3): 788801.

Liu, S. C., N. M. Tsang, W. C. Chiang, K. P. Chang, C. Hsueh, Y. Liang, J. L. Juang, K. P. Chow and Y. S. Chang (2013) "Leukemia inhibitory factor promotes nasopharyngeal carcinoma progression and radioresistance." J Clin Invest 123(12): 5269-5283.

Louis, D. N., H. Ohgaki, O. D. Wiestler, W. K. Cavenee, P. C. Burger, A. Jouvet, B. W. Scheithauer and P. Kleihues (2007). "The 2007 WHO classification of tumours of the central nervous system." Acta Neuropathol 114(2): 97-109. Ma, Y., G. V. Shurin, Z. Peiyuan and M. R. Shurin (2013). "Dendritic cells in the cancer microenvironment." J Cancer 4(1): 36-44.

Maes, W. and S. W. Van Gool (2011). "Experimental immunotherapy for malignant glioma: lessons from two decades of research in the GL261 model." Cancer Immunol Immunother 60(2): 153-160.

Mantovani, A., P. Allavena, A. Sica and F. Balkwill (2008). "Cancer-related inflammation." Nature 454(7203): 436444.

Mantovani, A., S. Sozzani, M. Locati, P. Allavena and A. Sica (2002). "Macrophage polarization: tumor-associated macrophages as a paradigm for polarized M2 mononuclear phagocytes." Trends Immunol 23(11): 549-555. Martinez, F. O., L. Helming and S. Gordon (2009). "Alternative activation of macrophages: an immunologic functional perspective." Annu Rev Immunol 27: 451-483.

Marzec, M., Q. Zhang, A. Goradia, P. N. Raghunath, X. Liu, M. Paessler, H. Y. Wang, M. Wysocka, M. Cheng, B. A. Ruggeri and M. A. Wasik (2008). "Oncogenic kinase NPM/ALK induces through STAT3 expression of immunosuppressive protein CD274 (PD-L1, B7-H1)." Proc Natl Acad Sci U S A 105(52): 20852-20857.

Mathieu, M. E., C. Saucourt, V. Mournetas, X. Gauthereau, N. Theze, V. Praloran, P. Thiebaud and H. Boeuf (2012). "LIF-dependent signaling: new pieces in the Lego." Stem Cell Rev 8(1): 1-15.

Merz, F., F. Gaunitz, F. Dehghani, C. Renner, J. Meixensberger, A. Gutenberg, A. Giese, K. Schopow, C. Hellwig, M. Schafer, M. Bauer, H. Stocker, G. Taucher-Scholz, M. Durante and I. Bechmann (2013). "Organotypic slice cultures of human glioblastoma reveal different susceptibilities to treatments." Neuro Oncol 15(6): 670-681.

Metcalfe, S. M. (2005). "Axotrophin and leukaemia inhibitory factor (LIF) in transplantation tolerance." Philos Trans R Soc Lond B Biol Sci 360(1461): 1687-1694.

Metcalfe, S. M., T. J. Watson, S. Shurey, E. Adams and C. J. Green (2005). "Leukemia inhibitory factor is linked to regulatory transplantation tolerance." Transplantation 79(6): 726-730.

Muthukumarana, P. A., G. E. Lyons, Y. Miura, L. H. Thompson, T. Watson, C. J. Green, S. Shurey, A. D. Hess, B. R. Rosengard and S. M. Metcalfe (2006). "Evidence for functional inter-relationships between FOXP3, leukaemia inhibitory factor, and axotrophin/MARCH-7 in transplantation tolerance." Int Immunopharmacol 6(13-14): 19932001. 
Noy, R. and J. W. Pollard (2014). "Tumor-associated macrophages: from mechanisms to therapy." Immunity 41(1): 49-61.

Oh, T., S. Fakurnejad, E. T. Sayegh, A. J. Clark, M. E. Ivan, M. Z. Sun, M. Safaee, O. Bloch, C. D. James and A. T. Parsa (2014). "Immunocompetent murine models for the study of glioblastoma immunotherapy." J Trans| Med 12: 107.

Okita, Y., H. Tanaka, M. Ohira, K. Muguruma, N. Kubo, M. Watanabe, W. Fukushima and K. Hirakawa (2014). "Role of tumor-infiltrating CD11b+ antigen-presenting cells in the progression of gastric cancer." J Surg Res 186(1): 192-200.

Pampaloni, F., E. G. Reynaud and E. H. Stelzer (2007). "The third dimension bridges the gap between cell culture and live tissue." Nat Rev Mol Cell Biol 8(10): 839-845.

Pedroza-Pacheco, I., A. Madrigal and A. Saudemont (2013). "Interaction between natural killer cells and regulatory T cells: perspectives for immunotherapy." Cell Mol Immunol 10(3): 222-229.

Penuelas, S., J. Anido, R. M. Prieto-Sanchez, G. Folch, I. Barba, I. Cuartas, D. Garcia-Dorado, M. A. Poca, J. Sahuquillo, J. Baselga and J. Seoane (2009). "TGF-beta increases glioma-initiating cell self-renewal through the induction of LIF in human glioblastoma." Cancer Cell 15(4): 315-327.

Peterson, J. E., D. Zurakowski, J. E. Italiano, Jr., L. V. Michel, S. Connors, M. Oenick, R. J. D'Amato, G. L. Klement and J. Folkman (2012). "VEGF, PF4 and PDGF are elevated in platelets of colorectal cancer patients." Angiogenesis 15(2): 265-273.

Phillips, H. S., S. Kharbanda, R. Chen, W. F. Forrest, R. H. Soriano, T. D. Wu, A. Misra, J. M. Nigro, H. Colman, L.

Soroceanu, P. M. Williams, Z. Modrusan, B. G. Feuerstein and K. Aldape (2006). "Molecular subclasses of high-grade glioma predict prognosis, delineate a pattern of disease progression, and resemble stages in neurogenesis." Cancer Cell 9(3): 157-173.

Pyonteck, S. M., L. Akkari, A. J. Schuhmacher, R. L. Bowman, L. Sevenich, D. F. Quail, O. C. Olson, M. L. Quick, J. T. Huse, V. Teijeiro, M. Setty, C. S. Leslie, Y. Oei, A. Pedraza, J. Zhang, C. W. Brennan, J. C. Sutton, E. C. Holland, D. Daniel and J. A. Joyce (2013). "CSF-1R inhibition alters macrophage polarization and blocks glioma progression." Nat Med 19(10): 1264-1272.

Quail, D. F. and J. A. Joyce (2013). "Microenvironmental regulation of tumor progression and metastasis." $\underline{\text { Nat Med }}$ 19(11): 1423-1437.

Roszer, T. (2015). "Understanding the Mysterious M2 Macrophage through Activation Markers and Effector Mechanisms." Mediators Inflamm 2015: 816460.

Ruffell, B. and L. M. Coussens (2015). "Macrophages and therapeutic resistance in cancer." Cancer Cell 27(4): 462472.

Salleh, N. and N. Giribabu (2014). "Leukemia inhibitory factor: roles in embryo implantation and in nonhormonal contraception." ScientificWorldJournal 2014: 201514.

Scheuerer, B., M. Ernst, I. Durrbaum-Landmann, J. Fleischer, E. Grage-Griebenow, E. Brandt, H. D. Flad and F. Petersen (2000). "The CXC-chemokine platelet factor 4 promotes monocyte survival and induces monocyte differentiation into macrophages." Blood 95(4): 1158-1166.

Schlecker, E., A. Stojanovic, C. Eisen, C. Quack, C. S. Falk, V. Umansky and A. Cerwenka (2012). "Tumor-infiltrating monocytic myeloid-derived suppressor cells mediate CCR5-dependent recruitment of regulatory $T$ cells favoring tumor growth." J Immunol 189(12): 5602-5611.

Schofield, G. and S. J. Kimber (2005). "Leukocyte subpopulations in the uteri of leukemia inhibitory factor knockout mice during early pregnancy." Biol Reprod 72(4): 872-878.

Sharma, P. and J. P. Allison (2015). "The future of immune checkpoint therapy." Science 348(6230): 56-61.

Sharma, P. and J. P. Allison (2015). "Immune checkpoint targeting in cancer therapy: toward combination strategies with curative potential." Cell 161(2): 205-214.

Shevach, E. M. (2004). "Fatal attraction: tumors beckon regulatory T cells." Nat Med 10(9): 900-901.

Shevach, E. M. (2009). "Mechanisms of foxp3+ T regulatory cell-mediated suppression." Immunity 30(5): 636-645. Shi, G., D. J. Field, K. A. Ko, S. Ture, K. Srivastava, S. Levy, M. A. Kowalska, M. Poncz, D. J. Fowell and C. N. Morrell (2014). "Platelet factor 4 limits Th17 differentiation and cardiac allograft rejection." J Clin Invest 124(2): 543-552. Sica, A. and V. Bronte (2007). "Altered macrophage differentiation and immune dysfunction in tumor development." J Clin Invest 117(5): 1155-1166.

Siegal, T. (2015). "Clinical impact of molecular biomarkers in gliomas." J Clin Neurosci 22(3): 437-444.

Singh, P. P., P. K. Sharma, G. Krishnan and A. C. Lockhart (2015). "Immune checkpoints and immunotherapy for colorectal cancer." Gastroenterol Rep (Oxf) 3(4): 289-297.

Stewart, C. L., P. Kaspar, L. J. Brunet, H. Bhatt, I. Gadi, F. Kontgen and S. J. Abbondanzo (1992). "Blastocyst implantation depends on maternal expression of leukaemia inhibitory factor." Nature 359(6390): 76-79. Strome, S. E., H. Dong, H. Tamura, S. G. Voss, D. B. Flies, K. Tamada, D. Salomao, J. Cheville, F. Hirano, W. Lin, J. L. Kasperbauer, K. V. Ballman and L. Chen (2003). "B7-H1 blockade augments adoptive T-cell immunotherapy for squamous cell carcinoma." Cancer Res 63(19): 6501-6505.

Stupp, R., W. P. Mason, M. J. van den Bent, M. Weller, B. Fisher, M. J. Taphoorn, K. Belanger, A. A. Brandes, C. Marosi, U. Bogdahn, J. Curschmann, R. C. Janzer, S. K. Ludwin, T. Gorlia, A. Allgeier, D. Lacombe, J. G. Cairncross, E. Eisenhauer, R. O. Mirimanoff, R. European Organisation for, T. Treatment of Cancer Brain, G. Radiotherapy and G. National Cancer Institute of Canada Clinical Trials (2005). "Radiotherapy plus concomitant and adjuvant temozolomide for glioblastoma." N Engl J Med 352(10): 987-996. 
Sumpter, T. L. and A. W. Thomson (2011). "The STATus of PD-L1 (B7-H1) on tolerogenic APCs." Eur J Immunol 41(2): 286-290.

Sunderkotter, C., T. Nikolic, M. J. Dillon, N. Van Rooijen, M. Stehling, D. A. Drevets and P. J. Leenen (2004). "Subpopulations of mouse blood monocytes differ in maturation stage and inflammatory response." $\underline{\mathrm{J} \text { Immunol }}$ 172(7): 4410-4417.

Tacke, F., F. Ginhoux, C. Jakubzick, N. van Rooijen, M. Merad and G. J. Randolph (2006). "Immature monocytes acquire antigens from other cells in the bone marrow and present them to $T$ cells after maturing in the periphery." $\underline{J}$ Exp Med 203(3): 583-597.

Tiemessen, M. M., A. L. Jagger, H. G. Evans, M. J. van Herwijnen, S. John and L. S. Taams (2007). "CD4+CD25+Foxp3+ regulatory $T$ cells induce alternative activation of human monocytes/macrophages." Proc Natl Acad Sci U S A 104(49): 19446-19451.

Tran, T. T., M. Uhl, J. Y. Ma, L. Janssen, V. Sriram, S. Aulwurm, I. Kerr, A. Lam, H. K. Webb, A. M. Kapoun, D. E. Kizer, G. McEnroe, B. Hart, J. Axon, A. Murphy, S. Chakravarty, S. Dugar, A. A. Protter, L. S. Higgins, W. Wick, M. Weller and D. H. Wong (2007). "Inhibiting TGF-beta signaling restores immune surveillance in the SMA-560 glioma model." Neuro Oncol 9(3): 259-270.

Trouillas, M., C. Saucourt, B. Guillotin, X. Gauthereau, J. L. Taupin, J. F. Moreau and H. Boeuf (2009). "The LIF cytokine: towards adulthood." Eur Cytokine Netw 20(2): 51-62.

Tso, C. L., P. Shintaku, J. Chen, Q. Liu, J. Liu, Z. Chen, K. Yoshimoto, P. S. Mischel, T. F. Cloughesy, L. M. Liau and S. F. Nelson (2006). "Primary glioblastomas express mesenchymal stem-like properties." Mol Cancer Res 4(9): 607-619.

van Rooijen, N. and E. Hendrikx (2010). "Liposomes for specific depletion of macrophages from organs and tissues." Methods Mol Biol 605: 189-203.

Verhaak, R. G., K. A. Hoadley, E. Purdom, V. Wang, Y. Qi, M. D. Wilkerson, C. R. Miller, L. Ding, T. Golub, J. P. Mesirov, G. Alexe, M. Lawrence, M. O'Kelly, P. Tamayo, B. A. Weir, S. Gabriel, W. Winckler, S. Gupta, L. Jakkula, H. S. Feiler, J. G. Hodgson, C. D. James, J. N. Sarkaria, C. Brennan, A. Kahn, P. T. Spellman, R. K. Wilson, T. P. Speed, J. W. Gray, M. Meyerson, G. Getz, C. M. Perou, D. N. Hayes and N. Cancer Genome Atlas Research (2010). "Integrated genomic analysis identifies clinically relevant subtypes of glioblastoma characterized by abnormalities in PDGFRA, IDH1, EGFR, and NF1." Cancer Cell 17(1): 98-110.

Wang, W. B., M. L. Yen, K. J. Liu, P. J. Hsu, M. H. Lin, P. M. Chen, P. R. Sudhir, C. H. Chen, C. H. Chen, H. K. Sytwu and B. L. Yen (2015). "Interleukin-25 Mediates Transcriptional Control of PD-L1 via STAT3 in Multipotent Human Mesenchymal Stromal Cells (hMSCs) to Suppress Th17 Responses." Stem Cell Reports 5(3): 392-404. Wang, Y. M. and S. I. Alexander (2009). "CD8 regulatory T cells: what's old is now new." Immunol Cell Biol 87(3): 192-193.

Wei, J., J. Barr, L. Y. Kong, Y. Wang, A. Wu, A. K. Sharma, J. Gumin, V. Henry, H. Colman, W. Priebe, R. Sawaya, F. F. Lang and A. B. Heimberger (2010). "Glioblastoma cancer-initiating cells inhibit T-cell proliferation and effector responses by the signal transducers and activators of transcription 3 pathway." Mol Cancer Ther 9(1): 67-78.

Wei, J., J. Barr, L. Y. Kong, Y. Wang, A. Wu, A. K. Sharma, J. Gumin, V. Henry, H. Colman, R. Sawaya, F. F. Lang and A. B. Heimberger (2010). "Glioma-associated cancer-initiating cells induce immunosuppression." Clin Cancer Res 16(2): 461-473.

Weisser, S. B., N. van Rooijen and L. M. Sly (2012). "Depletion and reconstitution of macrophages in mice." $\underline{\mathrm{J} \text { Vis }}$ Exp(66): 4105 .

Wolchok, J. D. and T. A. Chan (2014). "Cancer: Antitumour immunity gets a boost." Nature 515(7528): 496-498. Wolfle, S. J., J. Strebovsky, H. Bartz, A. Sahr, C. Arnold, C. Kaiser, A. H. Dalpke and K. Heeg (2011). "PD-L1 expression on tolerogenic APCs is controlled by STAT-3." Eur J Immunol 41(2): 413-424.

Wu, A., J. Wei, L. Y. Kong, Y. Wang, W. Priebe, W. Qiao, R. Sawaya and A. B. Heimberger (2010). "Glioma cancer stem cells induce immunosuppressive macrophages/microglia." Neuro Oncol 12(11): 1113-1125.

Wyckoff, J., W. Wang, E. Y. Lin, Y. Wang, F. Pixley, E. R. Stanley, T. Graf, J. W. Pollard, J. Segall and J. Condeelis (2004). "A paracrine loop between tumor cells and macrophages is required for tumor cell migration in mammary tumors." Cancer Res 64(19): 7022-7029.

Youn, J. I. and D. I. Gabrilovich (2010). "The biology of myeloid-derived suppressor cells: the blessing and the curse of morphological and functional heterogeneity." Eur J Immunol 40(11): 2969-2975.

Yu, H., X. Yue, Y. Zhao, X. Li, L. Wu, C. Zhang, Z. Liu, K. Lin, Z. Y. Xu-Monette, K. H. Young, J. Liu, Z. Shen, Z. Feng and W. Hu (2014). "LIF negatively regulates tumour-suppressor p53 through Stat3/ID1/MDM2 in colorectal cancers." Nat Commun 5: 5218

Yue, X., L. Wu and W. Hu (2015). "The regulation of leukemia inhibitory factor." Cancer Cell Microenviron. 


\section{ACKNOWLEDGEMENTS}


Llegó el momento. Después de los últimos años, que han pasado muy lentamente en algunas ocasiones, como un suspiro en otras, llegó la hora de agradecer a todas aquellas personas que me han acompañado en este viaje. A aquellos que se han quedado un tiempo largo y a los que han pasado de puntillas, y a los que aún en la distancia, siguen estando presentes. De todas y cada una de estas personas, me llevo alguna lección, y por eso quiero darles el reconocimiento que se merecen, ya que en este trabajo al que pongo punto y final con estas palabras, hay un trocito de cada uno de ellos.

A Joan, a quien le debo mi formación y madurez como científica. Me ha enseñado a perseverar, a no rendirme jamás, a darle la vuelta a un mal resultado, a pensar en nuevas hipótesis y a desarrollarlas, a ir siempre "a tope".

A todos los compañeros de laboratorio, que han hecho de este grupo un lugar ideal para crecer y madurar. Por ser mi segunda familia:

A antiguos compañeros: a Anna, Mari, Paco. A Andrea, "mi postdoc", quien me adentró en el mundo de LIF. A Paco, Gerard, Laura y Alba, los predocs del grupo, la experiencia de los cuales me ha servido para guiar mis pasos. En especial, a Laura, quien aún estando del otro lado del Atlántico, sigue estando presente. De ella me llevo su aparente calma, el saberse tomar un momento para pensar antes de hablar. A Alba, que con sus locuras me ha hecho reír. De Alba me llevo su pasión por la ciencia, y por cada una de las cosas que hace en la vida. A Eva Paradell, porque consigo traía la alegría y el "buen rollito" cada mañana. A Rosita, por su inestimable ayuda durante unos meses que resultaron duros. A las técnicos, Isa Cuartas y Cristina. Sin vuestro tremendo trabajo con los ratoncitos, esto no hubiera sido posible. A Sandra, por saber llevar el laboratorio y hacer que las cosas funcionen, y por todos los cortes de bloques de parafina pedidos para ayer. A Judit, quien me ha hecho ver el lado más pragmático de este camino.

A las nuevas personas que se han ido añadiendo al "A tope lab": Regina, con su bondad y sinceridad; Vanessa con su humor en portuñol, que nos hace reír a carcajadas, con la que ha sido un placer trabajar, siempre tan meticulosa en los experimentos; a Montse con su inocencia y paciencia; a Crisitina Arias por su disponibilidad en todo momento (aún con un brazo roto!); a Ester; a Mónica.

A Josep, el XY del lab, que con sus bromas nos escandaliza y nos hace reír. A él le agradezco que me haya transmitido su pasión por la investigación, y su ayuda completamente desinteresada, sólo por el puro placer de enseñar. Le doy las gracias por esa primera corrección de este trabajo. Por pasar horas y horas revisando. Por todas sus sugerencias.

A las dos Juds, Carol y Atenea. Carolina, que ha estado desde el principio, que me ha apoyado en tantísimos momentos cuando no veía la salida, que me ha hecho relativizar las situaciones a los largo de todos estos años. Sin ella, esos momentos se me habrían hecho insoportables. Eternamente agradecida. Porque además de compañera, se ha convertido en una de mis mejores amigas, con la que sé que se puede contar en cualquier momento, y para cualquier cosa. Porque cuando se supera la carcasa, esa primera barrera que la hace parecer una borde de primera, es todo corazón. A Atenea, la otra Jud, la dulzura personificada. Por todas las horas compartidas durante los eternos Días de Matanza, en el lab y en el citómetro. Gracias por estar a mi lado y poner un hombro al que arrimarme. Por ser mi compañera y amiga en el "último" sprint.

A Jjjjuber. Isa, mi mentora, mi modelo a seguir. Porque desde que llegaste, has estado a mi lado. Porque has sido un apoyo incondicional. Por toda tu positividad, alegría y paciencia. Por todos tus consejos. Por tu bondad y generosidad. Por ser tan fácil trabajar contigo. Por la corrección de la tesis. Porque eres una de las personas que más admiro en este mundo, tanto en el plano profesional como en el personal. Por tener tan claros tus ideales y no acobardarte ante ninguna situación. Me has enseñado, entre otras muchas cosas, que lo importante es ir 
con la verdad por delante, y actuar de tal manera que una esté cómoda consigo misma. $Y$ aunque me hayas hecho subir por paredes verticales de varias decenas de metros, me hayas hecho atravesar puentes tibetanos con viento, me hayas hecho cruzar entre paredes a varios metros de altura (sí sí... al Paso de la Fe me refiero!), me hayas hecho subir picos de más de $3000 \mathrm{~m}$ y bañarme en lagos con nieve alrededor, y alguna que otra locura, ya ves... te seguiría donde me guiaras.

Aunque ya haya agradecido por separado a todas la personas implicadas, quiero destacar el gran trabajo de todo el Equipo de las Matanzas. Días de locura que han dado sus frutos gracias al trabajo en equipo. Sin ellos, no hubiera sido posible. Muchas muchas gracias.

A Carmen Espejo, quien me ha abierto las puertas del mundo de la inmunología, y ha hecho que aprendiera tantísimo. Por todas la horas en su despacho discutiendo nuevas aproximaciones, nuevas técnicas. Por su paciencia infinita. Por su meticulosidad en el planteamiento de los experimentos.

Al grupo Relax Spa, con los que nos hemos reído tanto $y$ tenemos tantas salidas $y$ tantos buenos momentos a recordar: Marie-Eve, Dani, Toni, Albert, Oriol, Faiz, Sandra y AnnC, aunque ya no esté. Pero también porque en los malos momentos han estado conmigo para hacerme ver el lado bueno de las cosas. Vuestra positividad y generosidad han sido toda una lección de humanidad.

A Jony, por sus consejos y sus chocolatinas durante mi confinamiento en la Sala 3.10.

A las chicas de Anatomía Patológica, que han respondido a todas nuestras prisas y peticiones urgentes. A Jordi Temprana, por todos los escaneos de última hora. A Claudia y a Elena, por todas sus valoraciones de nuevas tinciones de IHC y por las cuantificaciones, siempre para ayer.

A Marian, por aportar la técnica de los organotípicos.

A todos los de la UAT, pero sobretodo a Irene. Gracias por todo lo que me ha enseñado de citometría, y por su ayuda en momentos muy muy MUY críticos.

A Xavi, un Gato Viejo, y a Carlos, compañero de viaje por lugares remotos, por el estupendo trabajo con la portada.

A Maria y Montse, a Eneko. A los que conocí hace más de 10 años al empezar la carrera, y todavía seguís aquí. $Y$ aunque nos veamos poco, seguimos tan unidos como siempre, y cuando nos encontramos, es como si el tiempo no hubiera pasado.

A los Gatos Viejos de Blanes, a Albita, a Anna. Siempre dispuestos a pasárnoslo bien. Porque sois los incondicionales, los de siempre.

A Nati y Antonio, que me han abierto las puertas de su casa como si fuera una más de la familia. Por todos los tuppers Nati! Gracias por entenderme y apoyarme.

Pero sobretodo, y por encima de todo, a mis padres, a Laura y a Toni, sin los que no hubiera sido posible nada de esto:

A Toni, porque durante estos 12 años, hemos crecido y madurado juntos. Por haberme acompañado en cada una de las aventuras en las que me he embarcado. Por aguantarme en todos los malos momentos, y por celebrar conmigo todos mis logros. Por confiar en mí más que yo misma. Por tu apoyo incondicional. Por quererme tanto. Por... ser como eres.

Y a mis padres, que me han dado la felicidad, me han dado un hogar, me han dado todas la oportunidades que he necesitado y muchas más. Que me han apoyado en cada una de mis decisiones, las compartieran o no. Les quiero dar las gracias porque me lo han dado TODO $y$ me han hecho ser quien soy. Gracias de todo corazón. 
